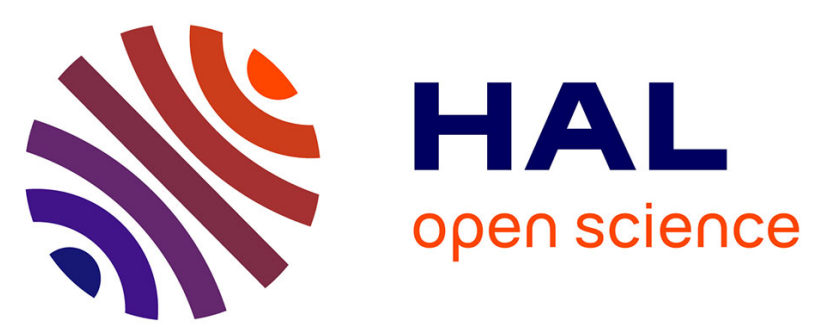

\title{
Stereoselective Construction of ( E,Z )-1,3-Dienes and Its Application in Natural Product Synthesis
}

Renata Marcia de Figueiredo, Pierre Hubert, Elena Seibel, Christine Beemelmanns, Jean-marc Campagne, Renata Marcia Figueiredo

\section{- To cite this version:}

Renata Marcia de Figueiredo, Pierre Hubert, Elena Seibel, Christine Beemelmanns, Jean-marc Campagne, et al.. Stereoselective Construction of ( E,Z )-1,3-Dienes and Its Application in Natural Product Synthesis. Advanced Synthesis and Catalysis, 2020, 362 (24), pp.5532-5575. 10.1002/adsc.202000730 . hal-03115140

\author{
HAL Id: hal-03115140 \\ https://hal.science/hal-03115140
}

Submitted on 19 Jan 2021

HAL is a multi-disciplinary open access archive for the deposit and dissemination of scientific research documents, whether they are published or not. The documents may come from teaching and research institutions in France or abroad, or from public or private research centers.
L'archive ouverte pluridisciplinaire HAL, est destinée au dépôt et à la diffusion de documents scientifiques de niveau recherche, publiés ou non, émanant des établissements d'enseignement et de recherche français ou étrangers, des laboratoires publics ou privés. 


\title{
Stereoselective Construction of (E,Z)-1,3-Dienes and Its Application in Natural Product Synthesis
}

\author{
Pierre Hubert, ${ }^{\mathrm{a}}$ Elena Seibel,,${ }^{\mathrm{b}}$ Christine Beemelmanns, ${ }^{\mathrm{b}}$ Jean-Marc Campagne, ${ }^{\mathrm{a}, *}$ and \\ Renata Marcia de Figueiredo ${ }^{a^{*}}$
}

a ICGM, Univ Montpellier, CNRS, ENSCM, France

Fax: (+33)4-6714-4322; phone: (+33)4-6714-7224 and (+33)4-6714-7221

E-mail: renata.marcia_de_figueiredo@enscm.fr; jean-marc.campagne@enscm.fr

b Hans-Knöll-Institute (HKI), Beutenbergstrasse 11a, 07745 Jena, Germany

\begin{abstract}
The E,Z-configured 1,3-diene unit is a common motif in numerous bioactive natural products. Although several powerful methods are available to produce these motifs with high levels of selectivity, their construction within a complex, polyfunctionalised structure, such as a natural product, requires well-defined strategies to avoid undesirable reactions and low-to-moderate selectivities. The aim of this review is to provide a full account of the stereoselective strategies for building E,Z-configured 1,3-dienes, as well as to highlight selected total syntheses that employ them.

1 Introduction

2 Stereoselective methods

2.1 Pericyclic reactions

2.2 Cross-coupling reactions
\end{abstract}

2.3 Heck reactions

$2.4 \mathrm{C}-\mathrm{H}$ activation reactions

2.5 Ir-catalysed olefinations

2.6 Carbonyl olefination reactions

2.7 Elimination strategies

2.8 Double bond isomerisation strategies

2.9 Metathesis strategies

2.10 Ene-yne triple bond reduction strategies

2.11 Organocatalysed 1,6-Michael additions

3 Applications in total synthesis: selected examples

Keywords: alkenes; 1,3-dienes; E,Z-configuration; natural products; synthetic methods; total synthesis

\section{Introduction}

Polyene motifs with $E, Z$ stereochemistry are prevalent in many natural and/or biologically active products (Figure 1), most notably in polyketide natural products. ${ }^{[1]}$ Building on seminal and classical crosscoupling and carbonyl olefination reactions, much effort has been devoted towards improving the existing methods towards conjugated dienes, as well as developing novel stereoselective synthetic approaches for $E, Z$-isomers in particular.

Due to their higher HOMO and lower LUMO levels, conjugated dienes are more reactive than isolated double bonds. In addition, $Z$-alkenes are thermodynamically less stable than $E$-alkenes, rendering $E, Z$-polyenes highly reactive in processes like cyclisations and addition reactions. The resulting intrinsic reactivity of E,Z-polyenes also poses important synthetic challenges, as methods for their formation are scarce compared to those for $E, E$ polyenes. $^{[2]}$

Despite the abundance of $E, Z$-conjugated dienes in natural products and the inherent challenges accompanied with their synthesis, to the best of our knowledge, no review dedicated to the accessibility of $E, Z$-conjugated dienes has been reported in the literature. ${ }^{[3]}$

Thus, the aim of this review is to provide a general overview on the existing strategies for forming these dienes and to highlight strategies that have been used to synthesise such complex molecules and natural products. Accordingly, syntheses of hetero-Xsubstituted $E, Z$-dienes ( $\mathrm{X}=$ halogens, boron, silicon, etc.) and $E, Z$-dienes where the $Z$-olefin is embedded into a cyclic compound (e.g. cyclopentene or cyclohexene) are not going to be exhaustively covered herein, and only examples belonging to novel methods or representative synthesis illustrations will be cited.

The second chapter of this review is organised into eleven sections (2.1-2.11) that detail the main strategies for obtaining E,Z-conjugated dienes. Each section will provide the reader with a comprehensive overview on $E, Z$-stereoselective methods and highlight their applicability in selected total syntheses.

The first section will discuss different pericyclic reactions that have been applied to generate 
stereodefined 1,3-dienes. Next, various cross-coupling reactions that constructed not only linear $E$,Z-dienes, but also macrocyclisations, will be considered. Mechanistically different, involving a carbopalladation step, the Heck (carbopalladation) reactions will be discussed separated in the third section. Subsequently, the fourth and fifth sections will review $\mathrm{C}-\mathrm{H}$ activation protocols, as well as Ir-catalysed reactions. The sixth section will summarise traditional and novel carbonyl olefination reactions, followed by elimination and isomerisation strategies in the seventh and eighth sections, respectively. Thus, metathesis strategies (ninth section), reductive approaches (tenth section) and 1,6-Michael additions (eleventh section) will be summarised. Finally, the applicability of the surveyed synthetic methods will be highlighted by illustrating the key steps of selected natural product total syntheses. Unfortunately, due to the large amount of bibliographic material available for total synthetic approaches, we apologise to those authors whose studies have not been cited in this review.
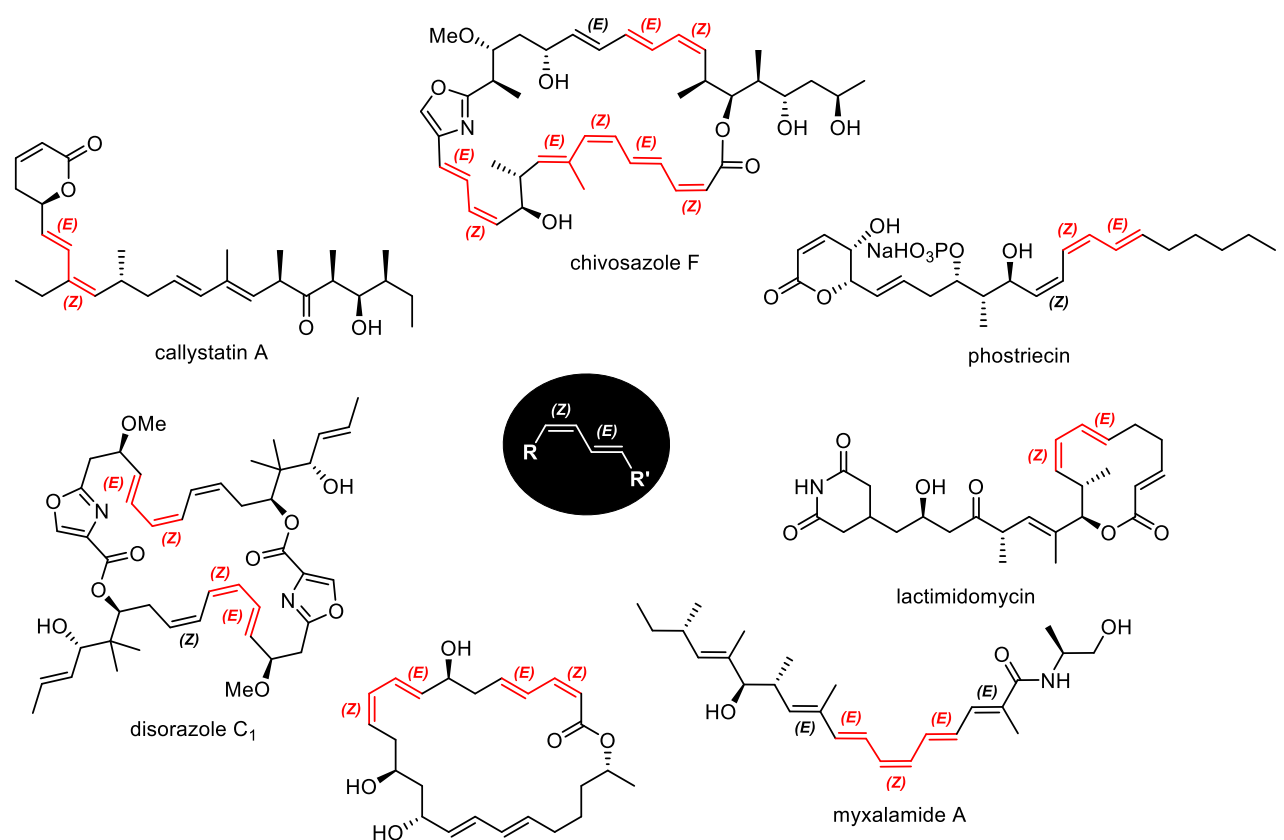

Figure 1. Selected examples of (E,Z)-1,3-dienes in natural products.

\section{Stereoselective methods}

\subsection{Pericyclic reactions}

Pericyclic reactions proceed through the simultaneous reorganisation of bonding electron pairs by way of cyclic transition states. The simultaneous bondbreaking and bond-making reactions within a single kinetic step are invaluable for the stereospecific construction of unsaturated systems. Accordingly, the three main types (electrocyclic, cycloreversion, and sigmatropic) of pericyclic reactions (Scheme 1) have been judiciously used for the stereoselective construction of $E$,Z-dienes and are described in the three following subsections.

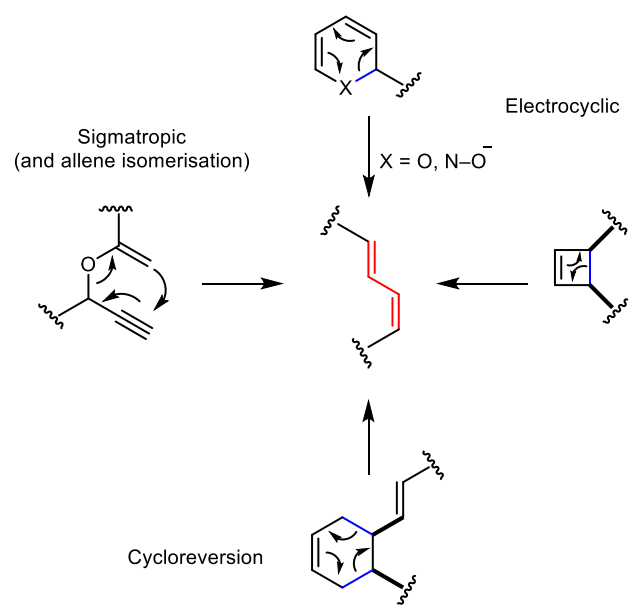

Scheme 1. Main types of pericyclic reactions. 


\subsubsection{Electrocyclic ring-opening strategies}

An electrocyclic reaction is a concerted cyclisation of a conjugated $\pi$-electron system by converting one $\pi$ bond to a ring-forming $\sigma$-bond. The reverse can also occur and is known as an electrocyclic ring opening reaction. Electrocyclic ring-opening reactions of ciscyclobutenes and pyrilium derivatives have emerged as efficient tools for constructing E,Z-dienes. The stereospecific access to $2 Z, 4 E$-dienals through the addition of organolithium reagents to pyrylium salts 1 has been described by Taylor et al. (Scheme 2, eq (a)). ${ }^{[4-6]}$ After adding the organilithium reagent to $\mathbf{1}$ at $-78{ }^{\circ} \mathrm{C}$, the electrocyclic ring opening was induced by warming the reaction mixture to $0{ }^{\circ} \mathrm{C}$, yielding the corresponding 2Z,4E-dienal $\mathbf{2}$ in good yields and high selectivities. Due to the resulting terminal and easily modified aldehyde group, this strategy has been applied to the synthesis of various natural products, including leukotrienes, umbraculumins, retinoids, cytostatin, and phostriecin. ${ }^{[7-9]}$

Related reactions with pyridine oxides (3) have also been described (Scheme 2, eq (b)), where dienal oximes (4) were stereoselectively constructed. ${ }^{[10]}$ Interestingly, the resulting oximes could be easily converted in situ to their corresponding nitriles (5) in the presence of the Vilsmeier-Haack reagent (Scheme 2 , eq (c)). Boger cleverly applied this electrocyclic ring-opening strategy to the synthesis of cytostatin and phostriecin. ${ }^{9]}$ After the electrocyclic ring opening, aldehyde 2a was readily transformed into the corresponding triene $\mathbf{6}$ using a sequence involving a Ramirez-Corey-Fuchs reaction. Thus, a selective $E$ bromide reduction via a Pd cross-coupling $\left[\mathrm{Bu}_{3} \mathrm{SnH}\right.$, $\left.\mathrm{Pd}\left(\mathrm{Ph}_{3} \mathrm{P}\right)_{4}\right]$ reaction afforded alkenylbromide 7, which underwent a halogen-metal exchange and was subsequently used to create a C-11 allylic alcohol (Scheme 2, eq (d)) (see also section 2.2).

An alternative, electrocyclic ring-opening strategy has been illustrated by Trost, where a cis cyclobutene ring opening approach was used for the total synthesis of verrucarin A. ${ }^{[1]}$ Starting from macrocyclic compound 8, a 2:1 mixture of the two E,Z-isomers ( 9 and 10) was obtained (Scheme 3, eq (a)). Later, Wallace described the electrocyclic ring opening of cis cyclobutenecarbaldehyde 11 (Scheme 3, eq (b)). ${ }^{[12]}$ This reaction occurs at low temperature with high selectivity, while the same reaction with the corresponding dicarboxylic acid requires higher temperatures $\left(80-110{ }^{\circ} \mathrm{C}\right)$ and exhibits lower selectivities.

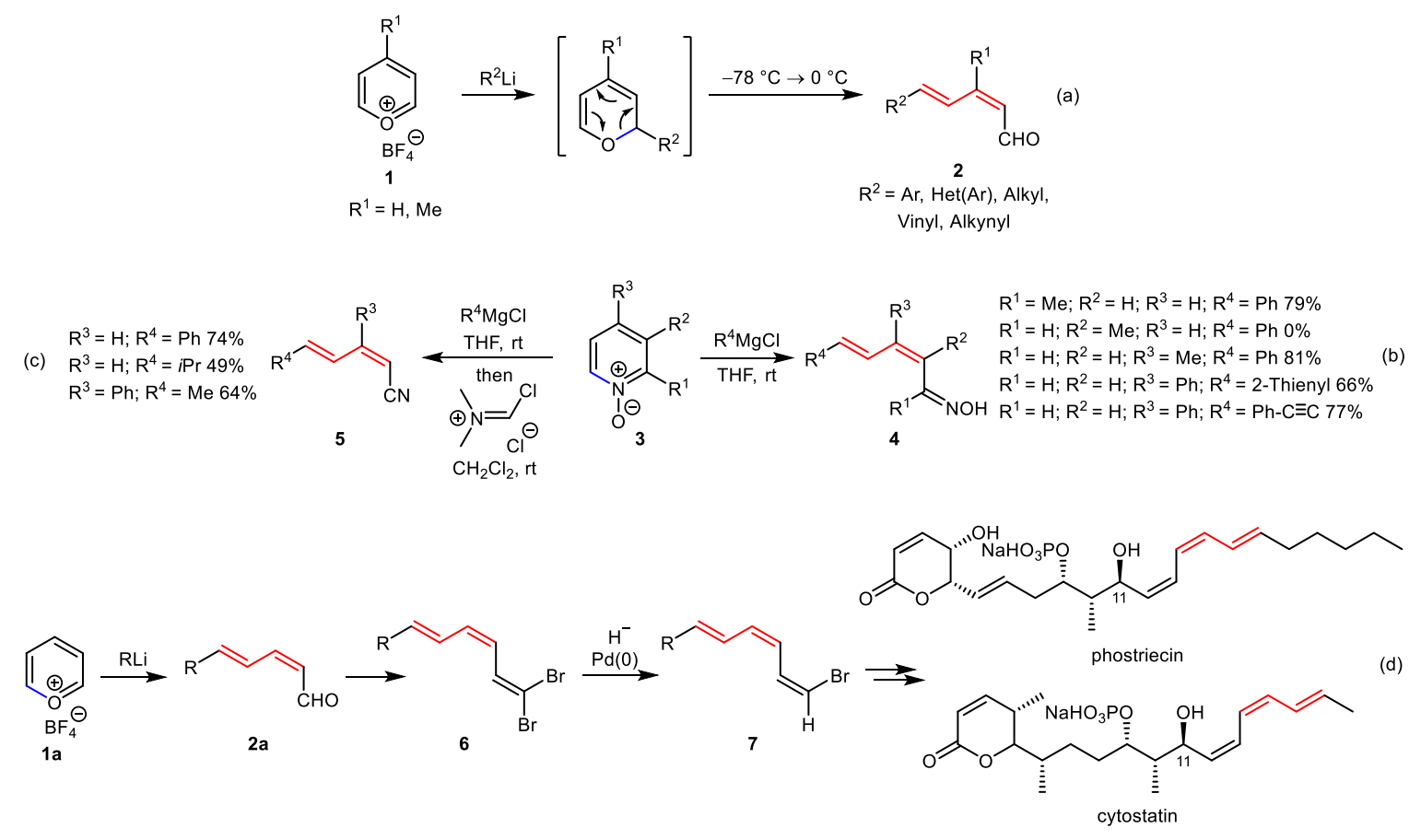

Scheme 2. Electrocyclic ring-opening of pyrylium $\mathbf{1}$ and pyridine oxides $\mathbf{3}$. 

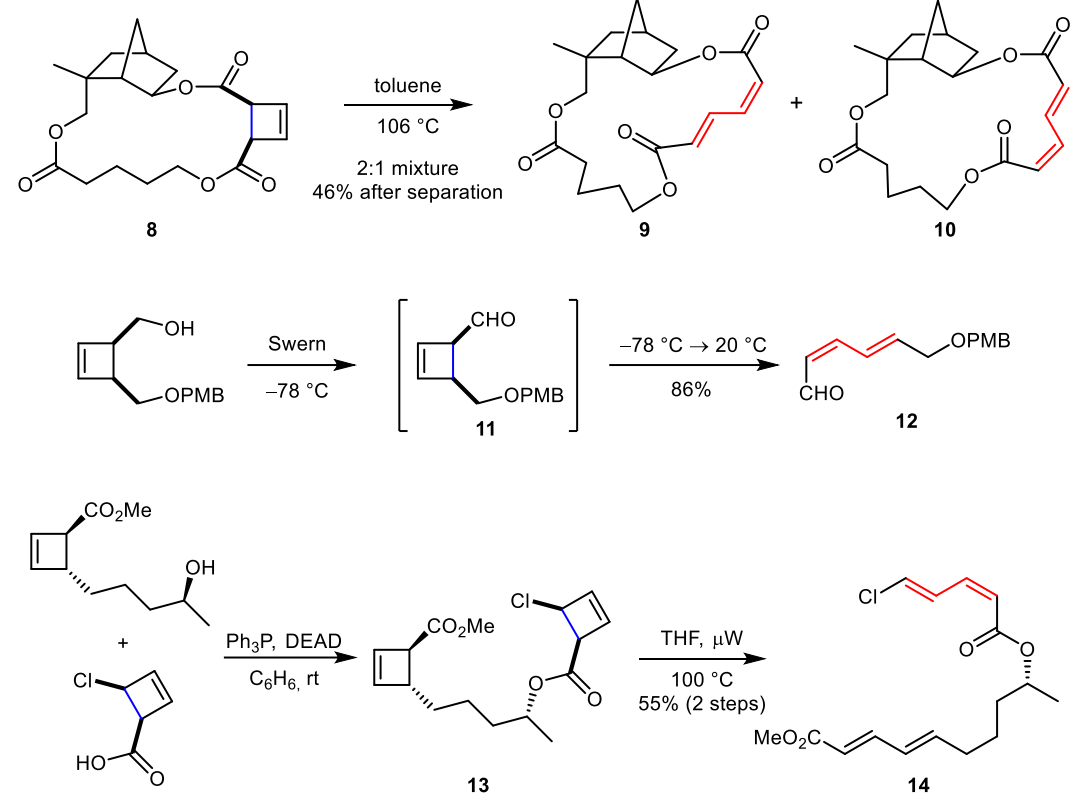

(c)

Scheme 3. Cyclobutene ring-opening strategies. PMB $=p$-methoxybenzyl.

Capitalizing on the selective ring-opening of cyclobutenes, Maulide described a double cyclobutene electrocyclic ring-opening on $\mathbf{1 3}$ that enabled the stereoselective formation of $\mathbf{1 4}$ with two $E, Z$ - and $E, E$ diene subunits of macrolactin A (Scheme 3, eq (c))..$^{[13,14]}$

While 3-sulfolene cheletropic ring-opening reactions via $\mathrm{SO}_{2}$ extrusion have been widely used to unmask 1,3-diene synthons, the use of trans 3sulfolenes (15) for the construction of E,Z-dienes (16 and 17) is rather scarce and inherently limited to symmetrical compounds, where $\mathrm{R}^{1}=\mathrm{R}^{2}$ (Scheme 4). ${ }^{[15-18]}$

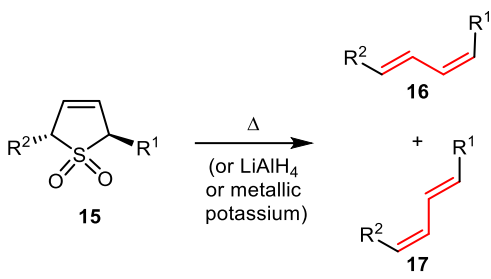

Scheme 4. Cheletropic $\mathrm{SO}_{2}$ extrusion in 3-sulfolenes.

\subsubsection{Cycloreversion strategies: Retro Diels-Alder reactions}

Diels-Alder (and related) reactions have been extensively used in organic synthesis, due to their highly convergent and stereospecific characteristics. On the other hand, the authorised reverse reactions, namely retro Diels-Alder reactions, have rarely been used. ${ }^{[19]}$

In the synthesis of monohydroxyeicosatetranoic acids (HETES), the $Z$ double bond of the $E, Z$-diene was first masked using bicyclic lactone 18 (Scheme 5). ${ }^{[19 a]}$ After further modifying the HETES core, the $Z$ - alkene was obtained in high yield using a retro DielsAlder reaction.

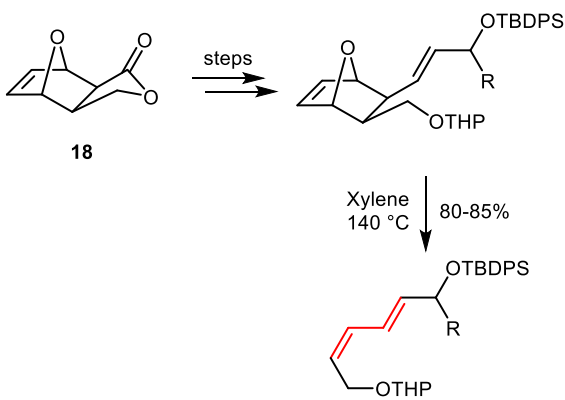

Scheme 5. Retro Diels-Alder strategy. TBDPS = tertbutyldiphenylsilyl.

\subsubsection{Sigmatropic strategies: Oxonia-Cope and Claisen rearrangements}

The high stereocontrol offered by highly organised transition states during [3,3]-sigmatropic rearrangements constitute an efficient tool for controlling the stereoselectivity in 1,3-diene syntheses. Although the oxonia-Cope is not the most popular amongst the [3,3]-sigmatropic rearrangements, it efficiently takes advantage of the equilibrium between two oxo-carbenium intermediates to construct stereodefined, homoallylic alcohols. Starting from stereodefined $\alpha$-vinylogous aldol products 19 and $\mathbf{2 0}$, Han described the stereoselective access to both E,Zand Z,E-bisvinylogous aldol products $\mathbf{2 1}$ and $\mathbf{2 2}$ through an oxonia-Cope rearrangement (Scheme 6). ${ }^{[20]}$ 

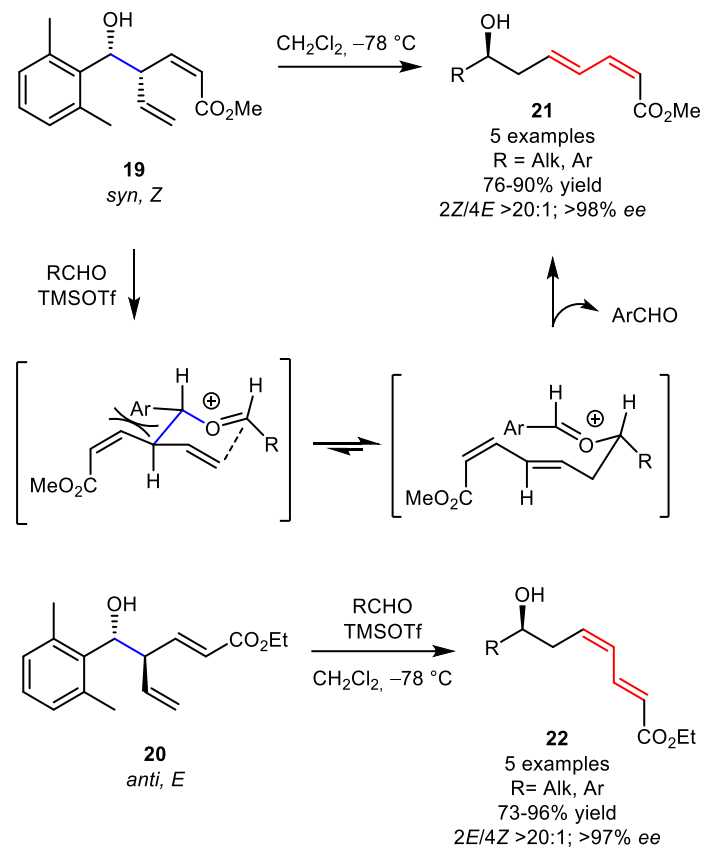

Scheme 6. Oxonia-Cope rearrangements.

As illustrated with the reaction of $s y n / Z$ adduct 19, this [3,3]-sigmatropic rearrangement allows the transfer of both the chirality and stereocontrol of the incoming double bond, due to the six-membered transition state.

Various Claisen rearrangements of propargylic alcohols have also been described. The JohnsonClaisen rearrangement of propargylic alcohols, ${ }^{[21]}$ followed by allene isomerisation to give the corresponding E,Z-dienoic esters was described by Tsuboi in $1982 .{ }^{[22,23]}$ Due to its versatility, this strategy has been used in numerous total syntheses, including those of insect sex pheromones, natural insecticides, and macrolactones. ${ }^{[24-27]}$ The synthesis of the C7-C15 fragment of macrolactin $\mathrm{A}^{[26]}$ demonstrates a propargyl Johnson-Claisen rearrangement that affords, starting from alcohol 23, allene 24, which can be stereoselectively isomerised using basic alumina to give compound $\mathbf{2 5}$ in good yield and selectivity (Scheme 7). ${ }^{[23]}$
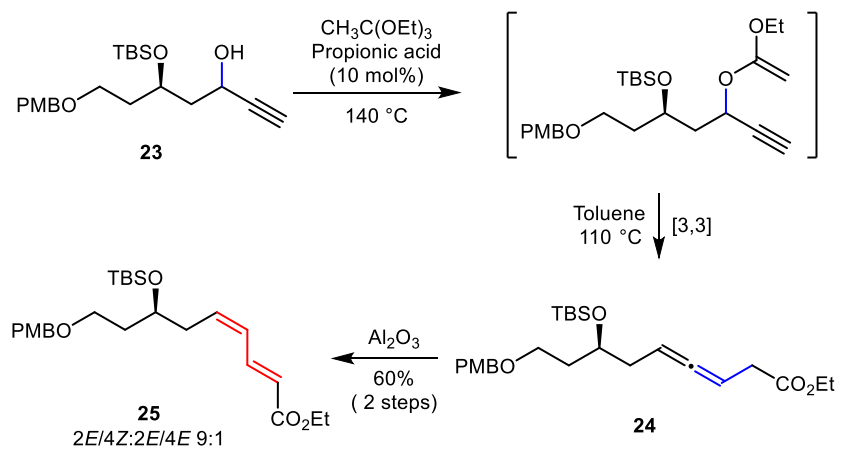

Scheme 7. Propargylic alcohols Johnson-Claisen rearrangement. TBS = tert-butyldimethylsilyl.

A related but mechanistically different approach was more recently developed by Vidhani and Alabugin to access (E,Z)-dienals (29) in good yields and high stereoselectivities. ${ }^{[28]}$ In this sequence, a $\mathrm{Rh}(\mathrm{I})$ catalysed propargyl Claisen rearrangement of compound $\mathbf{2 6}$ formed allene $\mathbf{2 8}$, which was followed by a stereoselective hydrogen transfer (Scheme 8). ${ }^{[29]}$ A thorough mechanistic study of this reaction highlighted that the formation of the allene-aldehyde product 28 is catalysed by a homogeneous $\mathrm{Rh}(\mathrm{I})$ catalyst, which then converts into a 'heterogeneous nano-cluster' catalyst that promotes the proton transfer. ${ }^{[28,30]}$

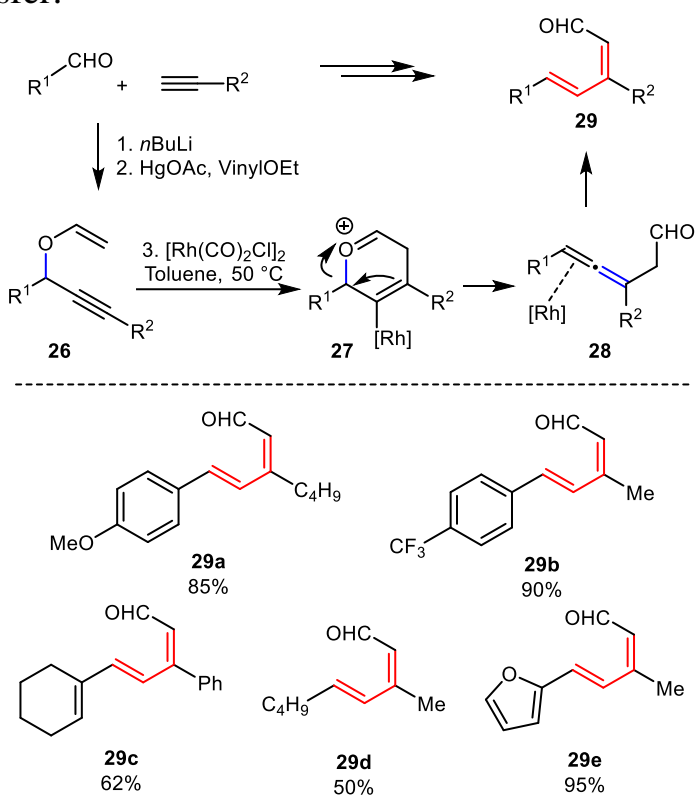

Scheme 8. $R$ h(I)-catalysed propargyl Claisen rearrangement/hydrogen transfer sequence.

Diver et al. combined an ene-yne cross-metathesis reaction $(\mathbf{3 0} \rightarrow \mathbf{3 1}$; for other metathesis strategies to obtain E,Z-dienes, see section 2.9) with an IrelandClaisen rearrangement to obtain stereoselective access to complex E,Z-diene derivatives 32 (Scheme 9). ${ }^{[31]}$ When starting with an enantiomerically enriched substrate, the Ireland-Claisen product can be obtained, albeit with marked erosion of the enantioselectivity.

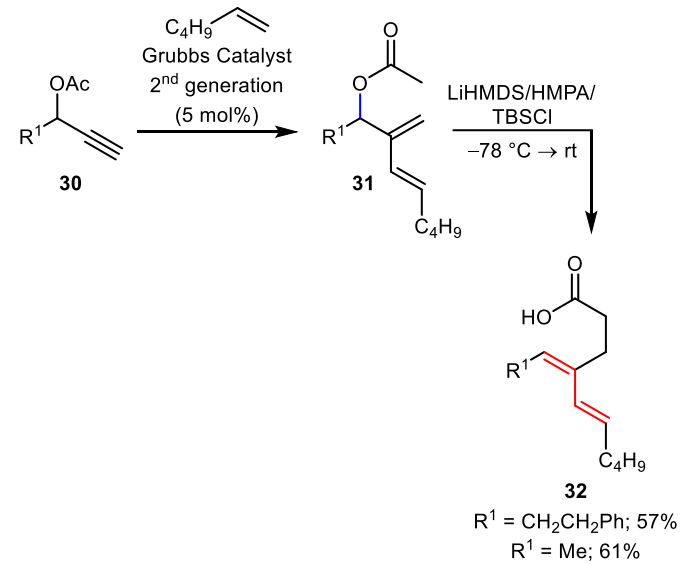

Scheme 9. Ene-yne cross-metathesis/Ireland-Claisen rearrangement sequence. 
The stereoselective rearrangement of allenyl alcohols (33) to give 1,3-dien-2-yl triflates (34a), chlorides (34b), or tosylates (34c) was conducted under mild conditions and showed high selectivities (Scheme 10). Moreover, the presence of a stereodefined, functionalised double bond allowed for further transition-metal cross-coupling functionalisations. ${ }^{[32]}$

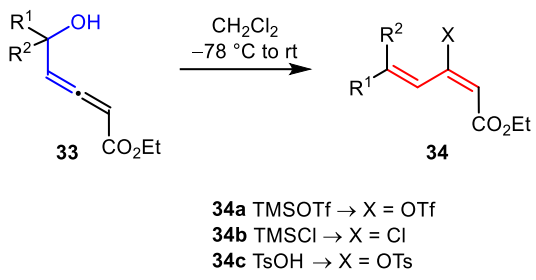

Scheme 10. Stereoselective rearrangement of allenic alcohols.

\subsection{Cross-coupling reactions}

Among the various approaches for synthesizing 1,3dienes ( $Z, E$-isomers in particular), transition-metalcatalysed cross-coupling reactions play a crucial role. Indeed, they are often used as a key step in synthesizing complex molecules. Generally, with some notable exceptions (see section 2.7), these crosscoupling reactions proceed while fully retaining the $Z / E$ geometries of the reagents, which makes this method a powerful tool.

\subsubsection{Pd (Ni)-catalysed cross-couplings}

Pd-catalysed (and in to lesser extent, Ni-catalysed) cross-coupling reactions ${ }^{[33,34]}$ are among the most common methods utilised to access 1,3-dienes. Capitalizing on the ability of transition-metals to catalyse $\mathrm{C}-\mathrm{C}$ bond formation between stereodefined vinyl electrophiles and stereodefined alkenyl metallic intermediates, these transformations have been extensively studied.

Indeed, since early seminal works in the $70 \mathrm{~s},{ }^{[35]}$ well-defined methodologies that are compatible with the total syntheses of complex molecules have been developed and broadly employed. The ability to choose each coupling partner [i.e. Z-vinyl metallic scaffolds and $E$-vinyl electrophiles (or vice-versa)], makes this methodology a benchmark in the field of conjugated $Z, E$-/E,Z-diene stereoselective synthesis (Scheme 11). In section 2.2.1, the potential of such strategies is going to be illustrated through arbitrarily chosen representative examples of total syntheses. 1,3Dienes can alternatively be obtained by Sonogashira cross-couplings, followed by alkyne reduction (see section 2.10). ${ }^{[36,37]}$

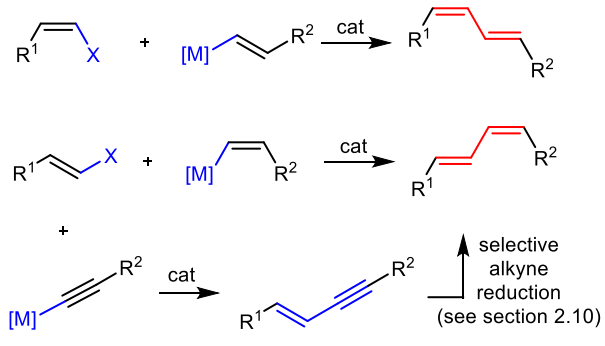

cat $=\mathrm{Pd}$ (mainly), Ir, (Fe or $\mathrm{Cu})$ $[\mathrm{M}]=\mathrm{Sn}, \mathrm{B}, \mathrm{Cu}, \mathrm{Zn}, \mathrm{Al}, \mathrm{Si}, \mathrm{Mg}$ $\mathrm{X}=\mathrm{Br}, \mathrm{I}, \mathrm{Cl}, \mathrm{OTf}, \mathrm{OMs}, \mathrm{OPO}(\mathrm{OR})_{2} \ldots$

Scheme 11. Cross-coupling reactions towards 1,3-dienes.

\subsubsection{Negishi-type cross-couplings $(M=Z n)^{[38]}$}

Alexakis and Normant disclosed a general methodology for developing conjugated-dienic insect sex pheromones based on the carbocupration of acetylene ${ }^{[39]}$ with lithium dialkyl cuprates, followed by a Pd-catalysed coupling reaction of the resulting Zdialkenyl cuprate with either $E$ - or $Z$-alkenyl iodides. ${ }^{[40]}$ A variety of sex pheromones were synthesised, including (10E,12Z)-10,12hexadecadien-1-ol (bombykol) and (5Z,7E)dodecadien-1-ol, the pheromones of female silkworm moths (Bombyx mori) and forest tent caterpillars (Malascoma disstria), respectively (Scheme 12).

The synthesis of substituted Z,E-dienes $\mathbf{3 5}$ was performed through cross-couplings between $Z$ - or $E$-2alkenyliodides and $Z$ - or $E$-organozinc intermediates (Scheme 13). ${ }^{[41]}$ A feature of this Negishi-type coupling is the ability to form $Z$-trisubstituted alkenes with high selectivities.

Later on, a methodology to obtain all four stereoisomers of ethyl undeca-2,4-dienoate (36) in excellent isomeric purities ( $\geq 98 \%)$ and yields $(>85 \%)$ was also developed. ${ }^{[42]}$ This strategy combined Pdcatalysed Negishi cross-couplings with $E$ - or Z-ethyl3-bromoacrylate and $E$ - or $Z$-vinyl metallic intermediates (Scheme 14). This methodology was advantageously experimentally compared to other Pdcatalysed alkenylation reactions (e.g. Heck and Suzuki) and carbonyl olefinations (e.g. HornerWadsworth-Emmons (HWE) and Still-Gennari). The synthesis of trienoic esters by merging the developed Pd-catalysed alkenylation method with carbonyl olefination reactions was also proposed. 


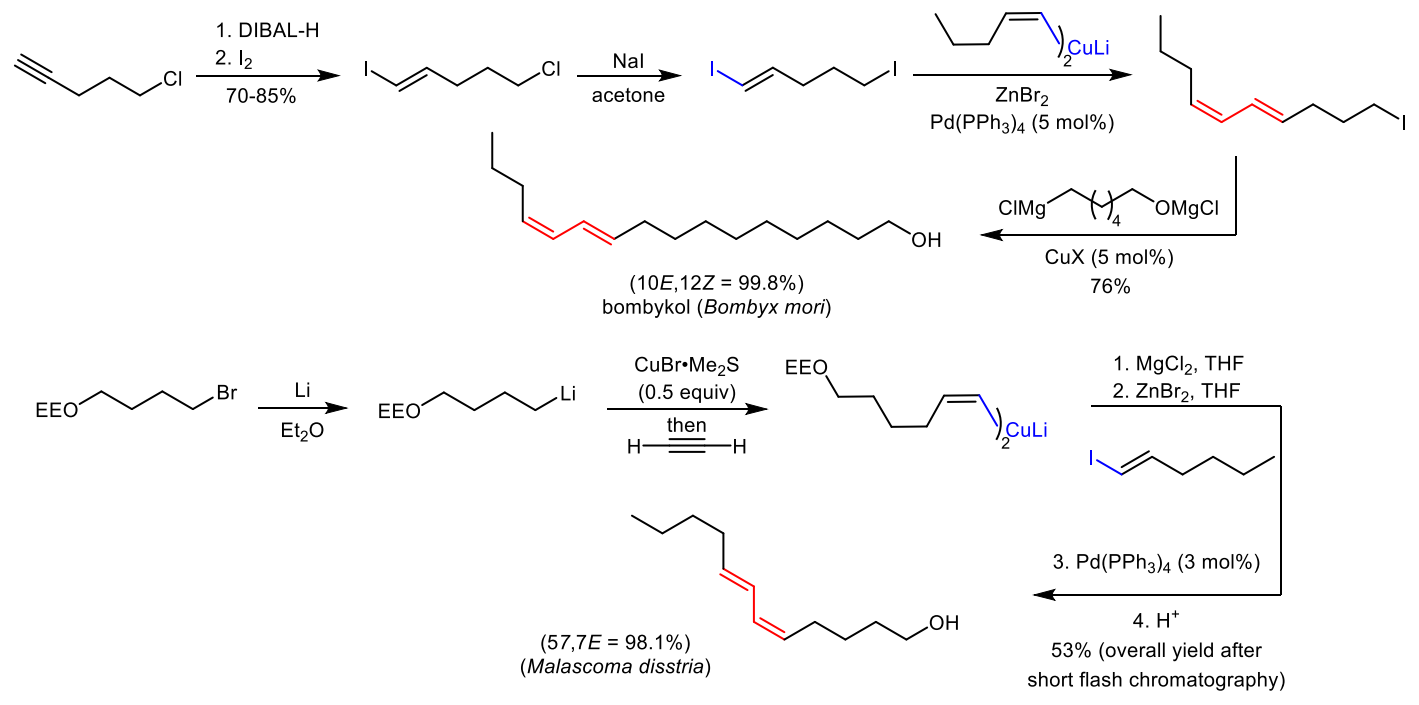

Scheme 12. Synthesis of E,Z- and Z,E-pheromones by Normant and Alexakis via carbocupration and Negishi cross-coupling. $\mathrm{EE}=$ ethoxyethyl ether.

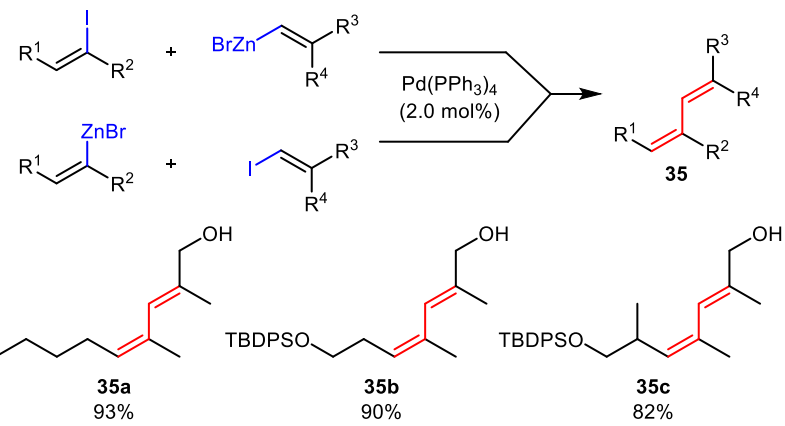

Scheme 13. Negishi's method for selective synthesis of (Z)-trisubstituted alkenes.

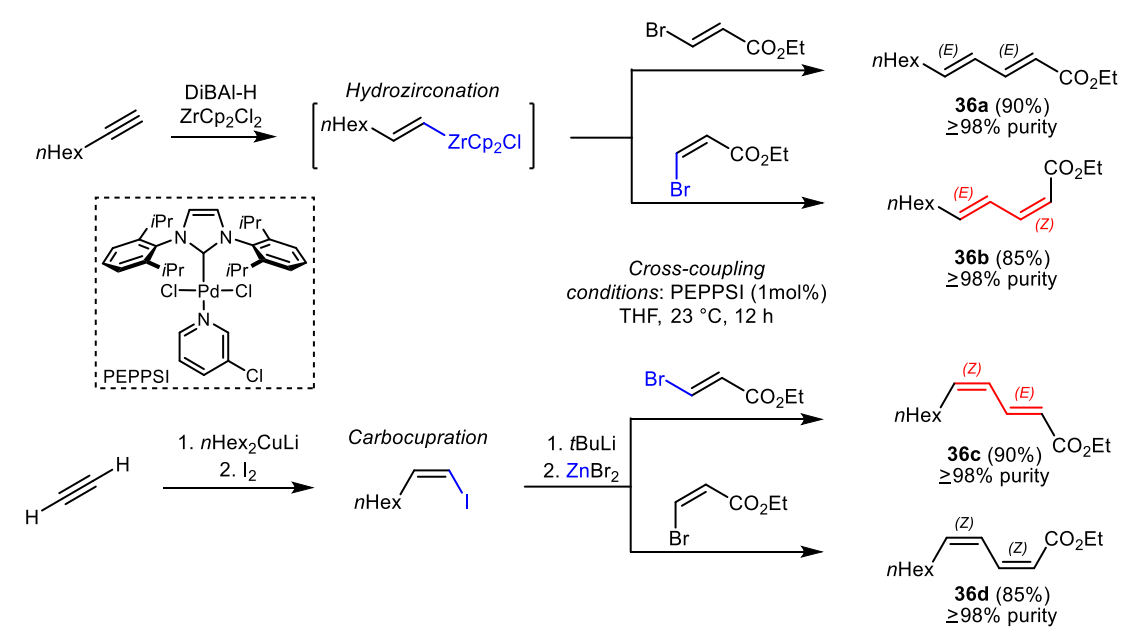

Scheme 14. Alkyne hydrozirconation/carbocupration-Pd-catalysed Negishi cross-coupling for the synthesis of all four isomers of dienoic esters 36 . 
Panek proposed a strategy to synthesise the $Z, E$ diene fragment (39) of (-)-callystatin A using a Pdcatalysed, Negishi-type cross-coupling reaction between $Z$-vinyl iodide $\mathbf{3 7}$ and $E$-vinyl zinc species $\mathbf{3 8}$ (Scheme 15). ${ }^{[43]}$

\subsubsection{Corriu-Kumada-Tamao-type cross-couplings $(M=M g)^{[44]}$}

Naso proposed the addition of Z-dialkenyl lithium cuprates $(\mathbf{4 0})$ to phenylthioacetylene (41) to obtain the stereodefined alkadienyl sulphide intermediates $\mathbf{4 2}$ and 43, respectively. Thus, cross-coupling via $\mathrm{Ni}$-catalysis in the presence of Grignard reagents afforded $E, Z$ - and $Z, E$-dienic insect pheromones, such as bombykol and (9Z,11E)-9,11-tetradecadien-1-yl acetate, the pheromone of the Egyptian cotton leafworm (Spodoptera littoralis, Scheme 16). ${ }^{[45]}$

Bombykol could also be obtained through a strategy that relied on the prior synthesis of a $(1 Z, 3 E)-1$ halodiene (44), followed by a Ni-catalysed CorriuKumada-Tamao cross-coupling reaction, which afforded the Z,E-conjugated diene $\mathbf{4 5}$ (Scheme 17). ${ }^{[46]}$
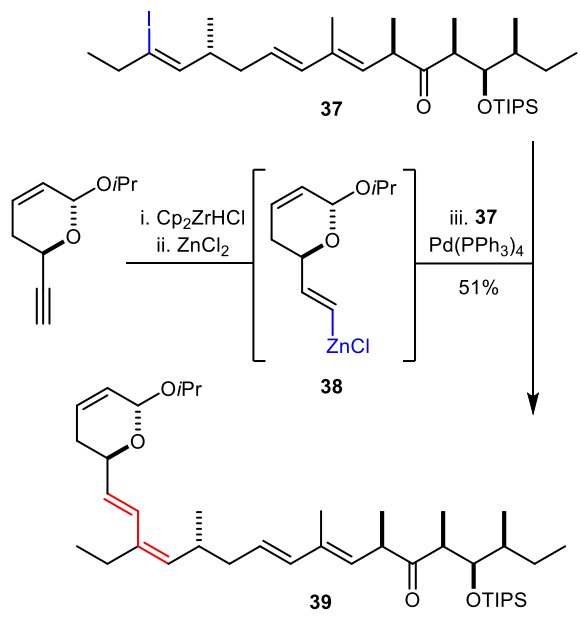

Scheme 15. Total synthesis of callystatin A by Panek using a Negishi cross-coupling for the Z,E-diene synthesis. TIPS $=$ Triisopropylsilyl.

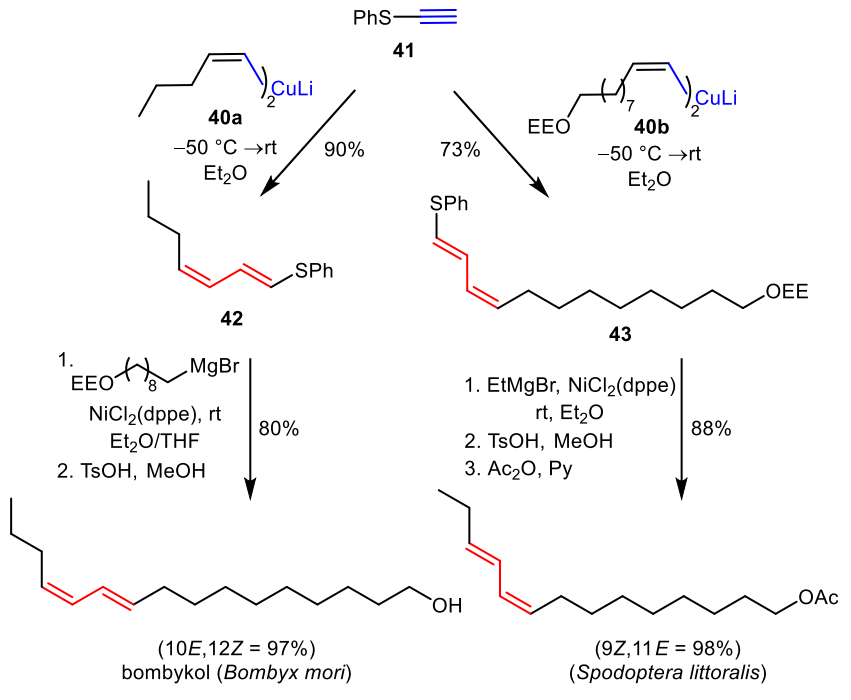

Scheme 16. $E, Z$ and $Z, E$-dienic sex pheromones synthesis by Naso.

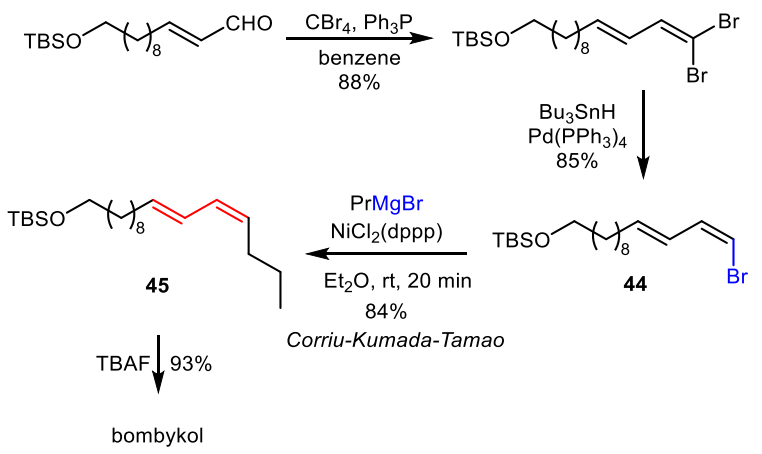

Scheme 17. Bombykol synthesis via Corriu-KumadaTamao cross-coupling.

\subsubsection{Hiyama-Denmark-type cross couplings $(M=$ $\mathrm{Si})^{[47]}$}

The syntheses of resolvins D3 and E1 were reported by Anderson, where Hiyama-Denmark cross-couplings of five- and six-membered cyclic alkenylsiloxanes, compounds 46a, 46b, and 47 respectively, were used in key fragment combination reactions (Scheme 18). ${ }^{[48]}$ These strategic steps controlled the $Z$-stereochemistry of both $Z, E$-diene and $Z, E, E$-triene moieties present on these natural products.

\subsubsection{Stille-type cross-couplings $(M=S n)^{[49]}$}

Stille cross-coupling reactions are probably utilised the most to form E,Z-dienes, particularly in the field of total synthesis. During the synthesis of (+)-sorangicin A, a natural product bearing a highly unsaturated, polyfunctionalised, 31-membered macrolactone ring, a Stille coupling was used to install the sensitive Z,Z,Etrienoate (Scheme 19). ${ }^{[50]}$ A combination of stannyl dienoate 49 ${ }^{[51]}$ and a large excess of $\mathrm{Ph}_{2} \mathrm{PO}_{2} \mathrm{NBu}_{4}{ }^{[52]}$ was needed to suppress isomerisation. In this case, the 
stereopure $Z, Z, E$-trienoate $\mathbf{5 0}$ was isolated in $88 \%$ yield.

The authors mentioned that the prior formation of dienyne $\mathbf{5 2}$ via the addition of alkynyl stannane $\mathbf{5 1} \mathbf{1}^{[53]}$ to a model vinyl iodide, followed by semihydrogenation into the $Z$-olefin, has also been tried. However, this sequence underwent extensive $E / Z$ isomerisation upon purification (Scheme 20, also see section 2.10). ${ }^{[50]}$

The Stille-type cross-coupling was also illustrated in the total syntheses of basiliskamides A and B by Panek and Dias. ${ }^{[54,55]}$ Another strategy, proposed by Yadav, relied on a Stille-type cross-coupling reaction of a $Z$ vinyl iodide fragment (obtained by a Stork-Zhao olefination) and $E$-vinyl stannane intermediate (synthesised via hydrostannation) to obtain a diacetonide analogue of thuggacin A. ${ }^{[56]}$ During the synthesis of (-)-archazolid B, Trauner combined an $E, Z$-vinyl stannane with a Z-vinyl iodide to install the sensitive $Z, Z, E$-triene unit during the endgame transformations to avoid potential (cyclo)isomerisations. ${ }^{[57]}$ Strategies based on Stille cross-coupling reactions to install $E, Z$-diene moieties were also used to synthesise stipiamide ${ }^{[58]}$ and lactimidomycin. ${ }^{[59]}$

When studying the total synthesis of putative chagosensine, a marine macrolide that possesses a unique chloro-1,3-diene unit, Fürstner et al. developed a straightforward strategy to install this $Z, Z$-configured entity by exploring a metal-catalysed-diboration, or distannation, of alkynes (Scheme 21). ${ }^{[6,61]}$ It was expected that the terminal and less encumbered carbon-metal $(\mathrm{C}-\mathrm{M})$ bond in $\mathbf{A}$ would react first during the cross-coupling to give intermediate $\mathbf{B}$, whose internal $\mathrm{C}-\mathrm{M}$ bond could undergo subsequent chlorodemetalation to form $\mathbf{C}$.

This methodology was successfully used to construct the sensitive Z,Z-chlorodiene entity. Consequently, the ability to obtain a double $\mathrm{C}-\mathrm{M}$ site in a single intermediate paved the way for finely tuned operational conditions that enable functional diversity (other than halogens). Furthermore, the access of functionalised $Z, E$-dienes might be also envisaged. In the total synthesis of putative chagosensine, the authors opted to first employ the Pd-catalyseddistannation of alkyne 53. Then, the resultant 1,2distannane 54 was subjected to site-selective, Pdcatalysed, Stille cross-coupling with Z-vinyl iodide 55. A bulky phosphine ligand was used in $\mathrm{Cu}$-free conditions to avoid premature destannation or problems regarding the regioselectivity of the internal vs external positions. Chloro-destannation of functionalised intermediate 56, in the presence of $\mathrm{CuCl}_{2}$ and lutidine, gave the expected 1,3-chlorodiene (57) with complete retention of the double bond configuration.

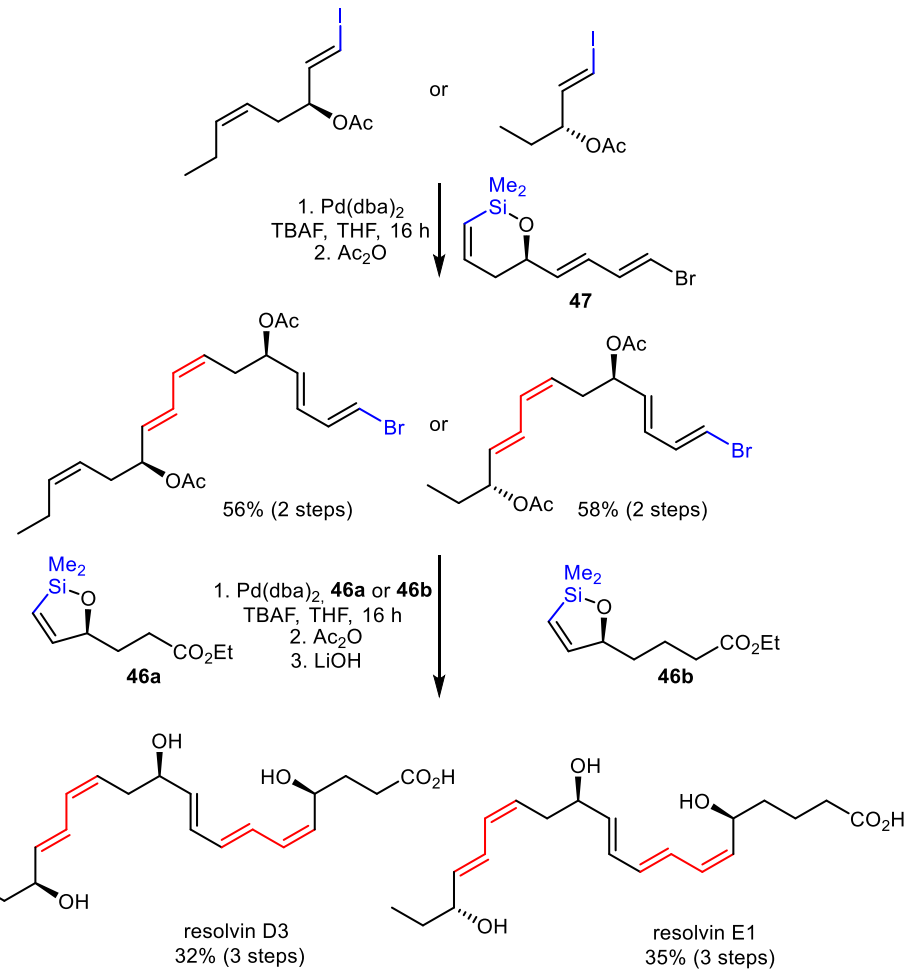

Scheme 18. Resolvins D3 and E1 synthesis using Hiyama-Denmark cross-couplings. 


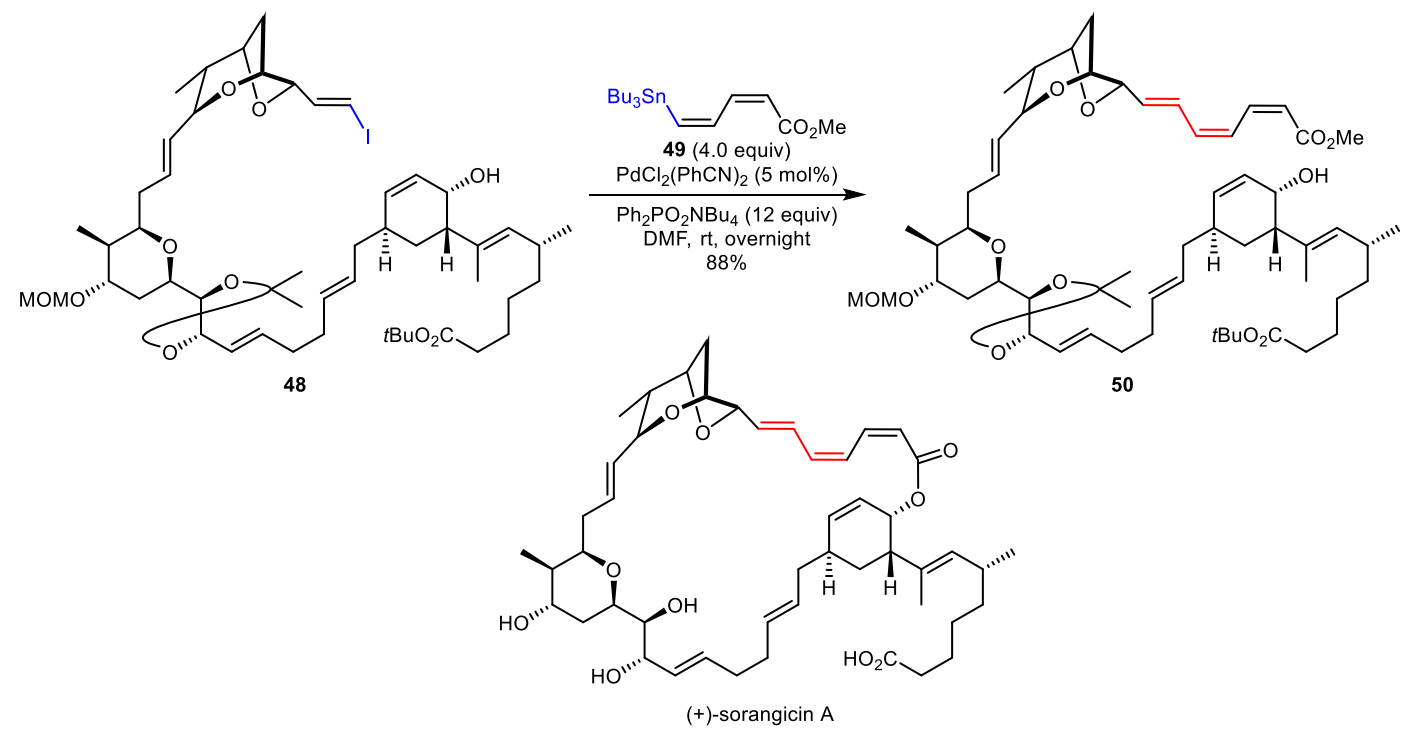

Scheme 19. Stille cross-coupling as key step for the synthesis of (+)-sorangicin A.

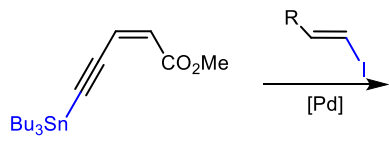

51

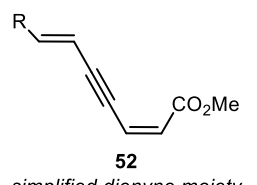

simplified dienyne moiety

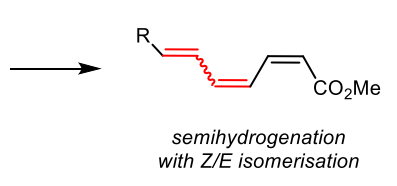

Scheme 20. Dienyne 52 synthesis and semi-hydrogenation with isomerisation.

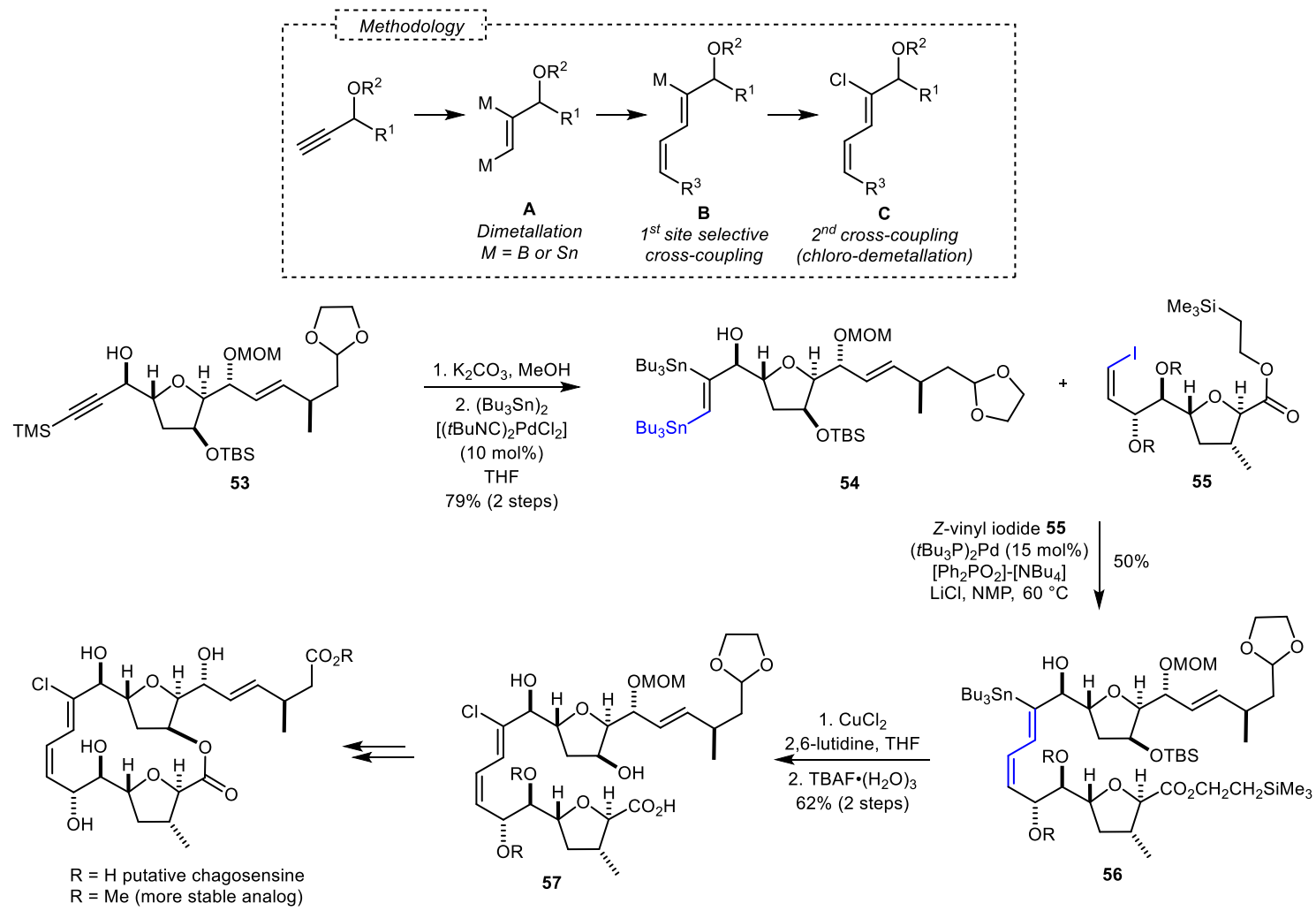

Scheme 21. Methodology through sequential dimetallation/cross-coupling/chloro-demetallation. 


\subsubsection{Suzuki-type cross-couplings $(M=B)^{[36 c]}$}

Kishi et al. utilised Suzuki cross-coupling to install the $Z$,E-diene moiety present in protected palytoxin carboxylic acid, a complex natural product ${ }^{[62]}$ (Scheme 22). Within this total synthesis, thallium(I) hydroxide was crucial for improving the reaction rate, affording intermediate $\mathbf{5 8}$ in good yield. Moreover, when beginning with an 8-10:1 mixture of $E$ - and $Z$ vinylboronic acids, perfect $Z$, $E$-stereoselectivity for the conjugated diene on $\mathbf{5 8}$ could be attained. Indeed, the rate of the $Z, E$-coupling reaction is faster than that of the $Z, Z$-coupling.

If fragments with fully protected hydroxyl groups were used to achieve the Suzuki cross-coupling during the palytoxin synthesis, ${ }^{[62]}$ Suginome ${ }^{[63]}$ showed that a free hydroxyl group is also compatible. Indeed, bombykol was synthesised using a Pd-catalysed Suzuki coupling between alkenyl boronic acid $\mathbf{5 9}$ and alkenyl halide $\mathbf{6 0}$ in the presence of a base (Scheme 23, see also scheme 25). ${ }^{[63,64]}$

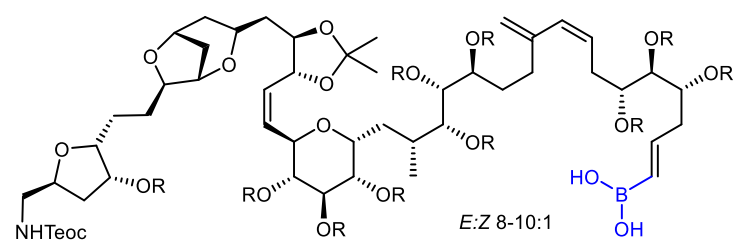

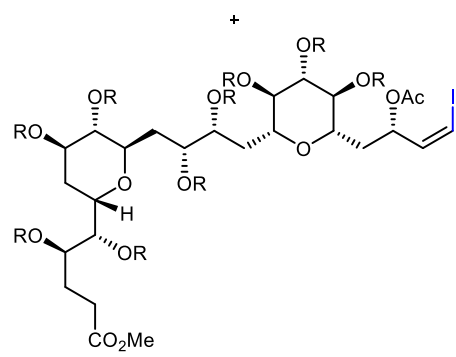

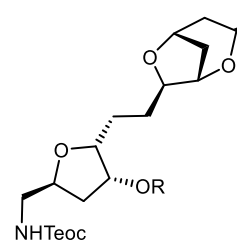

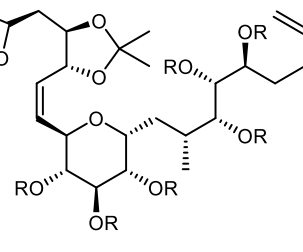<smiles>[12BH2]</smiles>

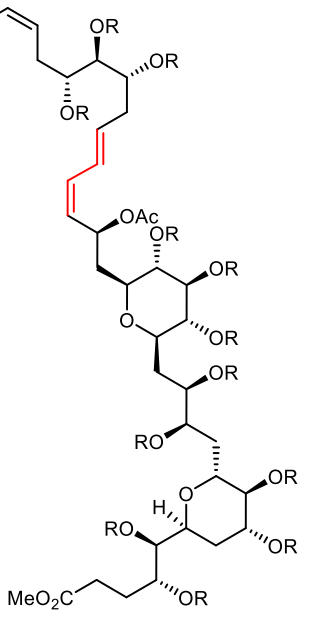

Scheme 22. Suzuki cross-coupling during the total synthesis of protected palytoxin carboxylic acid.

Fuwa used a late-stage Suzuki-Miyaura reaction to form the sensitive $E, Z, E$-triene side chain of (-)-exiguolide (Scheme 24). ${ }^{[65]}$ The cross-coupling takes place under mild conditions in the presence of $E$ vinyl iodide 61 and $Z$-vinyl boronic ester 62. Suzuki cross-coupling between $Z$-vinyl iodide $\mathbf{6 3}$ and $E$-vinyl boronic ester 64 was used by $\mathrm{Xu}$ and $\mathrm{Ye}$ for the assembly of two key fragments during the total synthesis and stereochemical reassignment of mandelalide A (Scheme 25, for other strategies used for the total synthesis of mandelalide A, see sections $2.3,2.6 .1,2.10) .{ }^{[66]}$

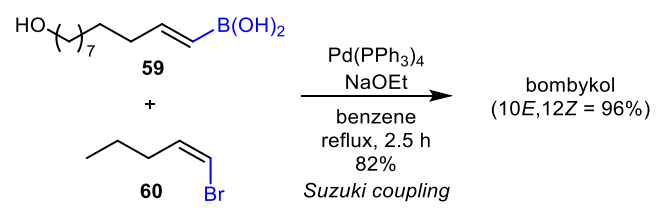

Scheme 23. Bombykol synthesis via Suzuki coupling.

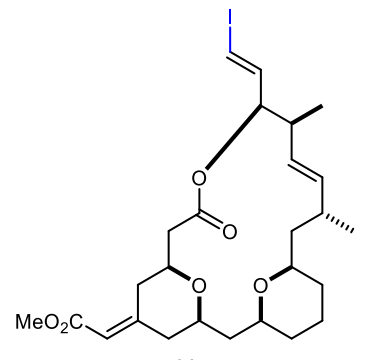

61
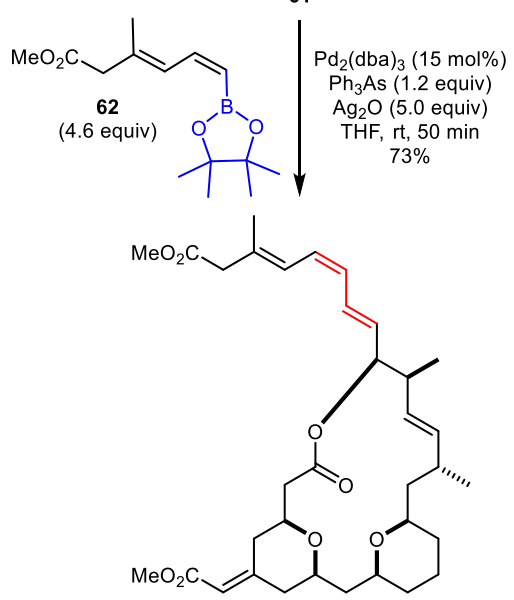

(-)-exiguolide

Scheme 24. Suzuki-Miyaura coupling as last step for the synthesis of (-)-exiguolide. 
Molander described a methodology for Pd-catalysed Suzuki-Miyaura cross-couplings using air-stable potassium alkenyltrifluoroborates as coupling partners (Scheme 26). ${ }^{[67]} \mathrm{A}$ range of $E, E-, E, Z-, Z, E-$, and $Z, Z-$ 1,3-dienes (65) was stereospecifically formed through couplings of $Z$ - and $E$-vinyltrifluoroborates with either $E$ - or $Z$-vinyl bromides. This method was successfully used to accomplish the macrocyclisation step $(\mathbf{6 6} \rightarrow \mathbf{6 7}$, Scheme 26) during the formal total synthesis of oximidine II. ${ }^{[68]}$

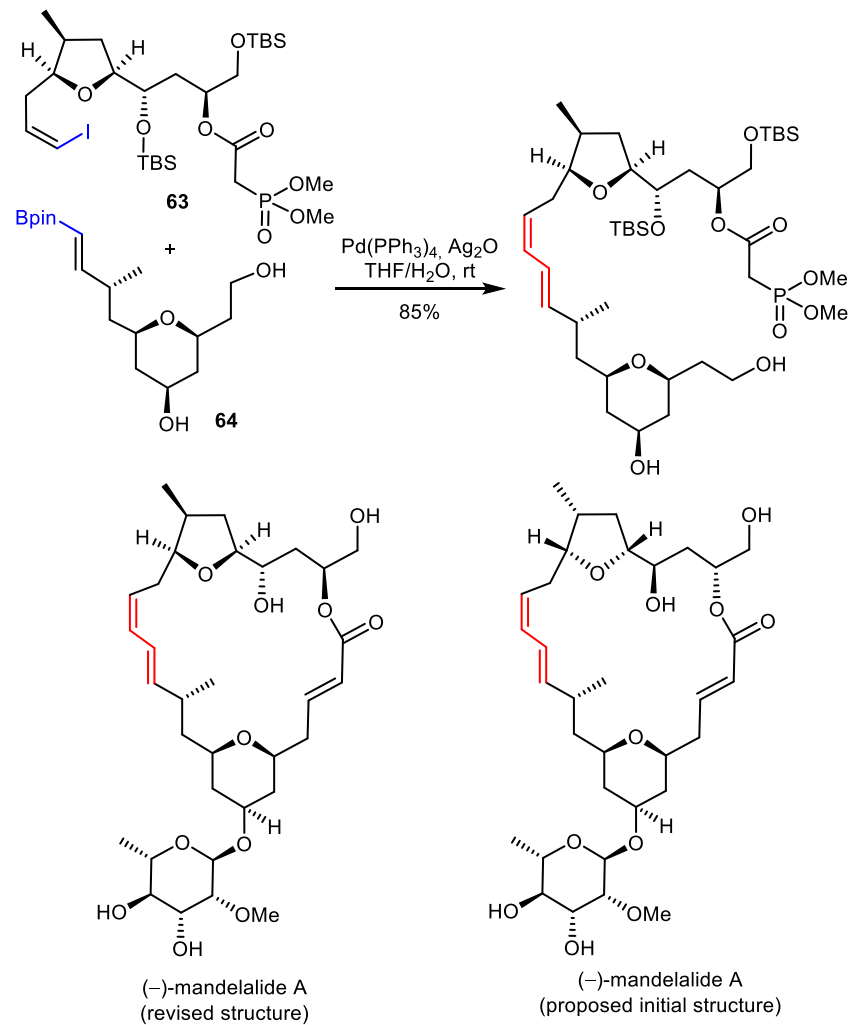

Scheme 25. Suzuki-type cross-coupling for the synthesis of mandelalide A.
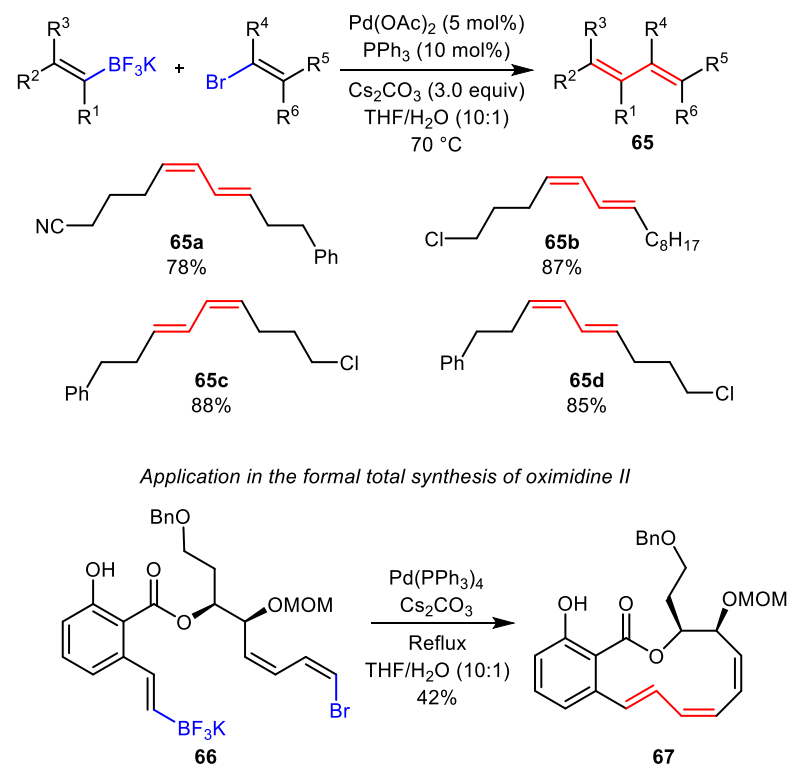

Scheme 26. Suzuki cross-coupling of potassium alkenyltrifluoroborates with vinyl bromides.

\subsubsection{Pd-catalysed co-oligomerisations}

$\mathrm{Lu}$ developed a straightforward method to stereoselectively synthesise E,Z-dienes via Pdcatalysed coupling reactions of lithium bromide, acetylene, and acrolein (Scheme 27). ${ }^{[69]}$

The reaction starts with a trans-bromopalladation of acetylene to give $E$-vinyl palladium $\mathbf{6 8}$, which reacts with a second molecule of acetylene through a cisinsertion to form E,Z-dienyl palladium 69. The coupling of this intermediate with acrolein leads to (2oxoalkyl)palladium intermediate $\mathbf{7 0}$ that can undergo either protonolysis (path A) or $\beta$-hydride elimination (path B) to give $\mathbf{7 1}$ and 72, respectively. Optimizing the reaction conditions showed that excess acetylene and coordinating halide, polar solvents, and low temperature all promote the formation of $\mathbf{7 1}$ in low to moderate yields. Thus, (E,Z)-bromodiene $\mathbf{7 1}$ was a suitable starting material for preparing key intermediates used in Kumada-type cross-coupling reactions for synthesizing insect sex pheromones. ${ }^{[70,71]}$

\subsubsection{Pd-catalysed oxidative macrocyclisations}

The Pd-catalysed oxidative cyclisation of tethered terminal bis(vinyl boronic esters) was developed by Merlic et al., which accessed cyclic E,E-, Z,Z-, E,Z- or exodimethylene-dienes in a stereospecific manner ${ }^{[72,73]}$ Using this method, E,Z-bis(vinyl boronic ester) substrates $\mathbf{7 3}$ and $\mathbf{7 4}$ were cyclised to give $E, Z$ macrocycles $\mathbf{7 5}$ and $\mathbf{7 6}$, respectively, in good yields (Scheme 28).

\subsubsection{Fe-catalysed cross-coupling}

Although iron-catalysed cross-couplings are less developed than those that are Pd-catalysed, they have still been studied to mediate such coupling reactions. ${ }^{[74]}$ Fürstner developed a formal ringopening/cross-coupling reaction that used 2-pyrones (77) and Fe-catalysis to form stereodefined dienyl carboxylates (78), relevant substrates in the field of natural product total synthesis (Scheme 29). ${ }^{[75]}$ A key feature of this transformation is the use of substrates that bear leaving groups within the heterocyclic scaffold. The reactions are rapid (20 to 40 minutes), and good selectivities towards the $2 Z, 4 E$-configured isomers were obtained when they were run and quenched at low temperature $\left(-60{ }^{\circ} \mathrm{C}\right)$. Indeed, complete isomerisation into $2 E, 4 E$-isomers (79) was detected when the reaction medium was allowed to reach room temperature prior to the work-up. The ironcatalysed transformation is highly solvent dependent, where diethyl ether ensures high levels of $E / Z$ selectivities. This methodology is illustrated in the syntheses of 82 and 83 , fragments of pateamine A and granulatamide $\mathrm{B}$, respectively (Scheme 30). ${ }^{[75]}$ 


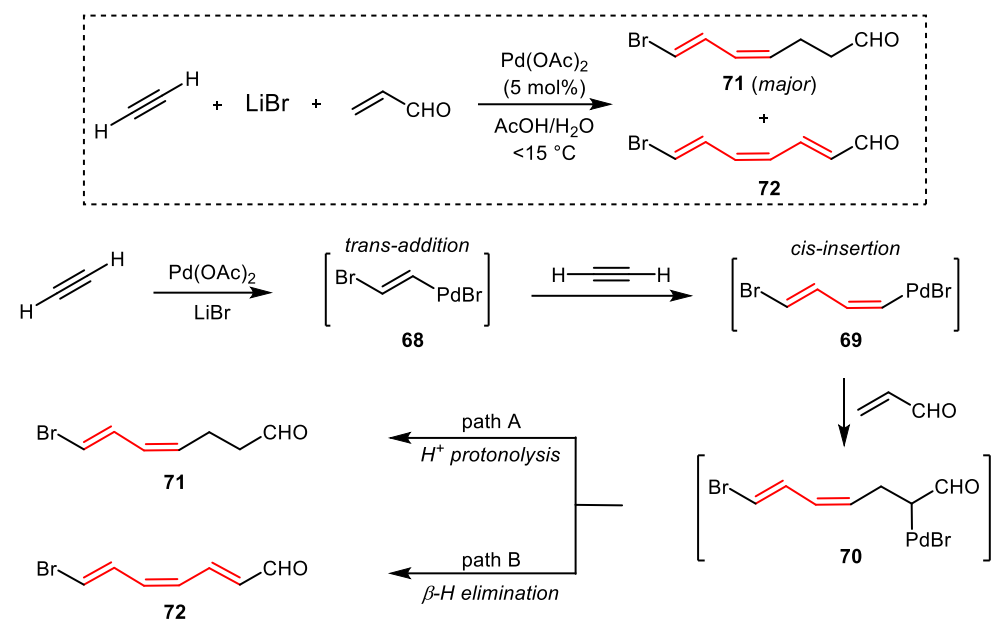

Scheme 27. Pd-catalysed coupling reaction of lithium bromide, acetylene, and acrolein.
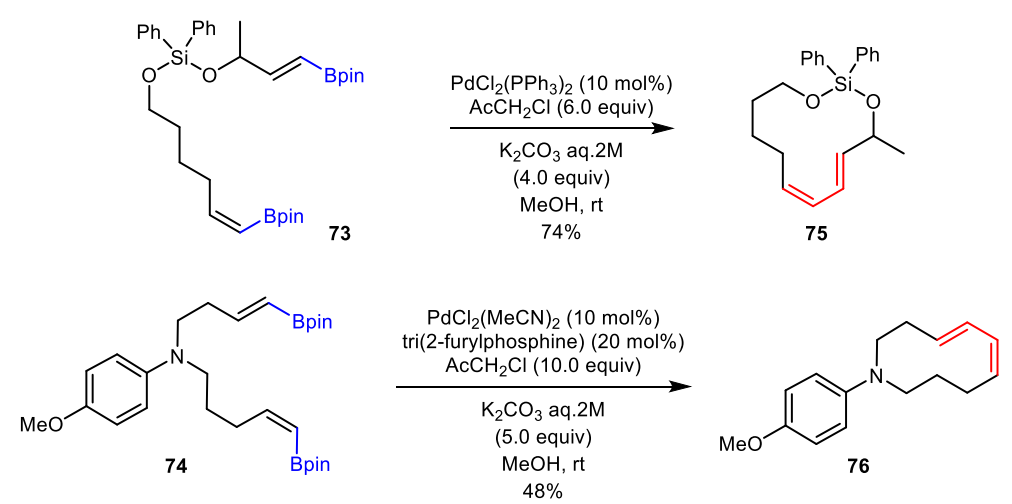

Scheme 28. Pd(II)-catalysed oxidative macrocyclisation.

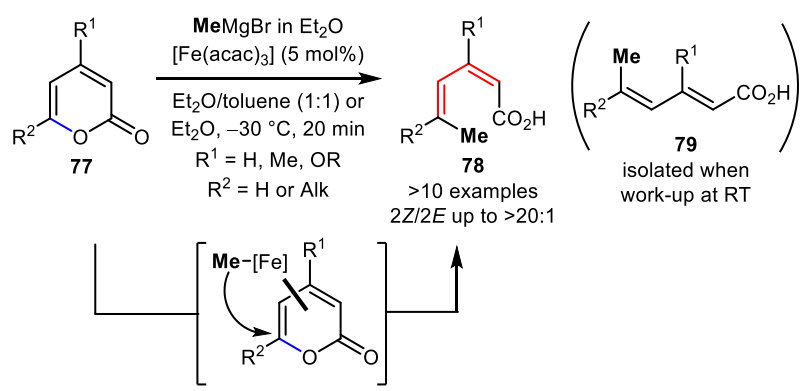

Scheme 29. Fürstner's Fe-catalysed formal ringopening/cross-coupling reaction of 2-pyrones.
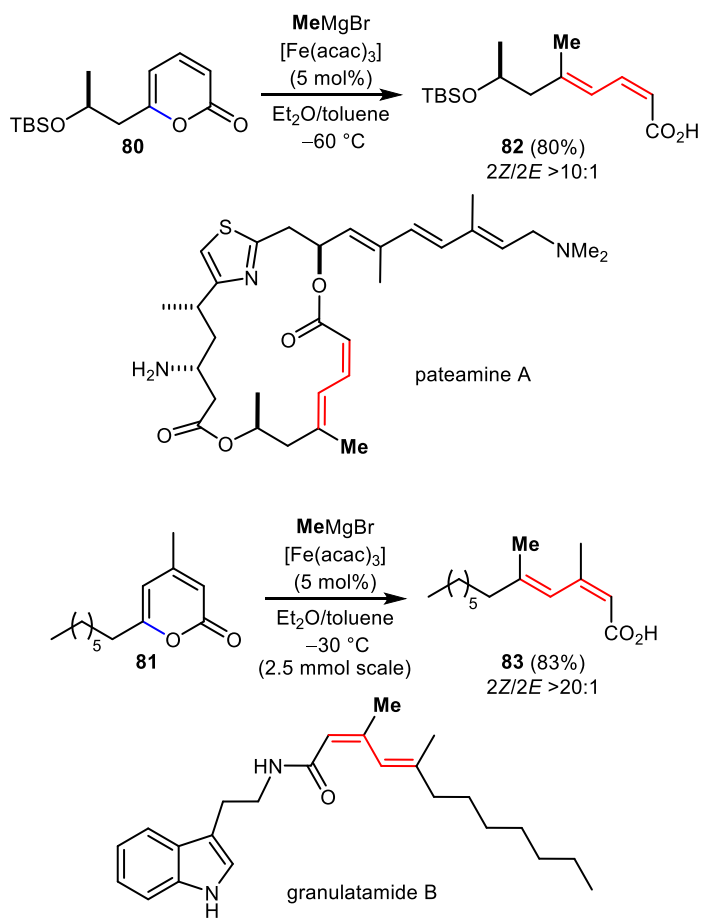

Scheme 30. Application of the Fe-catalysed formal ringopening/cross-coupling of 2-pyrone derivatives methodology in total syntheses. 


\subsubsection{Cross-coupling reactions between $\alpha$-lithiated epoxides and Grignard reagents}

Hodgson investigated the behaviour of epoxides with lithium 2,2,6,6-tetramethylpiperidide (LTMP) and organolithium/Grignard reagents towards the regioand stereoselective synthesis of olefins. ${ }^{\left[{ }^{[6]}\right.}$ It has been shown that coupling terminal epoxides (84) with stereodefined alkenyllithium or alkenylmagnesium derivatives (85) affords 1,3-dienes (88, Scheme 31). The transformation starts with the $\alpha$-deprotonation of the epoxide with LTMP. Then, the ring opening of the $\alpha$-lithiated epoxide $\mathbf{8 6}$ operates under exposure to the alkenylmetal compounds $\mathbf{8 5}$, followed by $\beta$ elimination of $\mathrm{Li}_{2} \mathrm{O}$. The reaction proceeds with full retention of the alkenylmetal precursor configuration. This method was applied to the total synthesis of the roller leaf moth pheromone, (3E,5Z)-dodecadienyl acetate.

Recently, a metal-free cross-coupling between benzothiophene $S$-oxides and styrene derivatives was developed to give $(E, Z)$-1,3-dienes via an interrupted Pummerer reaction/ligand-coupling sequence. ${ }^{[77]}$

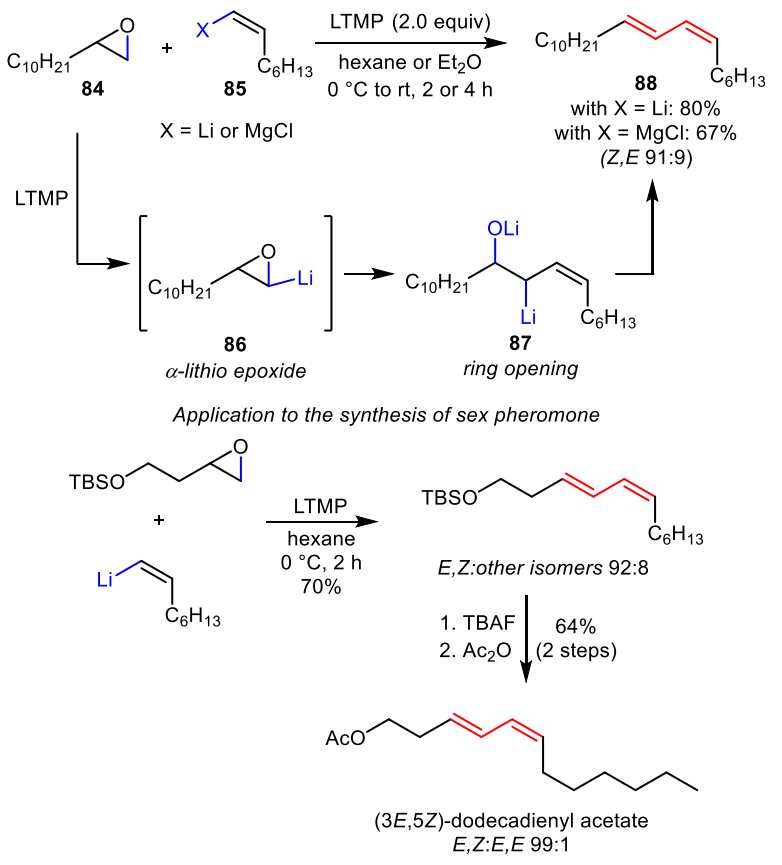

Scheme 31. 1,3-Dienes via ring-opening of $\alpha$-lithiated epoxides and application in the synthesis of a sex pheromone. LTMP = Lithium 2,2,6,6-tetramethylpiperidide.

\subsection{Heck reactions}

Pd-catalysed Heck reactions can be placed among the most important methods for forming C-C bonds. ${ }^{[78]}$ However, their application in 1,3-diene syntheses is less developed than the cross-couplings reactions described in the previous sections. The Heck reaction proceeds in the presence of a base, which is needed to promote reductive elimination and regenerate the catalytic species. However, the need for a base could be problematic for 1,3-diene syntheses because these sensitive dienes are prone to isomerisation. Nevertheless, the Heck reaction can afford a more practical, environmentally benign, and cost-effective method for the direct coupling of an alkene and a vinyl halide (Scheme 32). ${ }^{[79]}$

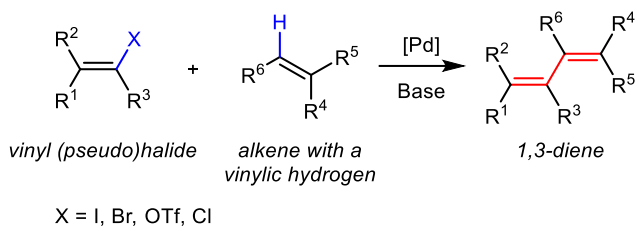

Scheme 32. Heck reaction for the synthesis of 1,3-dienes.

During the total synthesis of structurally revised (-)mandelalide A, the groups of Ghosh ${ }^{[80]}$ and Smith ${ }^{[81,82]}$ both employed an intramolecular Heck reaction to promote the macrocyclisation of $\mathbf{8 9}$, affording $\mathbf{9 0}$ (Scheme 33). In both cases, the reaction worked remarkably well. Recently, Ghosh published a full account displaying the setbacks they encountered for the macrocyclisation step, which proceeded through an ene-ene ring closing metathesis (RCM) and $E, Z$-diene formation using the Julia-Kocieński olefination (for other strategies used in the total synthesis of mandelalide A, see sections $2.2 .1 .5,2.6 .1,2.10) .{ }^{[83]}$

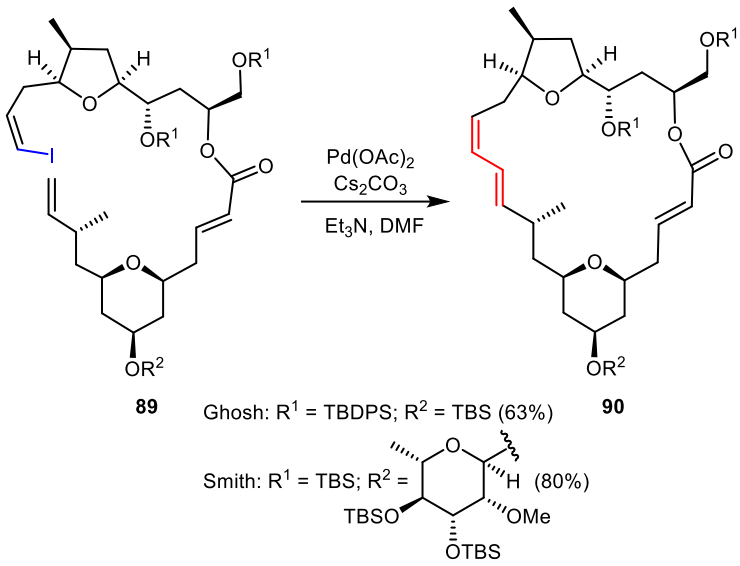

Scheme 33. Intramolecular Heck reaction for the synthesis of the macrocyclic core of (-)-mandelalide A.

Whiting reported the first synthesis of racemic phthoxazolin A by a strategy that relied on a series of Pd-catalysed reactions to stereoselectively forge the $Z, Z, E$-trienyl unit. ${ }^{[84]} \mathrm{A}$ Heck reaction under optimised, base-free conditions between a vinyl boronic ester (91) and a vinyl iodide (92) furnishes vinyl boronic ester intermediate $\mathbf{9 3}$ as the major product. A minor product (94) was also produced due to undesired Suzuki crosscoupling. Major product $\mathbf{9 3}$ then follows a deboronation-iodination sequence that inverts the alkene configuration. Finally, a Stille cross-coupling with oxazolyl alkenyl stannane concludes the synthesis (Scheme 34). A similar strategy has been used to synthesise the C1-C7 Z,Z,E-trienyl iodide moiety present in the structure of viridenomycin. ${ }^{[85]}$ Later, 
based on the selectivity problems raised by these total syntheses, a methodology for reductive dimerisation was developed that used electron-deficient terminal iodoalkenes and polyenes. ${ }^{[86]}$

In a second generation synthesis, a Heck reaction instead of a Sonogashira cross-coupling reaction (see section 2.10) was applied by Kirschning, where key fragments 96 and 97 were joined to achieve the synthesis of thuggacin derivatives (Scheme 35). ${ }^{[87]}$
Selecting the Heck reaction over the Sonogashira coupling was driven by difficulties found during a C13-C14 alkyne selective reduction. The Heck reaction was also utilised by Goswami in the total synthesis of the 14-membered macrocycle pestalotioprolide $\mathrm{G}$, where it concomitantly performed the macrocyclisation step and installed the E,Z-diene unit. ${ }^{[8]}$

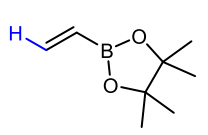

91

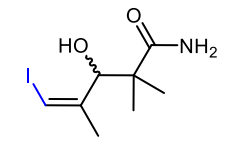

92

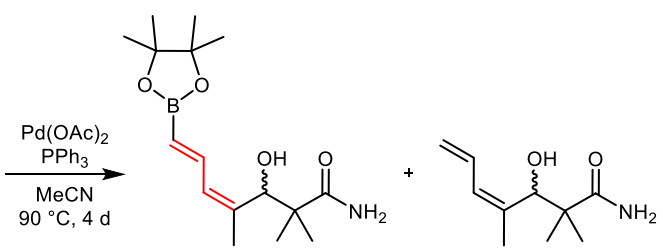

93

(Heck product)

$35 \%$

(Suzuki product)

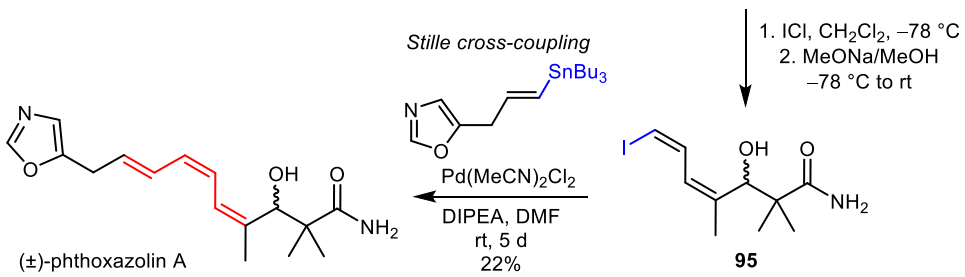

Scheme 34. Synthesis of ( \pm )-phthoxazolin A.

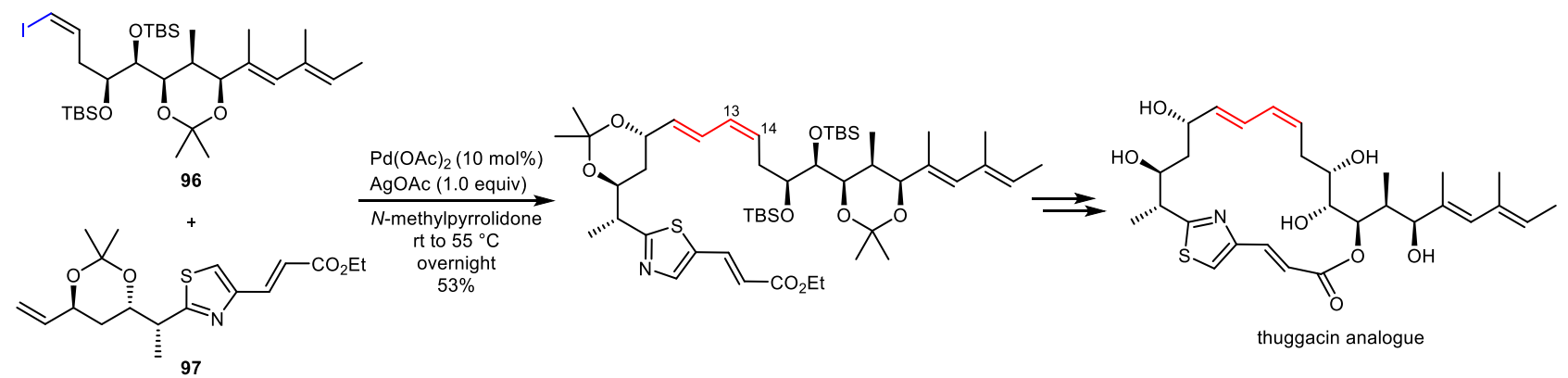

Scheme 35. Heck reaction for the synthesis of E,Z-diene on thuggacin derivatives.

\section{$2.4 \mathrm{C}-\mathrm{H}$ activation reactions}

Cross-coupling reactions are widely used to stereoselectively install E,Z-dienes; however, a major inconvenience of this method is the need for both halogenated and organometallic substrates. Thus, engaging simple, terminal olefins in transition-metalcatalysed $\mathrm{C}-\mathrm{H}$ bond activation might provide a more direct and atom-economic approach towards conjugated dienes. Following the seminal work on Pdcatalysed oxidative cross-coupling of specific terminal olefins by Ishii, ${ }^{[89]}$ Loh, ${ }^{[90]} \mathrm{Yu},{ }^{[91]}$ and Liu, ${ }^{[92]}$ the direct $\mathrm{Rh}$ - or Ru-catalysed oxidative olefination of vinylic $\mathrm{C}-$ $\mathrm{H}$ bonds has been developed by using directing groups (Scheme 36). Such methodology is beneficial due to its high selectivity for linear products over branched ones, mono-olefination, and Z-configurations.
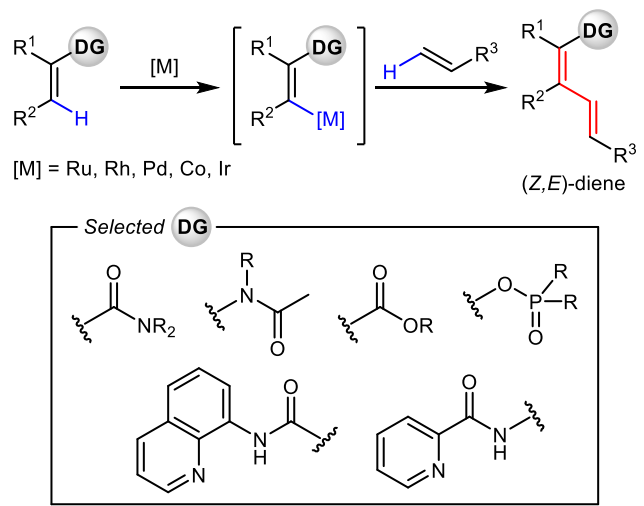

Scheme 36. Concept of direct cross-coupling reaction via $\mathrm{C}-\mathrm{H}$ activation providing $(Z, E)$-dienes. $\mathrm{DG}=$ Directing Group.

Glorius et al. combined reactive primary and tertiary crotonamides with either styrene derivatives or $n$ butylacrylate by a Rh-catalysed oxidative olefination of the vinylic $\mathrm{C}-\mathrm{H}$ bonds in the presence of $\mathrm{AgSbF}_{6}$ as an additive and $\mathrm{Cu}(\mathrm{OAc})_{2}$ as the oxidant (Scheme 
37). ${ }^{[93]}$ These reactions were performed at high temperatures and dienes (98) were obtained in moderate-to-good yields with good selectivities. By employing methyl 2-acetamidoacrylate as the directing partner, this procedure could be transposed to synthesise di-unsaturated $\alpha$-amino acid derivatives $\mathbf{9 9}$ (Scheme 38). ${ }^{[93]}$

A similar transformation with a larger scope was demonstrated by Loh and Zhang, where either $\mathrm{Ru}$ - or Rh-catalysts were used (Scheme 39). ${ }^{[94]}$ In this study, many $Z, E$-dienamides (100) were obtained in high yields with good stereoselectivities. The reaction was compatible with a broad range of electron-deficient alkenes containing various functional moieties, such as $\mathrm{CO}_{2} \mathrm{R}, \mathrm{COMe}, \mathrm{SO}_{2} \mathrm{Ph}, \mathrm{CONHBn}, \mathrm{CN}, \mathrm{PO}(\mathrm{OEt})_{2}$, and Weinreb amide. Furthermore, Zhang and Zhong published a paper on oxidant-free, $\mathrm{Ru}$-catalysed $\mathrm{C}-\mathrm{H}$ activations of unsaturated amides with allyl acetate (101). ${ }^{\left[{ }^{[5]}\right.}$ After optimisation studies, a straightforward protocol was devised to selectively allow the formation of 1,3-(Z,E)-butadienes (102) instead of 1,4-dienes (103, Scheme 40).

One year later, the same Ru-catalyst was used to synthesise primary $(Z, E)$-dienamide $\mathbf{1 0 5}$ through the assistance of an oxidizing directing group (Scheme 41, eq (a)). ${ }^{[96]}$ According to the authors, after the $\mathrm{C}-\mathrm{H}$ activation and olefin insertion, the ruthenium inserting into the $\mathrm{N}-\mathrm{OMe}$ bond is essential for regenerating the catalytic active $\mathrm{Ru}(\mathrm{II})$ species. Alternatively, in the presence of a stoichiometric oxidant, the $\mathrm{C}-\mathrm{H}$ activation of Weinreb acrylamides could be carried out under Rh-catalysed conditions, affording 106 (Scheme 41, eq (b)). ${ }^{[97]}$
Amide moieties could be successfully replaced by other functional groups that can act as directing groups to synthesise Z,E-dienes (Scheme 42). Liu and Zhang proposed an ester-directed selective olefination of arylacrylate derivatives via $\mathrm{Rh}$-catalysed vinylic $\mathrm{C}-\mathrm{H}$ activation to obtain dienes 107. ${ }^{[98]} \mathrm{A}$ similar transformation with a broader substrate scope was proposed one year later by Loh and $\mathrm{Xu}$, where they employed $\mathrm{Ru}$-catalysis to synthesise functionalised $Z, E$-muconate derivatives (108). ${ }^{[99]}$

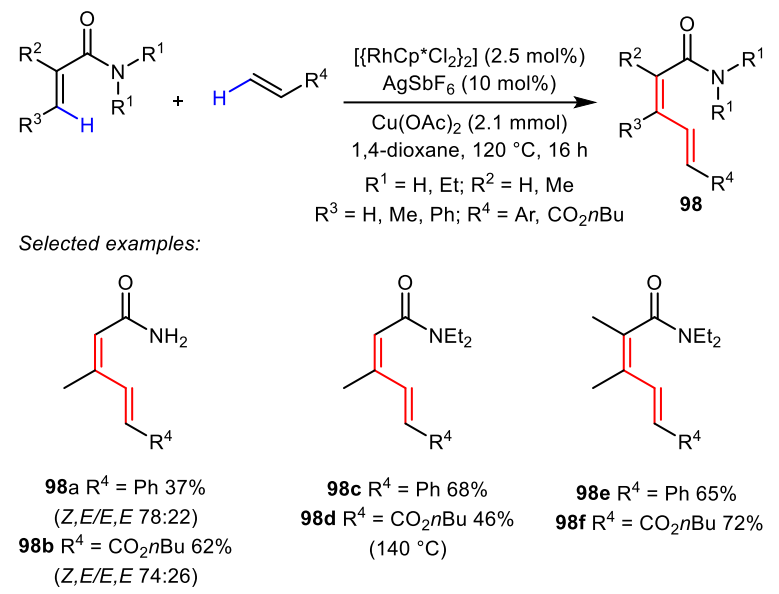

Scheme 37. Rh-catalysed oxidative olefination of vinylic $\mathrm{C}-\mathrm{H}$ bonds.

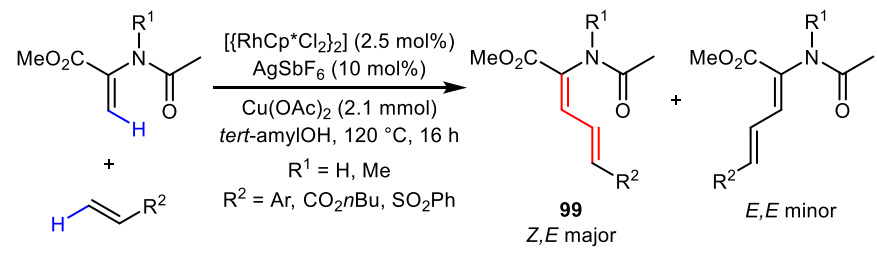

Selected examples:

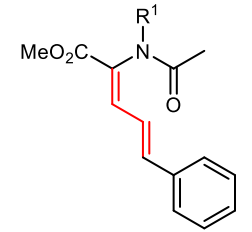

99a $\mathrm{R}^{1}=\mathrm{H}(Z, E / E, E 75: 12)$

99b $\mathrm{R}^{1}=\mathrm{Me}$

(only Z,E-isomer isolated in $63 \%$ )

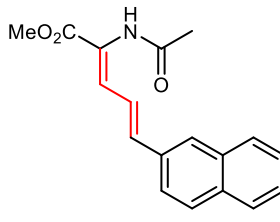

$\stackrel{99 c}{(Z, E / E, E 64: 11)}$

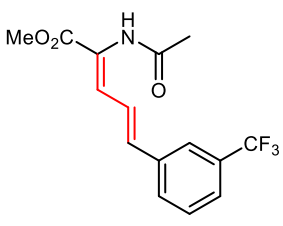

99d

$(Z, E / E, E 70: 11)$

Scheme 38. Glorius' conditions: Application to the synthesis of $\alpha, \beta-\gamma, \delta$-unsaturated amino acid derivatives. 


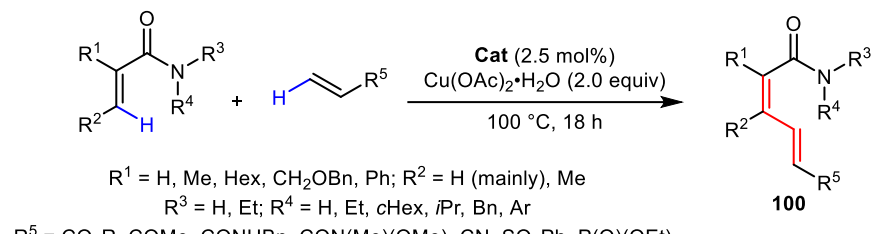

$\mathrm{R}^{5}=\mathrm{CO}_{2} \mathrm{R}, \mathrm{COMe}, \mathrm{CONHBn}, \mathrm{CON}(\mathrm{Me})(\mathrm{OMe}), \mathrm{CN}, \mathrm{SO}_{2} \mathrm{Ph}, \mathrm{P}(\mathrm{O})(\mathrm{OEt})_{2}$
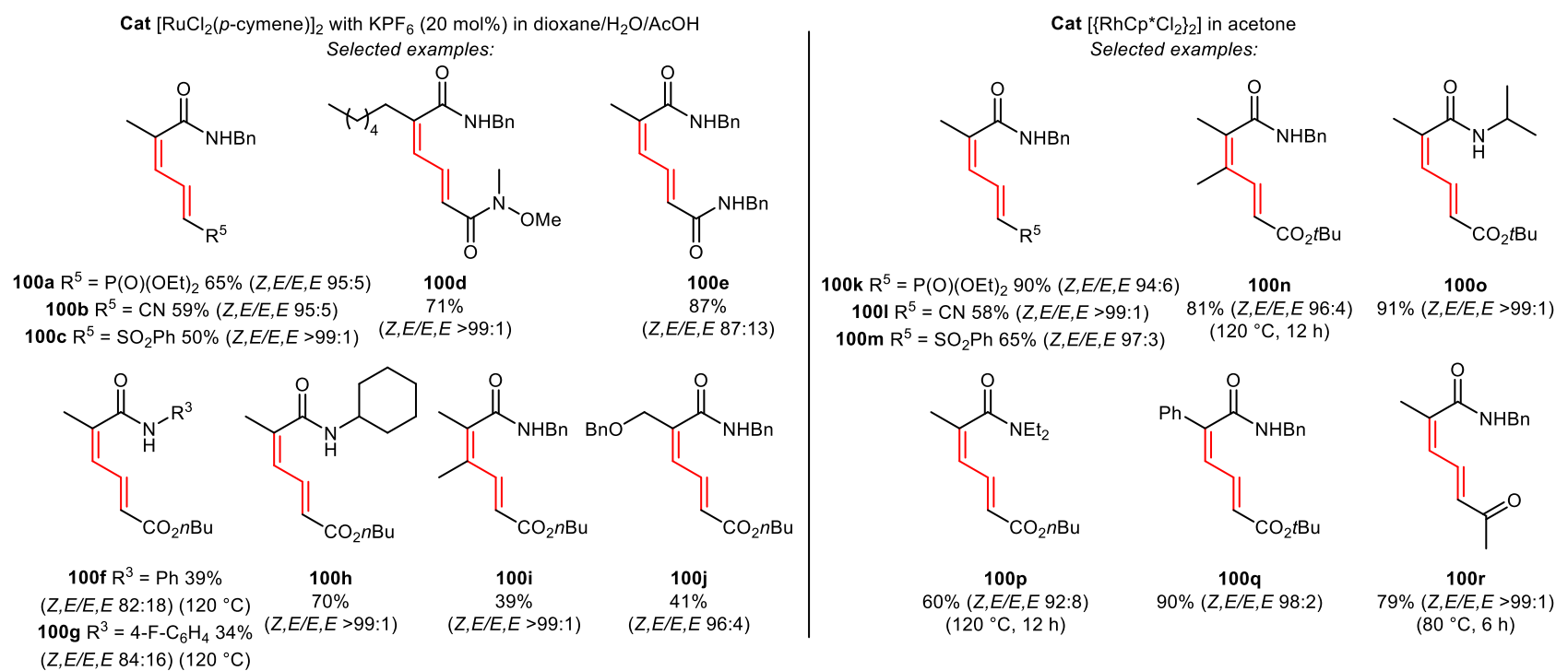

Scheme 39. Rh- or Ru-catalysed oxidative olefination of vinylic $\mathrm{C}-\mathrm{H}$ bonds.
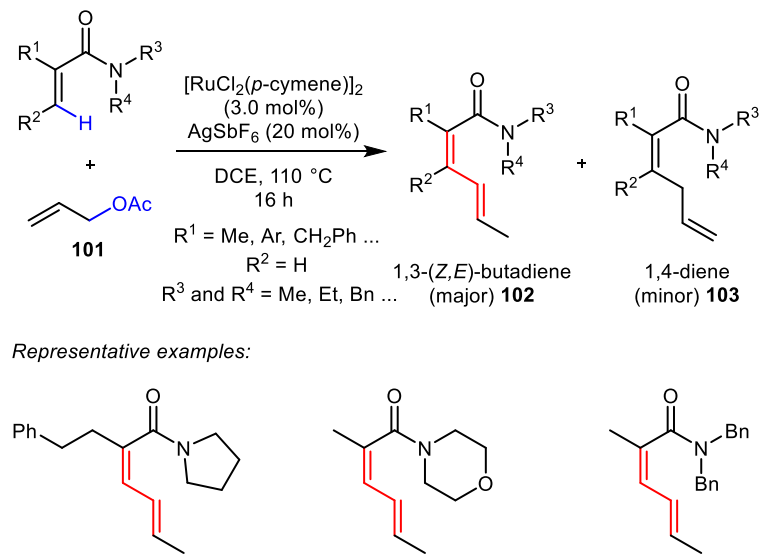

102/103 86:14 (47\%) $(Z, E / E, E 88: 12)$

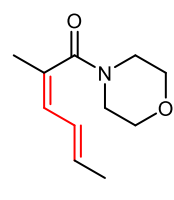

102/103 98:2 (59\%) $(Z, E / E, E$ 85:15)

Scheme 40. Oxidant free direct vinylic $\mathrm{C}-\mathrm{H}$ activation by $\mathrm{Ru}$-catalysis.

a) With N-methoxy-2-methyl-2-propenamide

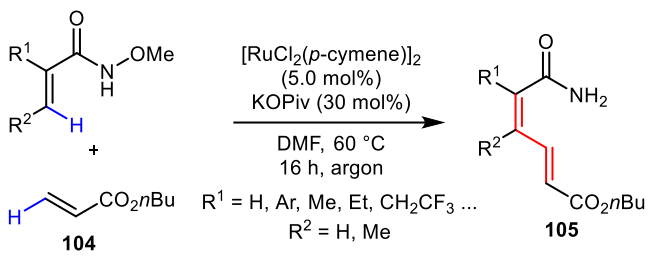

b) With Weinreb acrylamide

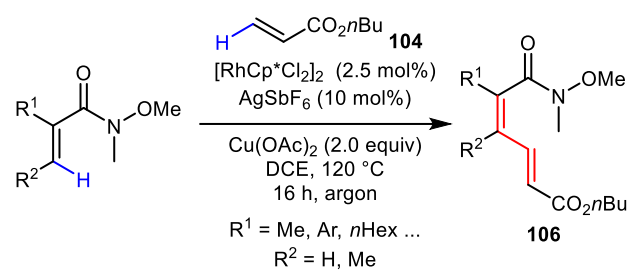

Scheme 41. Z,E-Dienamide synthesis with amides as directing groups. 
Esters as directing groups Liu and Zhang 2014

$\overbrace{\mathrm{OR}^{1}}$

$+$

$\mathrm{H}^{\mathrm{R}^{2}}$

Loh and Xu 2015<smiles>[R]C=C([R])C(=O)O[Z]</smiles>

${ }^{+}{ }^{+} \mathrm{CO}_{2} \mathrm{R}^{4}$
$\left[\mathrm{RhCp}^{*} \mathrm{Cl}_{2}\right]_{2}$
$(5.0 \mathrm{~mol} \%)$
$\underset{\mathrm{AgSbF}}{\mathrm{Au}(20 \mathrm{OAc})_{2}(2.0 \text { equiv })}$ acetone, HOAc (15 equiv) $110^{\circ} \mathrm{C}, 24 \mathrm{~h}, \mathrm{~N}_{2}$

$\mathrm{R}^{1}=\mathrm{Me}, \mathrm{Et}$ $\mathrm{R}^{2}=\mathrm{Ar}, \mathrm{CO}_{2} \mathrm{R}$

\section{$\left[\mathrm{RuCl}_{2}(p \text {-cymene })\right]_{2}$} (5. $\mathrm{mol} \%)$

$\underset{\mathrm{Cu}(\mathrm{OAc})_{2} \cdot \mathrm{H}_{2} \mathrm{O}}{\stackrel{\mathrm{AgSbF}_{6}(20 \mathrm{~mol} \%)}{\longrightarrow}}$

(2.0 equiv)

1,4-dioxane

$135^{\circ} \mathrm{C}, 24 \mathrm{~h}$

$\mathrm{R}^{1}=\mathrm{Ph}, \mathrm{Me}, c \mathrm{Hex}, n \mathrm{Hex}$

$\mathrm{R}^{2}=\mathrm{H}, \mathrm{Me}, \mathrm{Ar} ; \mathrm{R}_{3}=\mathrm{Et}, n \mathrm{Bu}, n \mathrm{Pr}$

$\mathrm{R}^{4}=\mathrm{Me}, \mathrm{Et}, \mathrm{Ph}, \mathrm{Bn}, \mathrm{CH}_{2} \mathrm{CF}_{3} \ldots$

Scheme 42. Esters as directing groups in $\mathrm{Rh} / \mathrm{Ru}$-catalysed direct vinylic $\mathrm{C}-\mathrm{H}$ functionalisation.

Glorius and Loh described protocols for $\mathrm{Rh}$ catalysed $\mathrm{C}-\mathrm{H}$ functionalisation via enol-carbamates and enol-phosphate derivatives, respectively, for the selective functionalisation of ketone-containing compounds. ${ }^{[100,101]}$ Later on, Zhong and Zhang developed the synthesis of Z,E-butadienes from enolcarbamates by using Ru-catalysis. ${ }^{[102]}$

Isotopically labelled experiments have been carried out to investigate the mechanism behind vinylic $\mathrm{C}-\mathrm{H}$ bond olefinations. ${ }^{[93-101]}$ The results showed that the catalytic cycle was initiated by a cyclometalation via $\mathrm{C}-\mathrm{H}$ bond activation, giving rise to a five-membered ruthanacycle or rhodacycle (109 and $\left.\mathbf{1 0 9}^{\prime}\right)$. Subsequent coordination of the alkene to the metal centre is followed by insertion of the double bond to afford a seven-membered ruthanacycle or rhodacycle species $(\mathbf{1 1 0}$ and $110 '$ '). Evolution through $\beta$-elimination affords the expected $Z, E$-dienes (100) and reduced metallic species, which is reoxidised to be used again (Scheme 43).

Liu and Engle recently described a procedure to synthesise (Z,E)-1,3-dienes (112) through a $\mathrm{Pd}$ catalysed C-H activation. ${ }^{[103]}$ This method relies on the combination of an electron-poor olefin with internal or terminal alkenes that are conjugated or non-conjugated (e.g. 4-pentenoic acids, allylic alcohols, and bishomoallylic amines) and bear a bidentate directing group (111, Scheme 44).

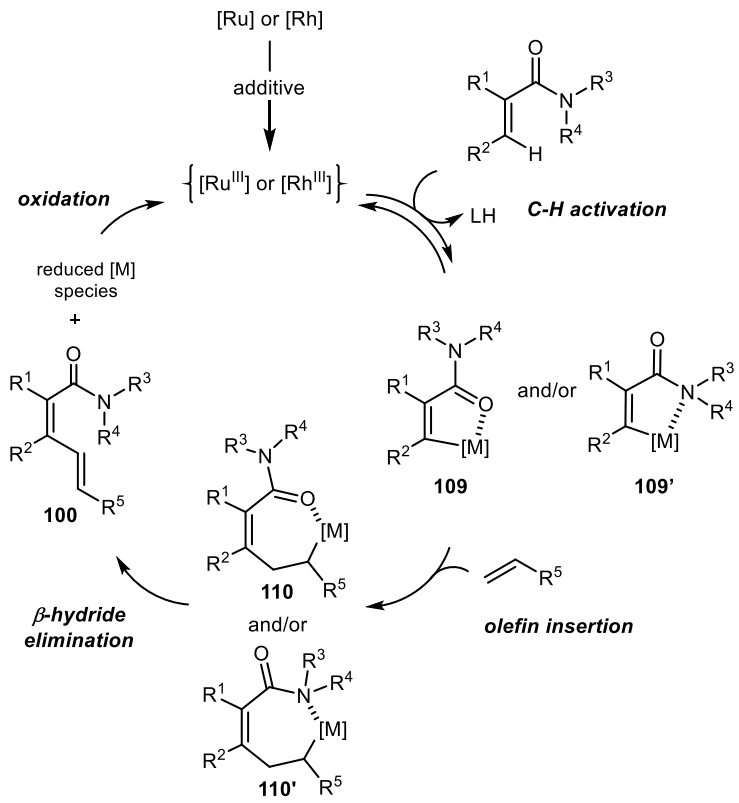

Scheme 43. Proposed general mechanism for the direct Rhor $\mathrm{Ru}$-catalysed oxidative olefination of vinylic $\mathrm{C}-\mathrm{H}$ bonds.
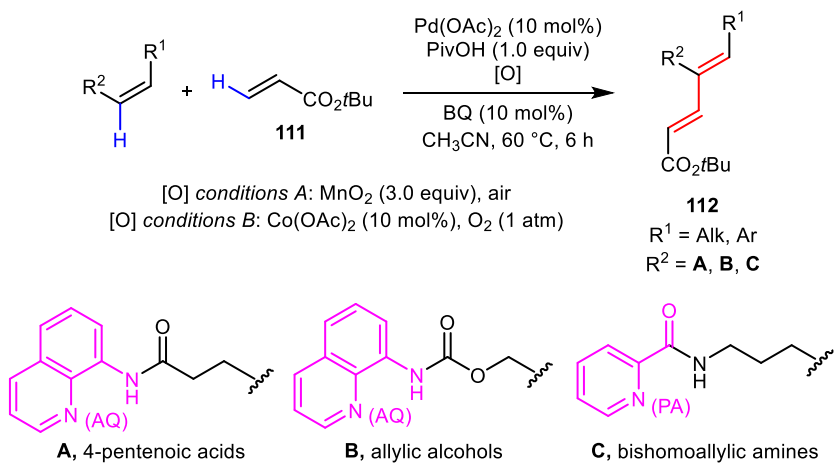

Scheme 44. 1,3-Diene 112 synthesis via Pd-catalysed C-H activation. $\mathrm{AQ}=8$-aminoquinoline, $\mathrm{PA}=$ picolinamide, $\mathrm{BQ}$ $=$ benzoquinone.

The 8-aminoquinoline ${ }^{[104]}(\mathrm{AQ})$ directing group can easily be removed by $\mathrm{Ni}$-catalysed methanolysis, ${ }^{[105]}$ and mechanistic studies have suggested the transient formation of a six-membered palladacycle. Zhang and Zhong also described the use of either Ir- or Cocomplexes to synthesise $Z, E$-dienamides with excellent selectivities $(Z, E / Z, Z>99: 1)$ through $\mathrm{C}-\mathrm{H}$ activation. ${ }^{[106,107]}$ 1,3-Dienes (113) were synthesised via Ir-catalysis thanks to the combination of $\mathrm{C}-\mathrm{H}$ activation and hydrogen transfer in a metal-oxidantfree procedure using chloranil (114) as a hydrogen acceptor (Scheme 45). ${ }^{[106]}$ 

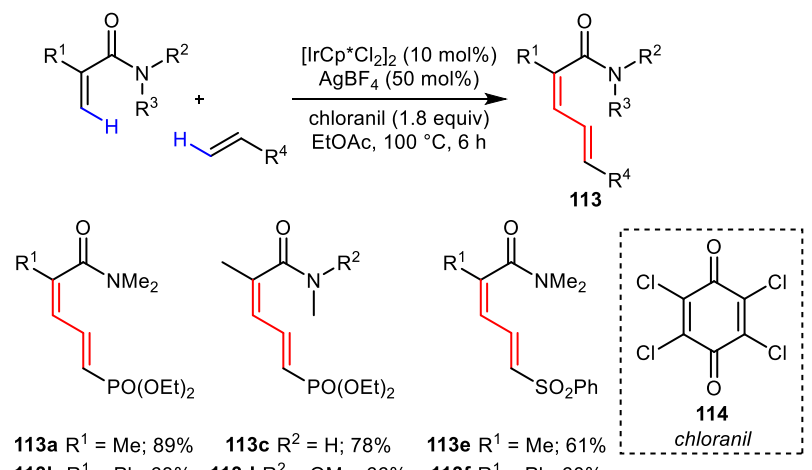

113b $R^{1}=P h ; 63 \% \quad 113 d R^{2}=O M e ; 66 \% \quad 113 f R^{1}=P h ; 60 \%$

Scheme 45. Ir-catalysed C-H(alkenylation) and hydrogen transfer for the synthesis of $(Z, E)-1,3$-dienamides 113.

Besides, Co-complexes can catalyse olefinic $\mathrm{C}-\mathrm{H}$ alkenylation of electron-deficient olefins in the presence of $\mathrm{Ag}$-salts (i.e. $\mathrm{AgSbF}_{6}$ as an additive and $\mathrm{AgOAc}$ as an oxidant) and $\mathrm{AcOH}$ to give dienamides (115, Scheme 46). ${ }^{[107]}$

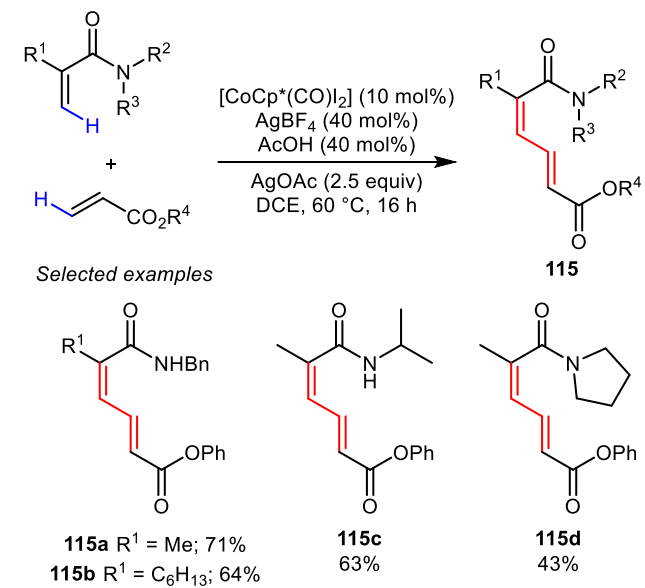

Scheme 46. Co-catalysed $\mathrm{C}-\mathrm{H}$ (alkenylation) for the synthesis of $(Z, E)$-1,3-dienamides $\mathbf{1 1 5}$.

$\mathrm{Xu}$ and Loh described an elegant procedure for the synthesis of macrolides through the intramolecular oxidative cross-coupling of tethered alkenes $\mathbf{1 1 6}$ through Rh-catalysis. ${ }^{[108]}$ Macrocycles $(117 ;$ e.g. 12-, 13-, 14-, 19- and 20-membered macrocyclic compounds) containing a 1,3-diene moiety were isolated in moderate yields and with excellent $Z, E$ selectivities (Scheme 47).

Mechanistic insights, supported by experimental observations and literature reports (see scheme 43), suggest that the amide group acts as the directing group during the $\mathrm{C}\left(\mathrm{sp}^{2}\right)-\mathrm{C}\left(\mathrm{sp}^{2}\right)$ bond formation step, ensuring the $Z, E$-configuration of the final macrolides. Vinylic $\mathrm{C}-\mathrm{H}$ activation reactions have received increasing interest and afforded the expected dienes in high yields and with high selectivities. Yet, to the best of our knowledge, none of these $\mathrm{C}-\mathrm{H}$ activation strategies have been applied to complex and/or natural product syntheses.

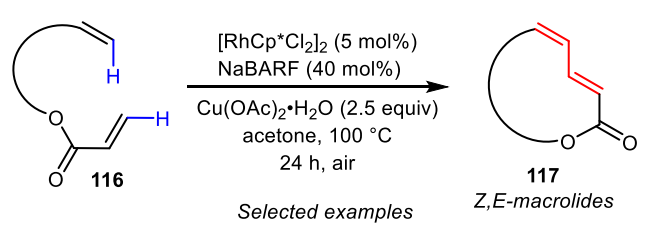

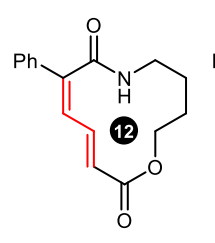

(24\% of $Z, Z$-macrolid $)$
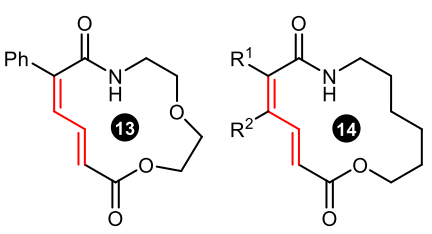

$117 b \quad 117 c R^{1}=P h, R^{2}=H ; 65 \%$ $117 \mathrm{~d} \mathrm{R} \mathrm{R}^{1}=\mathrm{Me}, \mathrm{R}^{2}=\mathrm{H} ; 69 \%$ $117 \mathrm{e} \mathrm{R}^{1}=\mathrm{Bn}, \mathrm{R}^{2}=\mathrm{H} ; 59 \%$ $117 f R^{1}, R^{2}=P h ; 26 \%$
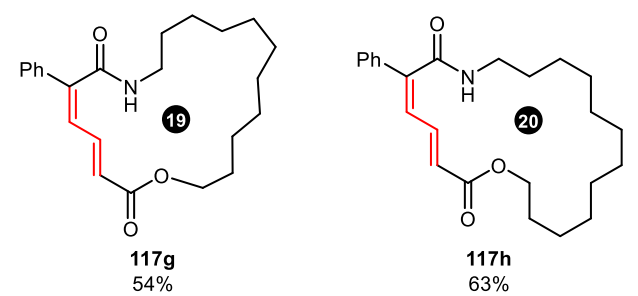

Scheme 47. Synthesis of macrocycles 117 bearing a $(Z, E)$ 1,3-diene moiety via intramolecular oxidative alkenes crosscouplings.

\subsection{Ir-catalysed olefinations}

Lundgren recently developed a Z-selective, $\mathrm{Ir}$ catalysed coupling reaction of $\alpha$-aryl diazo esters (118) with allyl carbonates (119) to form substituted Z,Edienoates (120, Scheme 48). ${ }^{[109]}$ Key features of the method are i) remarkable control of the Z-geometry of the newly formed carbon-carbon double bond, ii) higher selectivities than those of traditional olefinations of carbonyl compounds with hindered phosphate derivatives $(\mathbf{1 2 2} \rightarrow \mathbf{1 2 3}, \quad$ Still-Gennari modification of HWE, see section 2.6), and iii) unique reactivity and selectivity stemming from merging $\mathrm{Ir}$ carbene and Ir-allyl species.

The proposed mechanism is depicted in Scheme 49. Catalyst activation with $\mathrm{Et}_{3} \mathrm{~N}$ (121) and concomitant liberation of the allylic ammonium species (124) is followed by the insertion of diazo compound 118. The Ir-carbene species (125) formed might endure oxidative addition of the allylic carbonate (119) to form an $\eta^{1}$-allyl/carbene intermediate (126). The expected diene (120) and free catalyst are released after sequential migratory insertion and $\beta$-hydride elimination. Though it has not yet been completely established, the authors assume that the $Z$-selectivities might be associated with the hindrance of the ester group, the nature of the allylic leaving group, and the large coordination sphere of the catalyst. The Ircatalysed carbene coupling to obtain $Z, E$-dienoates is a nice alternative for coupling reactions and broadens the scope of Z-selective alkene olefination. 


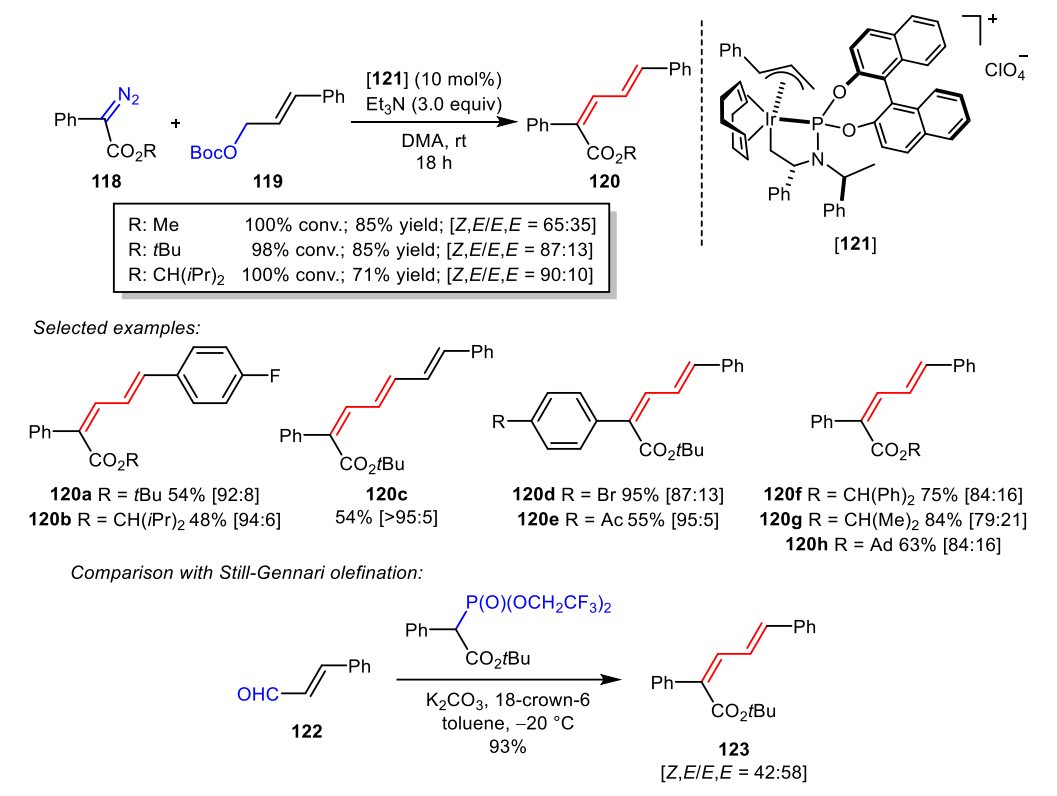

Scheme 48. Ir-catalysed coupling reaction of allylic carbonates and $\alpha$-aryl diazo esters. Ad = 1-Adamantyl.

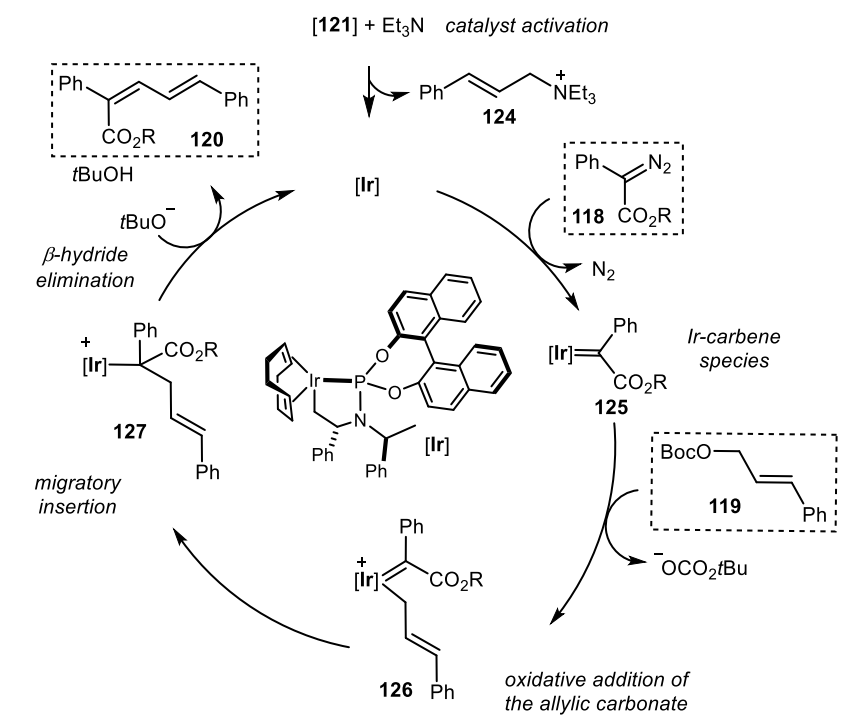

Scheme 49. Proposed mechanism for the Ir-catalysed coupling reaction devised by Lundgren.

\subsection{Carbonyl olefination reactions}

In addition to cross-coupling reactions, carbonyl olefination ${ }^{[110]}$ represents another widespread approach for the synthesis of $(E, Z)-1,3$-dienes. Overall, they present good functional group tolerance and the reactants are often readily available. However, low atom economy, difficulty reaching high levels of stereocontrol (in some cases), and the use of strong bases are also associated with these reactions, which may reduce their attractiveness. Despite these drawbacks, olefinations of carbonyl compounds are broadly used to fix either $E$ or $Z$ double-bond configurations of important intermediates during total syntheses of complex molecules and natural products.

In this section, we chose to highlight the formation of $E, Z$-dienes that combines $\alpha, \beta$-unsaturated aldehydes (as the electrophilic partner) with alkyl-derived nucleophiles, such as phosphonium salts, sulfones, and silyl derivatives (Scheme 50, eqs (a) and (b)). Nevertheless, examples of coupling simple aldehydes with allylic nucleophiles (Scheme 50, eq (c)) and olefinations from unsaturated lactols (Scheme 50, eq (d)) are also reported in this section. Carbonyl olefinations that are associated with cross-couplings (section 2.2) $)^{[42]}$ and forming conjugated dienes in natural products (section 3 ) are also discussed. 
(a)

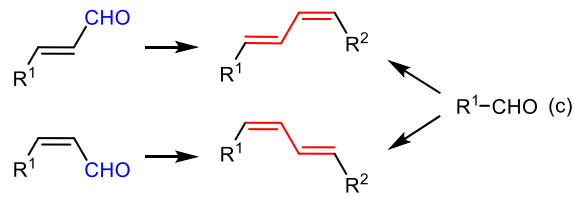

(d)

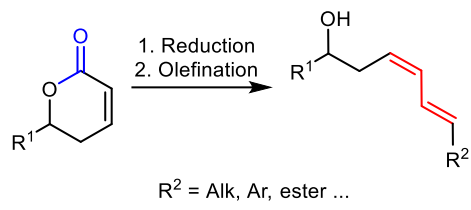

Scheme 50. Olefination reactions of unsaturated aldehydes towards conjugated dienes.

\subsubsection{Wittig-type reactions}

Among the various carbonyl olefination methods that construct E,Z-dienes, the Wittig reaction and its variants are the most commonly used. ${ }^{[111]}$ Likewise, they are a powerful tool in organic chemistry to functionalise 1,3-dienes when enals are engaged as starting materials. In this sub-section, we are going to illustrate the use of Wittig-type reactions to settle the second $Z$ or $E$ double bond within a conjugated $E$,Z- or $Z$, $E$-diene, starting from either an $E$ or $Z$ enal.

Insect sex pheromones containing $E, Z$-dienes are often the substrate of choice for efficient strategies based on Wittig olefinations. Indeed, Huang described the synthesis of four insect sex pheromones via a $Z$ selective Wittig olefination of $(E)$ - $\alpha, \beta$-unsaturated aldehydes in the presence of phosphonium salts and $n \mathrm{BuLi} / \mathrm{HMPA}$. Starting from enal 128, the synthesis of two of aldehydes, $\mathbf{1 2 9}$ and 130, is highlighted in Scheme 51 (Z:E 92-96\%). ${ }^{[12]}$

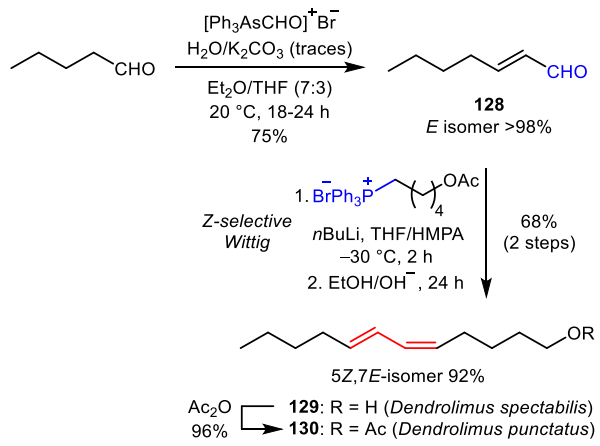

Scheme 51. Sex-pheromones via Z-selective Wittig olefinations.

Additionally, Christmann proposed a bidirectional, organocatalytic synthesis of a small library of lepidopteran sex pheromones via a double Wittig olefination followed by a second Z-selective Wittig reaction to afford trienals. ${ }^{[113]}$ To illustrate this strategy, tethered $(E)$ - $\alpha, \beta$-unsaturated bis-aldehyde $\mathbf{1 3 1}$ was converted into 132 by Z-olefination, followed by a regioselective, organocatalysed transfer hydrogenation that afforded $\mathbf{1 3 3}$ (Scheme 52).

The synthesis of polyunsaturated fatty acid derivatives was also accomplished by taking advantage of Wittig olefinations to install the E,Z-diene moieties that are common in compounds of this type. ${ }^{[114-118]} \mathrm{As}$ an example, the synthesis of primary alcohol 136, a key intermediate for preparing $(14 S, 21 R)$-dihydroxy docosahexaenoic acid (diHDHA), is depicted in Scheme 53. ${ }^{[15]}$

A target that inspired the use of Wittig and related olefination reactions is (-)-callystatin A (Scheme 54). Crimmins and Marshall proposed a sequence of StillGennari/E-selective Wittig reactions to install the $Z, E$ diene present in this compound (see intermediate 138). ${ }^{[19,120]}$ Later on, Enders showed that using the conditions of Ando considerably improved the ratio of the Z-olefin on 137 from 8:1 to 34:1. ${ }^{[121]}$ Similar approaches were also used during total syntheses of $(-)$-kazusamycin A and (+)-ratjadone. ${ }^{[122-125]}$

An $E$-selective Wittig reaction between enal 139 and phosphonium salt $\mathbf{1 4 0}$ was used by Roush during the total synthesis of (+)-superstolide A, giving isomerically pure pentaene $\mathbf{1 4 1}$ (Scheme 55). ${ }^{[126]}$

White developed a methodology for synthesizing $(Z, E)$-1,3-dienes (145) via a three-component coupling reaction. ${ }^{[127]}$ The transformation encompasses tandem addition of an enolate dianion (142) to a dienylphosphonium salt (143) to form an ylide intermediate (144), which is prone to react with an aldehyde via a $Z$-selective Wittig reaction (Scheme 56). Improved stereoselectivities were observed using $\alpha$ branched aldehydes and $\beta$-dicarbonyl dianions. Good nucleophiles were required to suppress the reversibility of the first step (nucleophile addition) and the reactive aldehydes to avoid isomerisation of the ylide $(E \rightarrow Z)$ through a rapid Wittig reaction. The method was successfully applied to the total synthesis of the macrolide (+)-latrunculin A (Scheme 57). ${ }^{[128,129]} E, Z$ diene 147 was almost exclusively formed, as only traces of the $E, E$-isomer were detected.

Carter proposed using a $Z$-selective Wittig olefination between 148 and 149 to install the E,Zdiene moiety present on the structure of mandelalide A (intermediate 150, Scheme 58). ${ }^{[130]}$ Sections 2.2.1.5, 2.3, and 2.10 discuss other strategies used for the total synthesis of mandelalide A. 


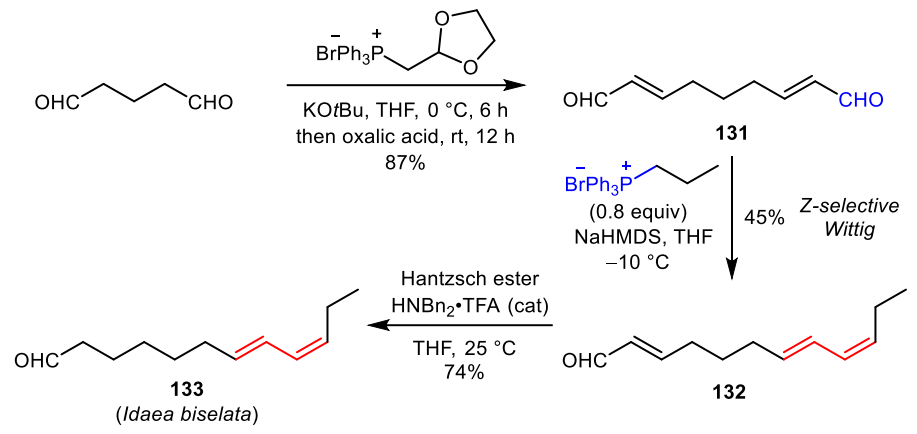

Scheme 52. Bidirectional synthesis of sex-pheromones via Wittig olefinations.

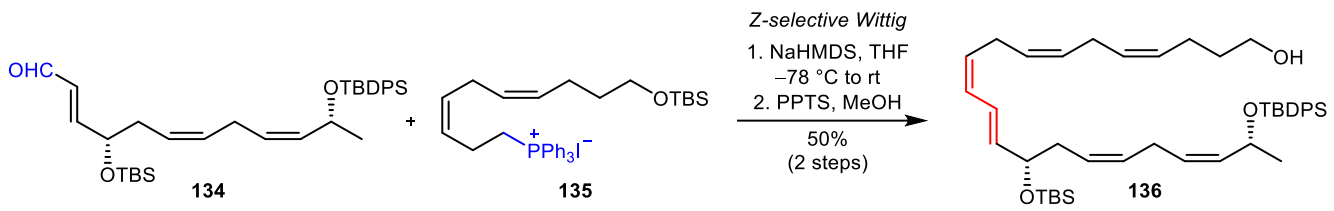

Scheme 53. Synthesis of polyunsaturated alcohol 136 using Wittig olefination.

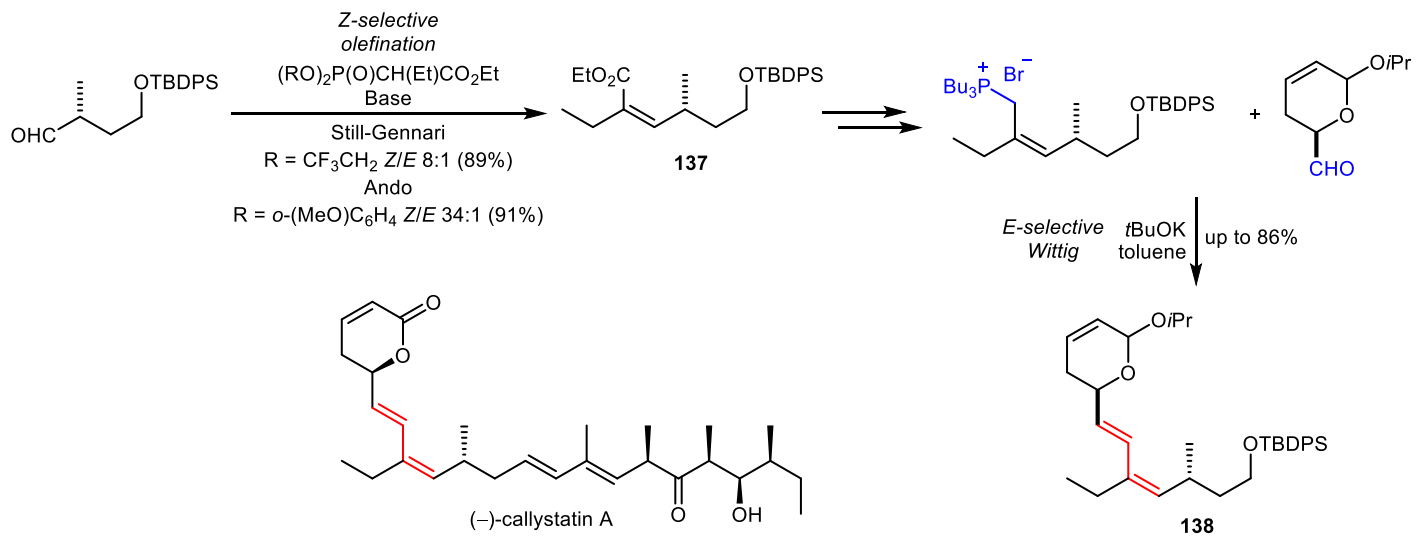

Scheme 54. Olefination reactions on the Z,E-diene synthesis of callystatin A.
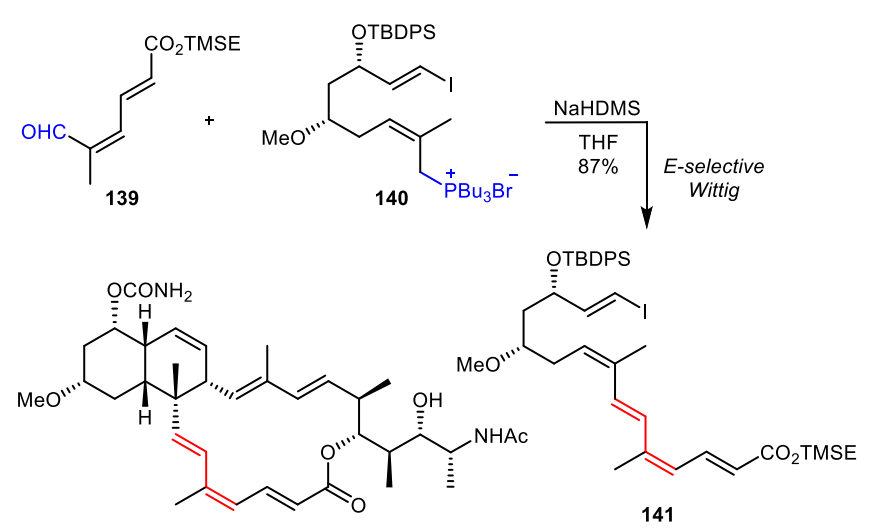

(+)-superstolide A

Scheme 55. Synthesis of the Z,E-diene 141 unit during the total synthesis of superstolide A. TMSE = trimethylsilylethyl. 


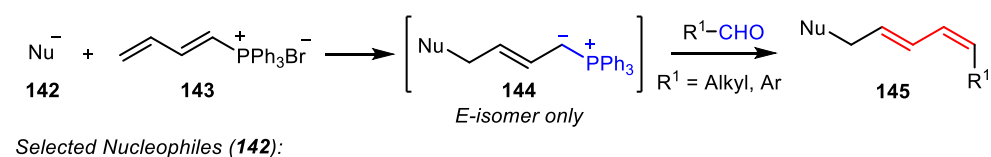

Selected Nucleophiles (142)

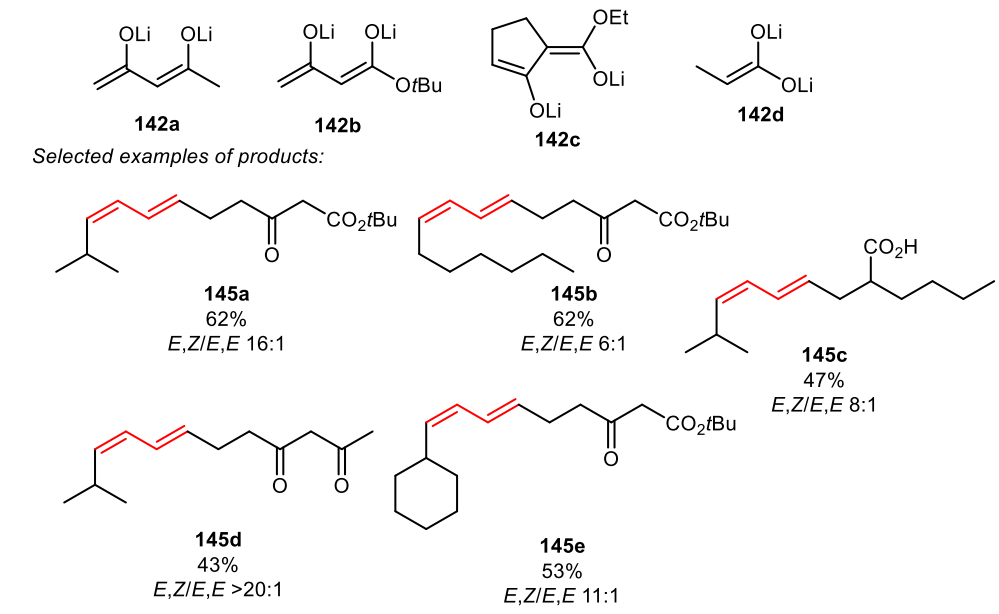

Scheme 56. (Z,E)-1,3-Dienes via a three-component coupling reaction.

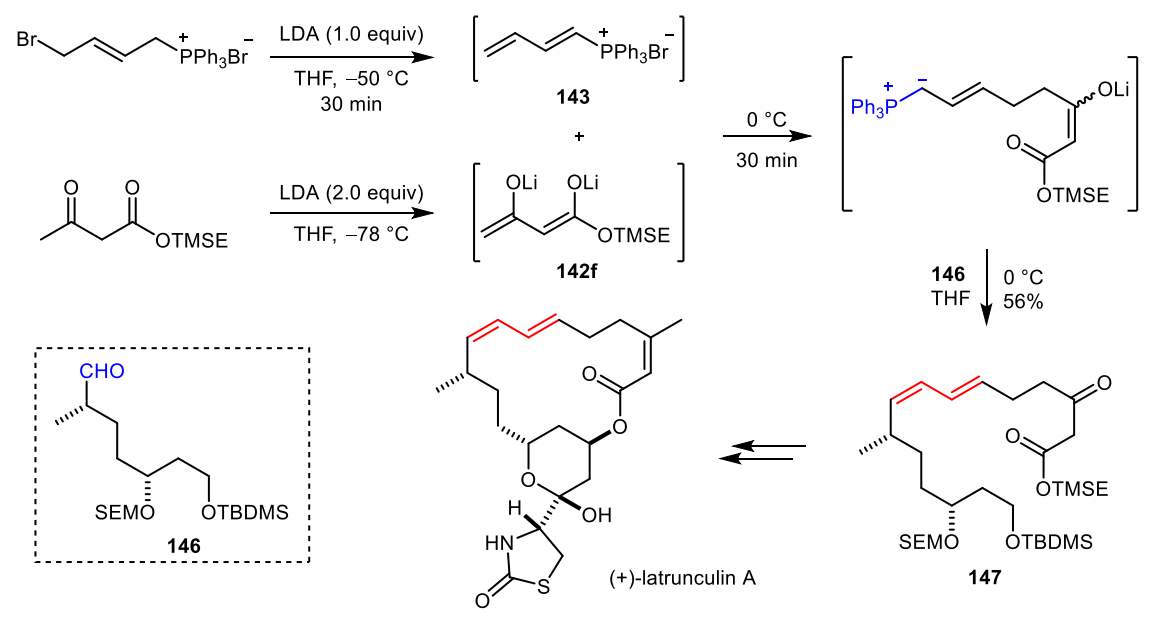

Scheme 57. Synthesis of (+)-latrunculin A. SEM = 2-(trimethylsilyl)ethoxymethyl.
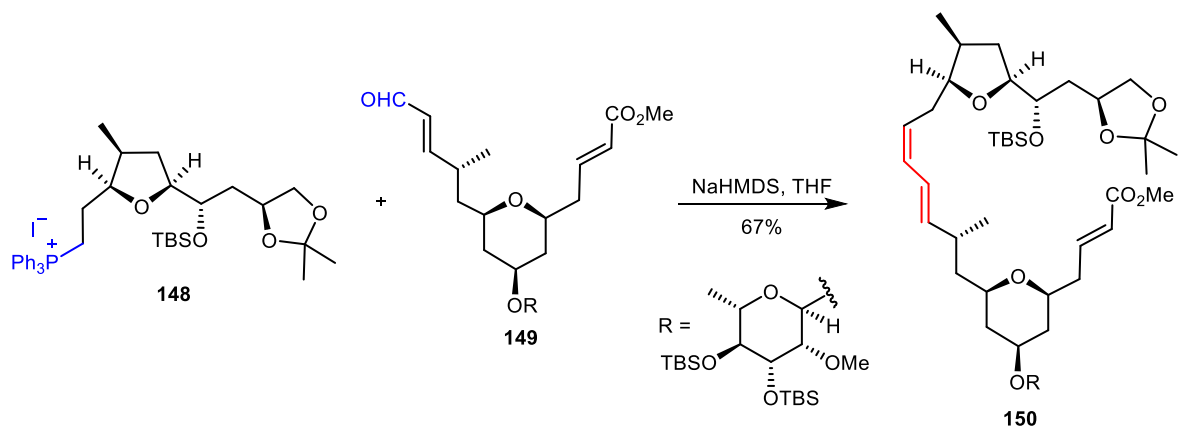

Scheme 58. Z-Selective Wittig olefination on the synthesis of mandelalide A.

During the synthesis of a simplified disorazole analogue, Kalesse employed a strategy that used unsaturated lactone $\mathbf{1 5 1}$ as the starting material. This lactone, prepared from a catalytic asymmetric vinylogous Mukaiyama (CAVM) reaction, ${ }^{[131]}$ was first reduced by DIBAL before $E$-selective HWE olefination. ${ }^{[132]}$ The method allowed the synthesis of key fragment 152 that contained the required $E, Z$-diene unit (Scheme 59). 


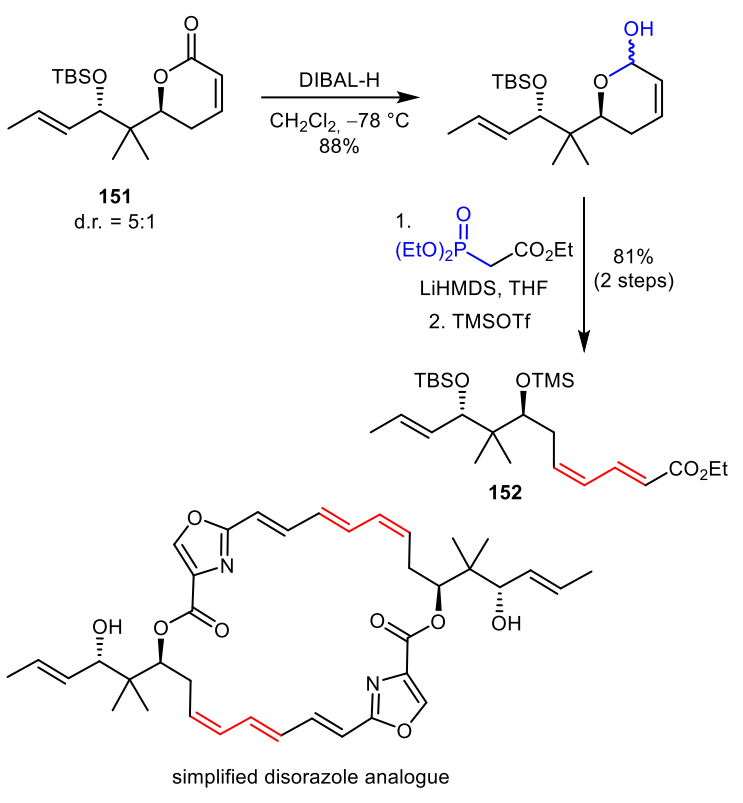

Scheme 59. Synthesis of a simplified disorazole analogue.

In a program aiming to establish structural details of the esters chains at the $\mathrm{C} 4$ position of trichothecene mycotoxins, triacetyl-D-glucal (153) was used as starting material to obtain E,Z-dienoates. ${ }^{[133]}$ Accordingly, compound $\mathbf{1 5 5}$ was synthesised from pseudoglucal (154) using an E-selective Wittig reaction followed by methanolysis (Scheme 60).

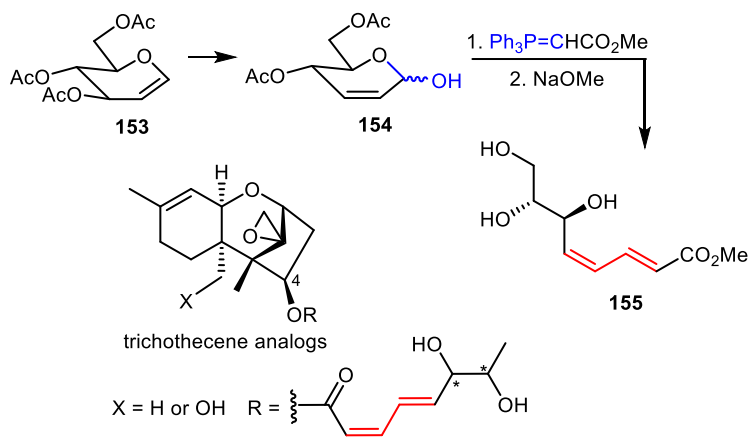

Scheme 60. E,Z-Dienoate synthesis for structural studies of the ester chains of trichothecenes.

\subsubsection{N-Sulfonyl imine olefinations}

While the variants of the above mentioned Wittig olefination often rely on changes in the nature of the nucleophiles (i.e. phosphonium salts or phosphonates), Tiang developed a tuneable and stereoselective synthesis of conjugated dienes by merging $N$-sulfonyl imines with either semi-stabilised or non-stabilised phosphonium ylides. ${ }^{[134,135]}$ The key rational for this transformation was to replace aldehydes by appropriate imines using a Wittig-like reaction. $\mathrm{N}$ -
Sulfonyl imines were then chosen as the electrophilic partners, as the sulfonyl groups enhance their reactivity and favours the carbon-nitrogen bond cleavage under mild conditions. To form conjugated $Z, E$-dienes (158) with very high selectivities, 2,6dichlorobenzenesulfonyl-activated imines (156) were combined with semi-stabilised phosphonium salts $(\mathbf{1 5 7}$, Scheme 61). ${ }^{[134]}$

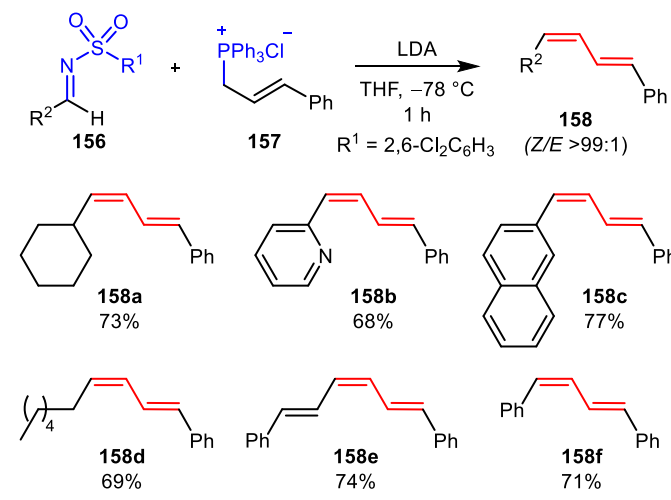

Scheme 61. $N$-Sulfonyl imines as electrophilic partners in Wittig-type reaction.

\subsubsection{Peterson olefinations}

The reaction of $\alpha$-silylcarbanions with aldehydes (or ketones) affords $\beta$-hydroxysilanes that can either be isolated or further transformed into alkenes via an elimination step. ${ }^{[136-138]}$ Less widespread than Wittigtype reactions, the Peterson olefination offers a nice alternative to stereoselectively synthesise dienes where the geometry of the new double-bond formed during the elimination step can be controlled. It is important to mention that aldehydes are not exclusively chosen as the electrophilic partner. In certain cases, the combination of Peterson olefination with other strategies (e.g. rearrangement) were successfully achieved.

Yamamoto described the synthesis of $(E, Z)-1,3$ dienes (159) from aldehydes using organotitanium reagents (Scheme 62). ${ }^{[139]}$ The key behind the E,Z stereocontrol is the excellent diastereoselectivity observed during the allylation reaction, which is due to the Zimmermann-Traxler-type transition state (160). This method was applied to the synthesis of spilanthol. Furthermore, Katsuki developed a strategy to access $(2 E, 4 Z)$-dien-1-ols $(\mathbf{1 6 1})$ that are key intermediates for synthesizing insect sex pheromones, where a $\mathrm{Zr}$ mediated, [2,3]-Wittig rearrangement and a Peterson reaction are the key transformations (Scheme 63). ${ }^{[140,141]}$ 


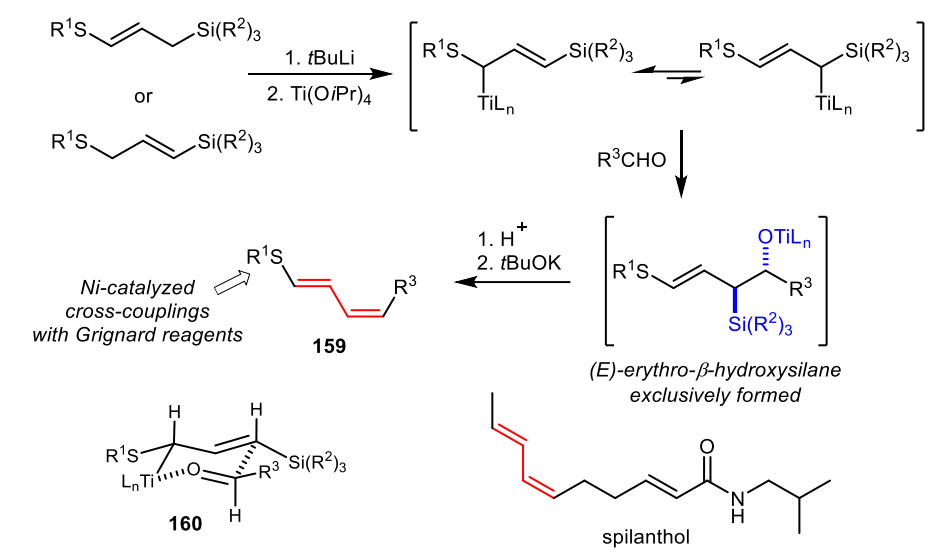

Scheme 62. (E,Z)-1,3-Dienes using organotitanium reagents and aldehydes.

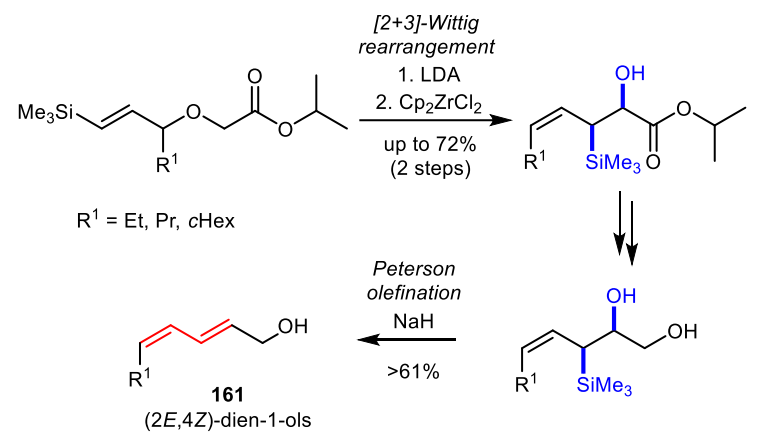

Scheme 63. (2E,4Z)-Dien-1-ols via [2,3]-Wittig rearrangement and Peterson reactions.

Later, Alexakis described the synthesis of two lepidopteran sex pheromones: bombykol and $(E, Z)$ 7,9-dodecadienyl acetate, the pheromone of the European grapevine moth (Lobesia botrana). ${ }^{[142]}$ The methodology relied on the regio- and stereoselective ring-opening of trans or cis epoxysilanes by Z-alkenyl cuprates, in the presence of a Lewis acid, to give either threo- or erythro- $\beta$-hydroxysilanes, respectively. An anti- or syn-elimination step (acidic or basic conditions) affords (E,Z)-1,3-dienes with high selectivities. This method is illustrated in Scheme 64, where the synthesis of bombykol from 162 and 163 is demonstrated.

A similar approach was proposed by Fiandanese, where $\alpha, \beta$-epoxysilanes were opened by lithium halides in the presence of acetic acid to give $Z, E$-dienyl halides. ${ }^{[143]}$ In addition, the concept of the vinylogous Peterson reaction, first observed by Clive, ${ }^{[144]}$ was used by Fleming to stereospecifically synthesise $(E, Z)-1,3$ dienes from 1,4-hydroxysilanes. ${ }^{[145]}$

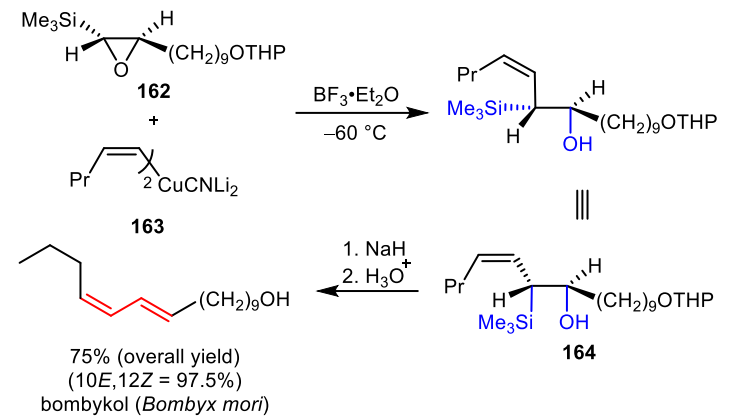

Scheme 64. Conjugated dienes via epoxysilane ringopening reactions with $Z$-alkenyl cuprates and Peterson olefination.

\subsubsection{Julia-type olefinations}

Julia-Lythgoe olefinations, and related processes, are reactions between aldehydes (or ketones) and aryl sulfones, in the presence of a base, that initially give an alcohol intermediate, which then undergoes reductive elimination to provide alkenes. ${ }^{[146,147]}$ Some modified protocols were also devised to afford more practical one-pot procedures (e.g. the Julia-Kocieński olefination). As for the previously described olefination methods, this transformation was successfully used to construct conjugated dienes present in the chemical structures of natural products. During the synthesis of iejimalide B, enal 166 (obtained employing a $Z$-selective Wittig olefination) was coupled with benzothiazol-2-yl sulfone (165) using the Julia-Kocieński olefination to obtain $(Z, E)$ 1,3-diene 167 (Scheme 65). ${ }^{[148]}$

Moreover, Charette developed reaction conditions to synthesise 1,3-dienes from enals and heteroarylsulfones (Scheme 66). ${ }^{[149]}$ The E,Z-dienes (169) were isolated in good yields. The highest selectivities ( $E, Z / E, E$ up to $92: 8)$ were reached when 2pyridylsulfones (168) were used and the reaction was run at room temperature. 


\subsection{Elimination strategies}

Examples based on elimination strategies were also successfully utilised to install E,Z-dienes. Menche described, in the total synthesis of archazolid A and B, an unsuccessful HWE reaction (even under very mild, Masamune-Roush conditions) to obtain the $E$ double bond of the requisite $E, Z, Z$-triene subunit 171. ${ }^{[150]}$ This obstacle was nicely overcome using an aldolisationelimination sequence on the same aldehyde derivative 170 (Scheme 67).
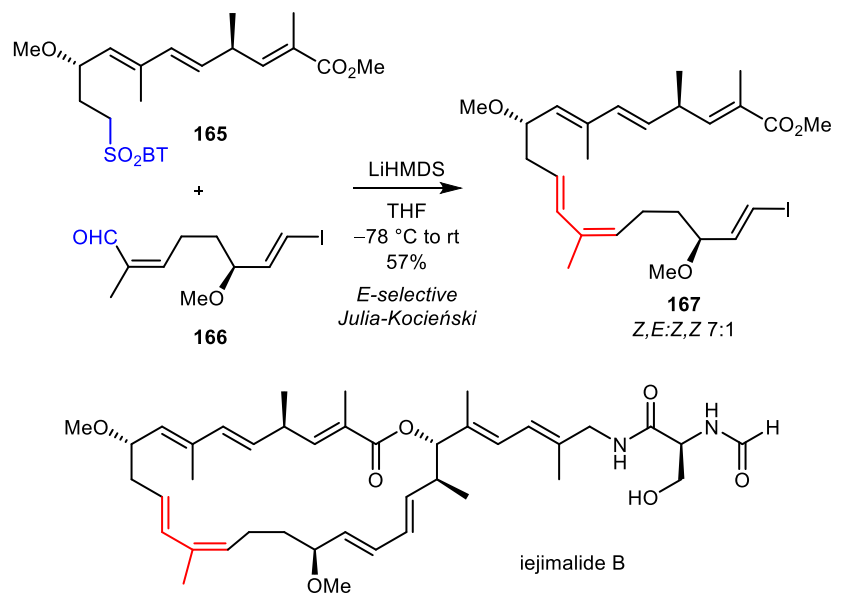

Scheme 65. Julia-Kocieński olefination during the synthesis of $(E, Z)$-1,3-diene accounted in iejimalide B. BT = Benzothiazole
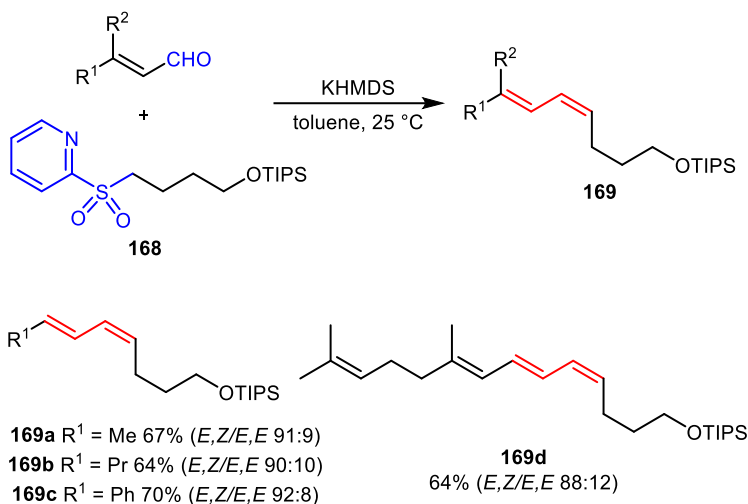

Scheme 66. E,Z-Dienes using Julia olefination conditions.

In the total synthesis of the $(9 S, 18 R)$-diastereomer of cyclamenol A, Waldmann described an elimination strategy where a Corey-Winter-type olefination was used to construct the $Z$ double bond of this polyene macrolactam. ${ }^{[151]}$ While lactamisations or McMurry macrocylisations failed to accomplish this, an intramolecular pinacolisation reaction of $\mathbf{1 7 2}$, followed by a stereospecific Corey-Hopkins syn-elimination of the cis diol derivative 173, afforded macrolactam 174 in $20 \%$ yield (Scheme 68 ).

Relatedly, Hopf described McMurry-type olefinations of tethered aldehydes (175) that synthesised cyclo-1,3-dien-5-ynes (176) in moderate yields (Scheme 69). ${ }^{[152]}$ The obtained cyclodienynes were thus subjected to thermal isomerisation into the corresponding benzocycloalkenes (177).

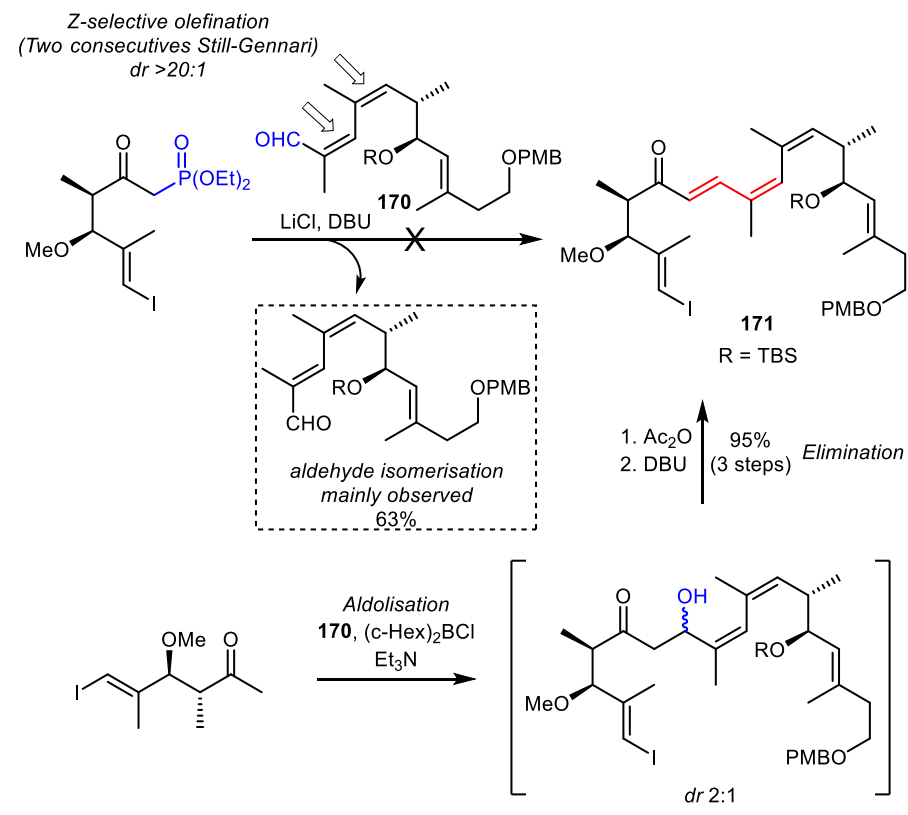

Scheme 67. E,Z-Diene trough aldolisation-elimination sequence. 


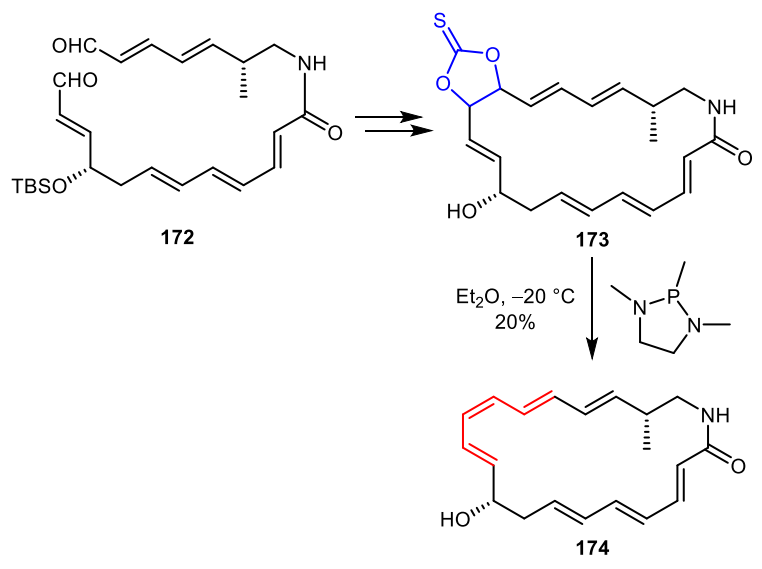

Scheme 68. Corey-Winter type olefination giving E,Z-diene.

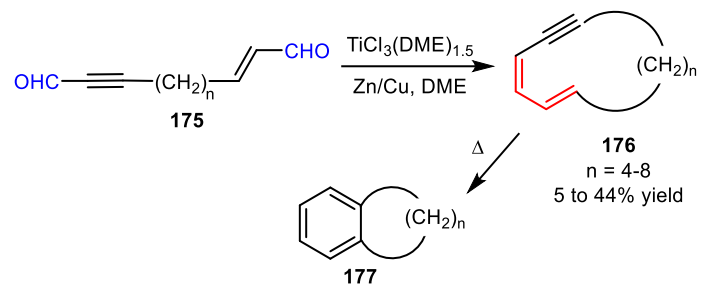

Scheme 69. McMurry-type olefination giving cyclo-1,3dien-5-ynes.

As seminally illustrated by Hofmann, ${ }^{[153]} \alpha, \beta$ unsaturated $\delta$-lactones (see scheme 70) are also prone to $\beta$-elimination under basic conditions, which unmasks $(Z, E)$-2,4-dienoic acids. Owing to the progress made in stereoselective syntheses of such unsaturated lactones, ${ }^{[154]}$ this strategy has emerged as an efficient tool for constructing $E, Z$-dienes. This is illustrated in the syntheses of dehydronerol isovalerate, trichoverrol B (178 $\rightarrow$ 179), rifamycin, salinisporamycin, and saliniketals $A$ and $B(\mathbf{1 8 0} \rightarrow \mathbf{1 8 1}$, Scheme 70)..$^{155-159]}$ A related strategy was developed by Kunz featuring a one-pot sequence involving the esterification of vinyl acetic acid, an RCM, and a $\beta$ elimination. ${ }^{[153,160]}$ This strategy was notably used in the total syntheses of $S$-atractylodemayne C and F, stagonolide E, and curvulide A. ${ }^{[161,162]}$

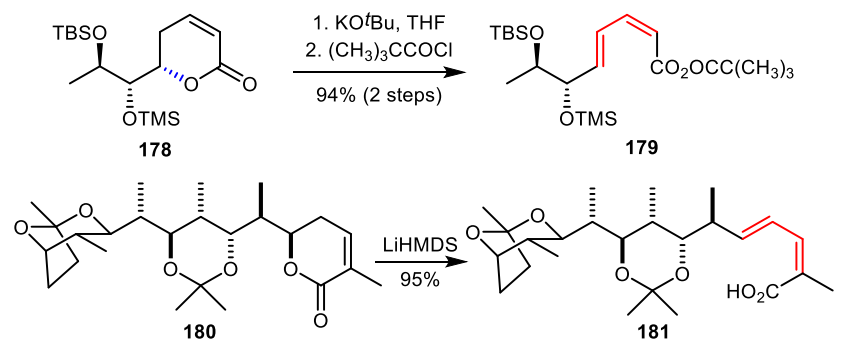

Scheme 70. Synthesis of $(Z, E)-2,4$-dienoic acids via $\beta$ elimination of unsaturated lactones.

\subsection{Double bond isomerisation strategies}

Natural and synthetic polyene products can undergo $E$ $\rightarrow Z$ photoisomerisation under various conditions, where light, silica, acids, and heat could be used. ${ }^{[58,151,163,164]}$ However, this strategy has scarcely been described as one for constructing E,Z-dienes. In the total syntheses of mycolactones $\mathrm{A}$ and $\mathrm{B}$, Blanchard described the visible-light photoisomerisation of the pentadienyl system of $\mathbf{1 8 2}$ to give a 1:1 mixture of the E,Z-double bond at the C4C5 junction of 183 , found in the natural source (Scheme 71). ${ }^{[165,166]}$

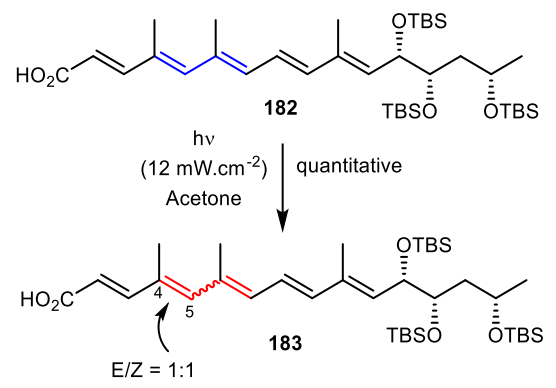

Scheme 71. Polyene photoisomerisation.

In another study of the total synthesis of marinisporolide C, Dias observed a serendipitous isomerisation during the last step. Starting from tetraene 184 (with only E-configurations), an HWE intramolecular reaction, followed by alcohol deprotection, resulted in the formation of macrocyclic pentaene 185 with $E$ to $Z$ isomerisation of the C15-C16 double bond (Scheme 72). ${ }^{[167]}$

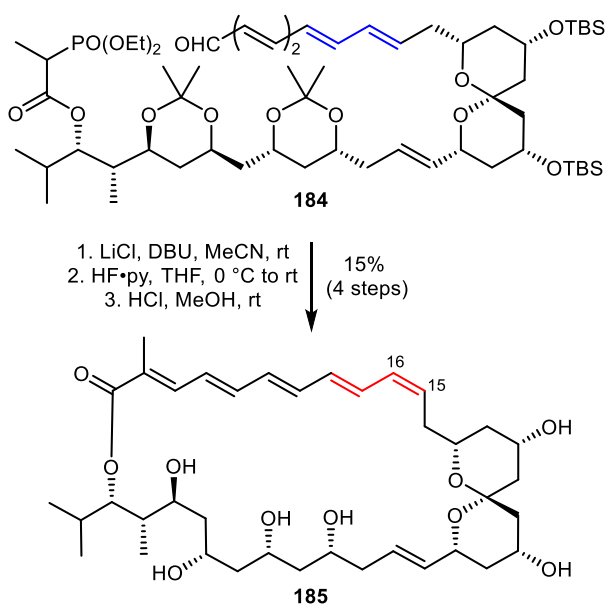

Scheme 72. $E$ to $Z$ pentaene isomerisation in the total synthesis of marinisporolide $\mathrm{C}$.

In the total synthesis of dihydroretinoic acid, a $Z$-stereoselective Julia reaction (see section 2.6) involving 186 and 187 enabled the formation of $Z, Z, E$ triene 188. In the next step, during a Sn-I exchange reaction, in the presence of $I_{2}$, an isomerisation of $\mathbf{1 8 8}$ to the E,Z,E-geometric isomer $\mathbf{1 8 9}$ was observed (Scheme 73). ${ }^{[168]}$ This compound was next engaged in a Suzuki cross-coupling reaction (see section 2.2). In addition, Morken described the catalytic enantioselective allylation of $E, E$-dienals that, through a 3,3'-reductive elimination, exhibited a clean isomerisation of the 2-E double bond to afford allylic alcohol derivatives (190, Scheme 74). ${ }^{[169,170]}$ 

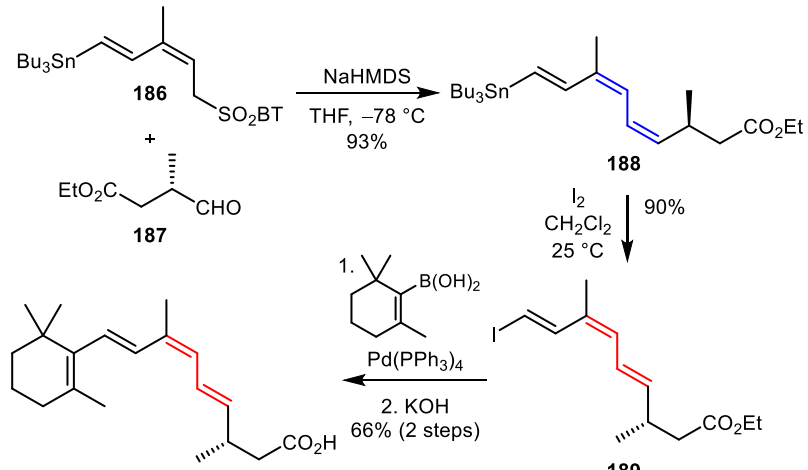

(S)-9-cis-13,14-dihydroretinoic acid

189

Scheme 73. (S)-9-cis-13,14-Dihydroretinoic acid synthesis through Julia olefination and isomerisation.
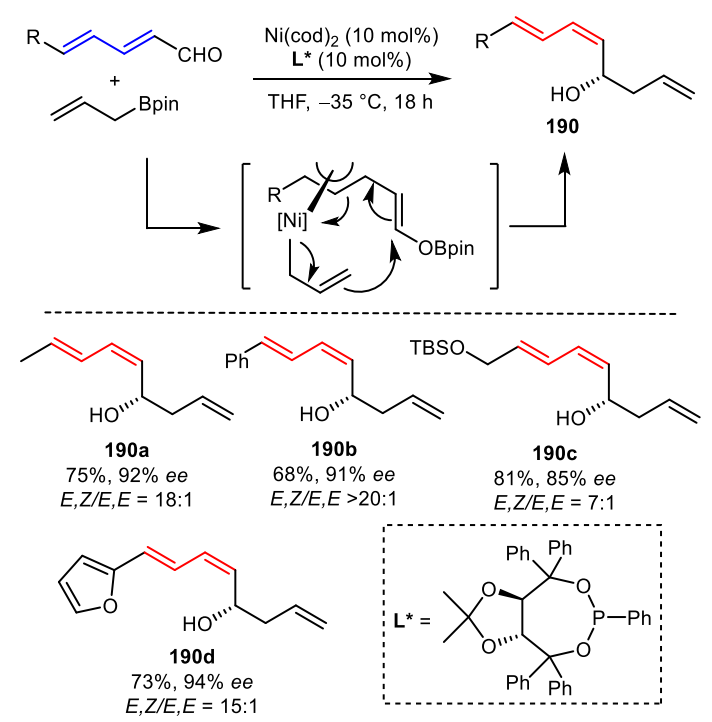

Scheme 74. Ni-catalysed enantioselective addition of allylboronic acid to $\alpha, \beta-\gamma, \delta$-unsaturated aldehydes with double bond isomerisation.

Palladium-catalysed cross-coupling reactions are known to be highly stereoretentive processes (see section 2.2). ${ }^{[171]}$ In 2003, Negishi described a Znmediated cross-coupling reaction that proceeded with stereoinversion. ${ }^{[172]}$ Starting from product 191, a Pdcatalysed cross-coupling occurred, in the presence of (E)-BrZnCH=CH-C $\equiv \mathrm{C}-\mathrm{TMS}$ (192), with the trans selectivity for compound 193 expected to be high. Upon a subsequent, second cross-coupling reaction with $\mathrm{MeZnBr}$, a clean stereoinversion was observed, leading to $Z$, $E$-diene 194 in $91 \%$ yield $(Z, E>97 \%$, Scheme 75).
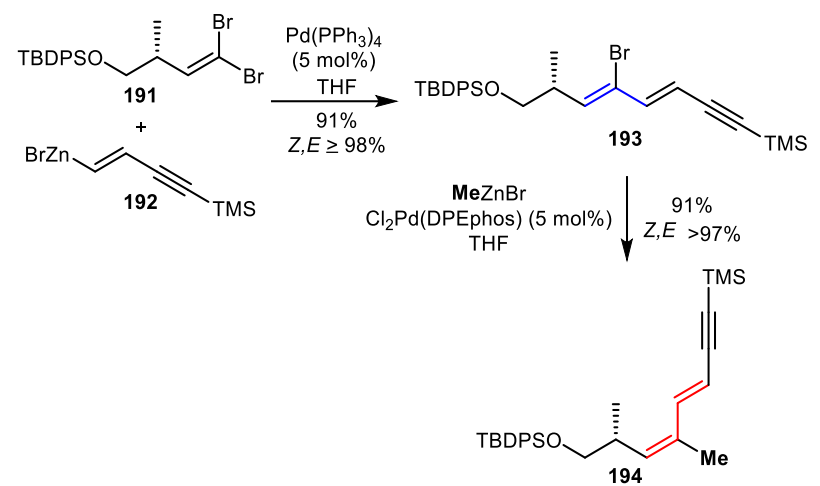

Scheme 75. Negishi cross-coupling with double bond stereoinversion.

The reaction could be used with other substrates (ten examples were given) and organozinc reagents, such as $n$-BuZnBr, EtZnBr, $\mathrm{PhZnBr}, \mathrm{H}_{2} \mathrm{C}=\mathrm{CHZnBr}$, and $\mathrm{HC} \equiv \mathrm{C}-\mathrm{ZnBr}$. Although the mechanism of such a stereoinversion process is not yet fully understood, strain-induced isomerisation of the oxidative addition product (195) was advocated through the formation of an allenyl-Pd derivative (196), giving intermediate 197 (Scheme 76). ${ }^{[173]}$

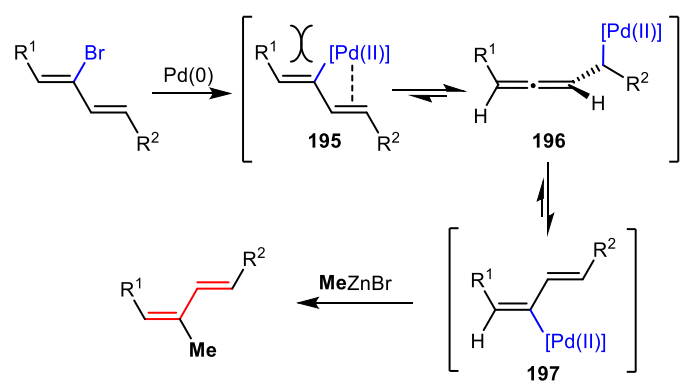

Scheme 76. Stereoinversion mechanistic rationale.

\subsection{Metathesis strategies}

Ene-ene RCM strategies have been successfully used in the total syntheses of natural products containing $E, Z$-dienes. Indeed, the structures of radicicol (199, Scheme 77) that contain sulphur atoms and sensitive vinyl epoxides, ${ }^{[174]}$ ansa-bridged macrolactams, ${ }^{[175]}$ iejimalides, ${ }^{[176,177]}$ heronamides, ${ }^{[178]}$ and oximidine II $^{[179]}$ have been obtained in high yields and with good selectivities.

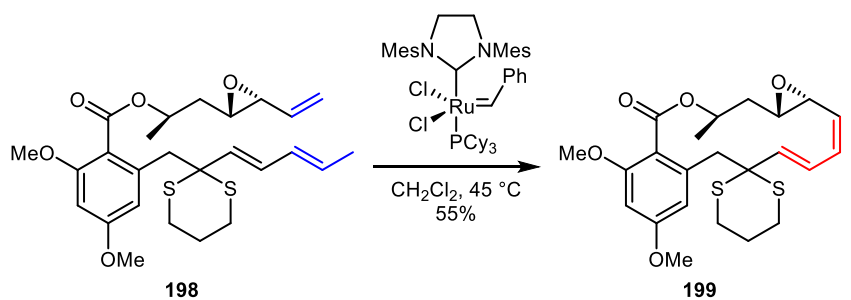

Scheme 77. Z-selective RCM. 
However, depending on the starting material and catalyst structures, unwanted ring-contraction products (201 vs 202) can occur as major or by-products and low $E, Z$ selectivities (through activation of the internal double bond or terminal double bond isomerisation) can be observed from these 1,3-diene RCM strategies (Scheme 78)..$^{[180-182]}$ Moreover, as illustrated in the synthesis of oximidine II, small modifications to the substrate structure might have a profound impact on the reactivity and diene selectivity outcome. ${ }^{[179]}$

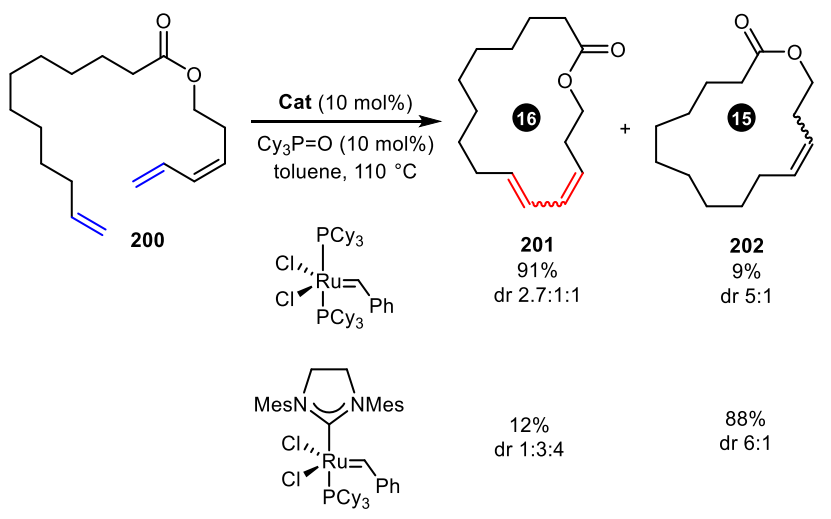

Scheme 78. Selectivity issues in RCM.

To promote selective E,Z-diene access, Fürstner devised a silyl-protected diene to both prevent ring contraction and ensure high $E, Z$ diastereoselectivity. The silyl-protecting group could be removed using TBAF or, alternatively, it could be used in HiyamaDenmark-type cross-coupling reactions. ${ }^{[182]}$ Lately, this strategy has been used in the total synthesis of lactimidomycin $(\mathbf{2 0 3} \rightarrow \mathbf{2 0 4}$, Scheme 79). However, a rather encumbered carbene catalyst was necessary to prevent the unwanted formation of an 11-membered by-product.

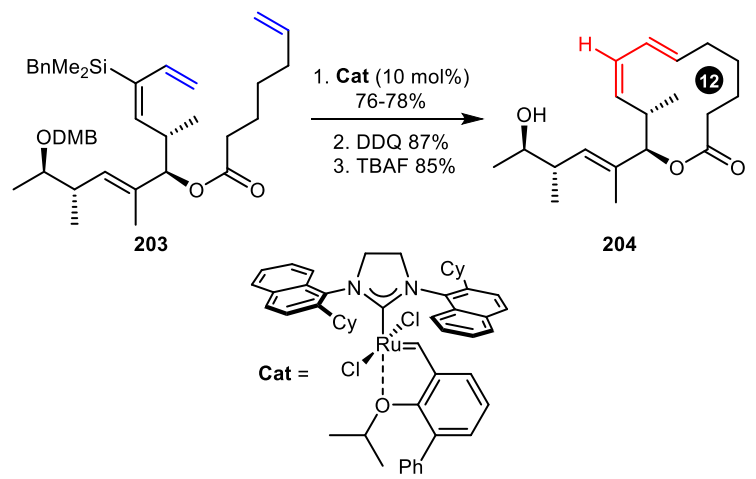

Scheme 79. Selective RCM in the total synthesis of lactimidomycin.

More recently, the rise of $Z$-selective ring- and cross-metathesis catalysts has enabled new developments in E,Z-diene construction. ${ }^{[183-186]}$ Molybdenum-catalysed, $Z$-selective cross-metathesis reactions have been developed by Hoveyda and Schrock, and their potential is highlighted by their application to construct $Z$ - and Z,E-dienylboron(pin) double-bond subunits (Scheme 80). Dienylboron(pin) (205) was next used in the construction of the 30membered macrolide disorazole $\mathrm{C}_{1}$ through inter- and intramolecular double, Pd-catalysed, cross-coupling reactions (see section 2.2) ${ }^{[187]}$ These $Z$-selective RCM catalysts have also been used to synthesise 2,4-(E,Z)macrolactone 208 and $(Z, E)$-macrolactone 209 from compounds 206 and 207, respectively (Scheme 81). They were also employed in the formal synthesis of aspicilin. $^{[188]}$

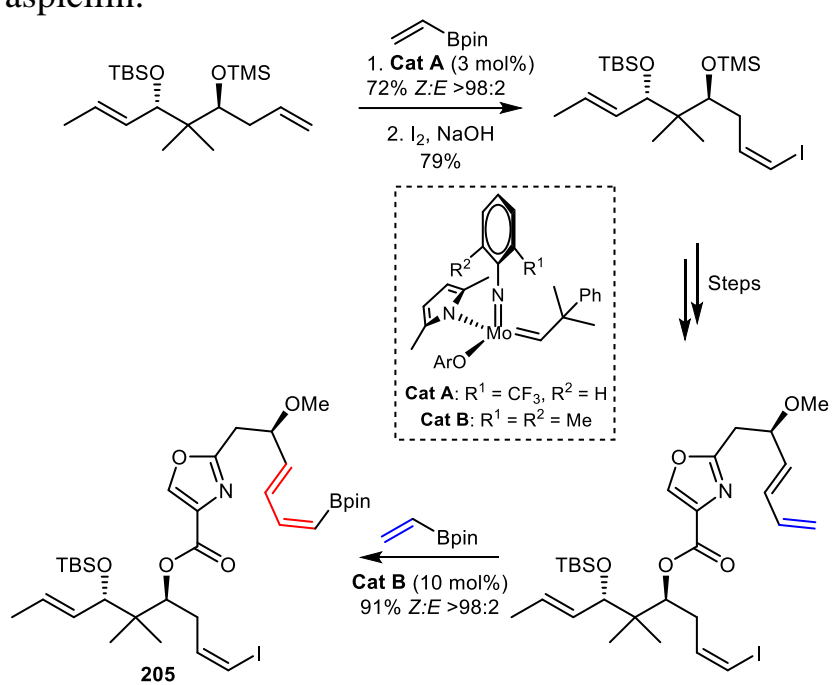

Scheme 80. Mo-catalysed $Z$-selective cross-metathesis reactions.

Relatedly, Grubbs developed a Ru-based catalyst ${ }^{[184,186]}$ that allowed the clean and selective formation of $E, Z$-dienes (210) from 1.5 equiv. of diene (Scheme 82). This methodology was also applied to the efficient and rapid synthesis of two insect pheromones. RCM strategies to construct unsaturated $\delta$-lactones that can enable the formation of $Z, E$-dienoic acid derivatives after $\beta$-elimination are discussed in section 2.7. Moreover, as will be discussed in the next section, yne-yne RCM reactions (and further reduction of the alkynes) have also been widely used to form E,Zdienes.

\subsection{Ene-yne triple bond reduction strategies}

As a result of the development of efficient methodologies to cleanly and mildly reduce alkynes to $Z$ double bonds, ${ }^{[189]}$ the reduction of ene-yne acyclic and macrocyclic compounds has been used as a late functionalisation step in the construction of $E, Z$-dienecontaining natural products (Scheme 83). E-Ene-yne substrates have traditionally been obtained through Sonogashira cross-coupling reactions of alkynes and vinyl-halides, followed by reduction of the triple bond by either hydrogenation (Lindlar catalyst), activated $\mathrm{Zn}(\mathrm{Cu} / \mathrm{Ag}), \quad \mathrm{P}-2$ nickel, $(\mathrm{NHC}) \mathrm{Cu}-\mathrm{H}$, or a hydroboration/protonolysis sequence. ${ }^{[68,190-199]}$

To highlight this strategy, the total synthesis of thuggacin B is illustrated in Scheme $84 .{ }^{[190]}$ Highly functionalised vinyl-iodide $\mathbf{2 1 1}$ and terminal alkyne 212 underwent an efficient Sonogashira coupling 
reaction to obtain compound 213. Then, the triple bond of 214 could be selectively reduced using hydrogenation in the presence of the Lindlar catalyst. ${ }^{[200]}$ Due to difficulties associated with this partial reduction, a second generation synthesis involving a Heck coupling was described (see section 2.3). Furthermore, in the total synthesis of resolvin D1, Kobayashi described a late $\mathrm{Pd} / \mathrm{Cu}$-catalysed Sonogashira coupling of $\mathbf{2 1 6}$ and $\mathbf{2 1 7}$, followed by the $\mathrm{Zn}$-mediated reduction of the alkyne to obtain the desired $E, E, Z, E$-tetraene unit $\mathbf{2 1 8} .^{[201]}$ Interestingly, a related Suzuki-Miyaura strategy was initially validated on model compounds, but was unsuccessful for more complex partners, like 219 and 220 (Scheme 85).

The combination of Sonogashira cross-coupling and selective triple-bond reduction was also used by Altmann during the total synthesis of mandelalide A (Scheme 86), ${ }^{[202]}$ where the E,Z-diene moiety was installed prior to the macrolactonisation step. For other strategies towards the total synthesis of mandelalide A, see sections 2.2.1.5, 2.3, and 2.6.1.
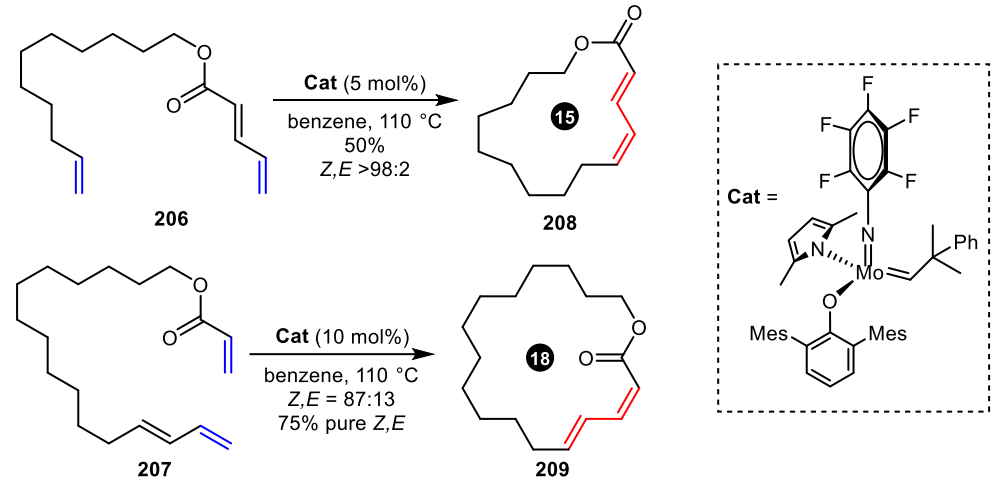

Scheme 81. Mo-catalysed Z-selective RCM.
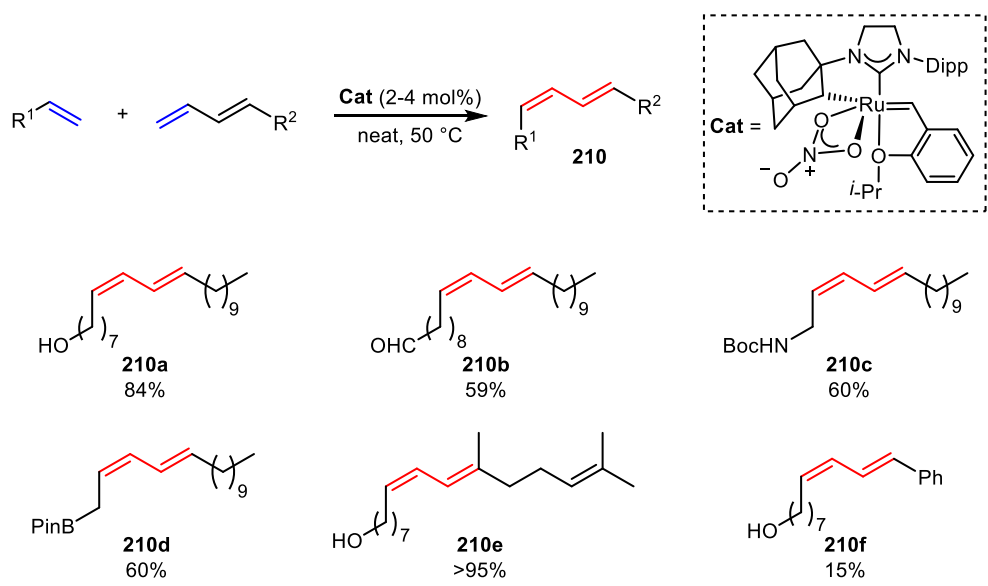

Scheme 82. Ru-catalysed Z-selective cross-metathesis reactions.
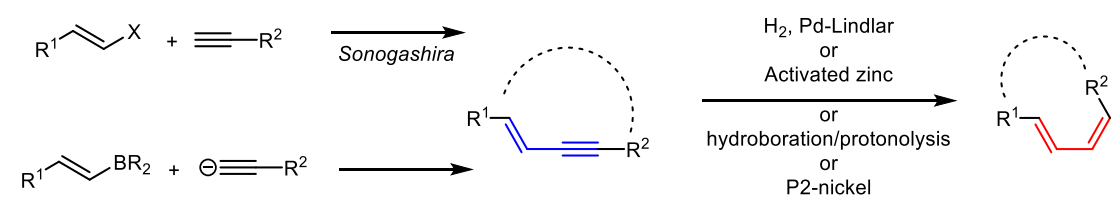

Scheme 83. Ene-yne triple bond reduction strategies. 

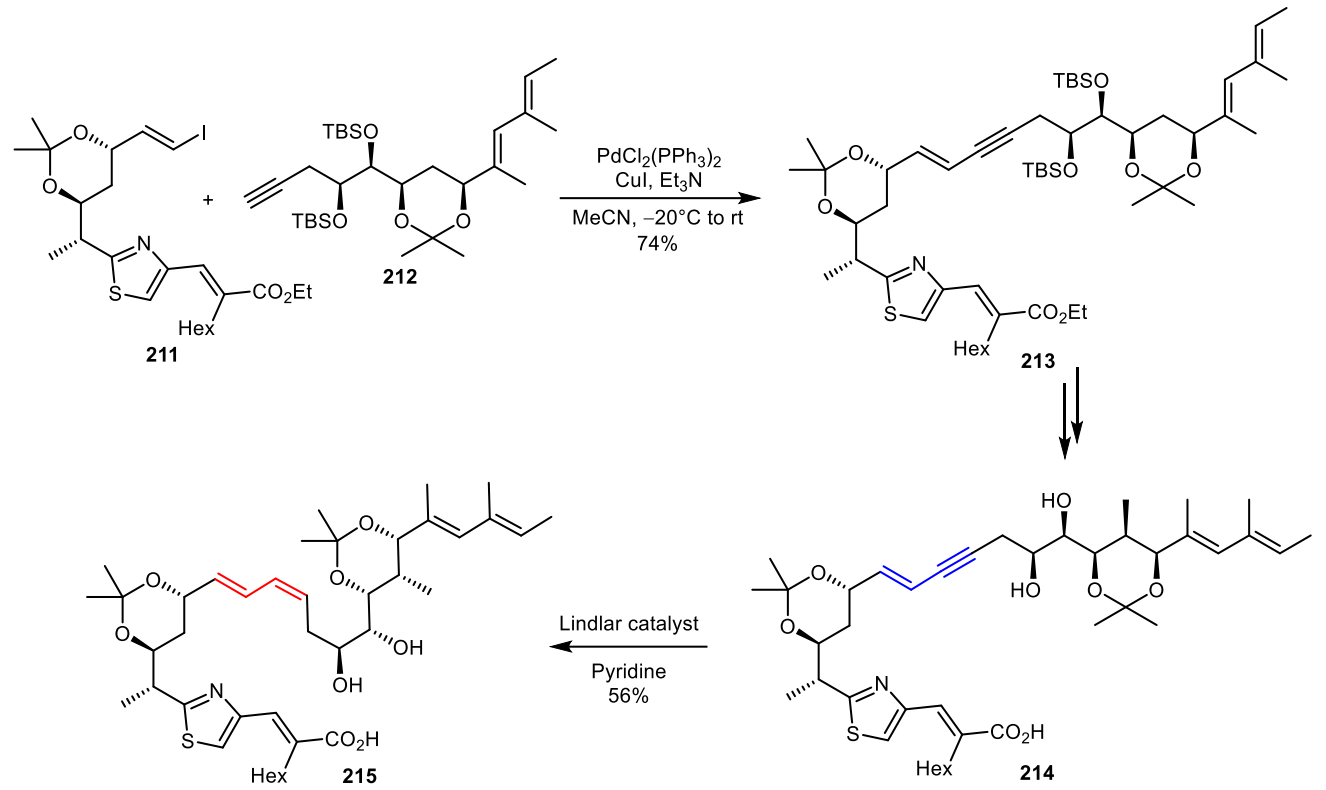

Scheme 84. Thuggacin B total synthesis highlighting an ene-yne hydrogenation.
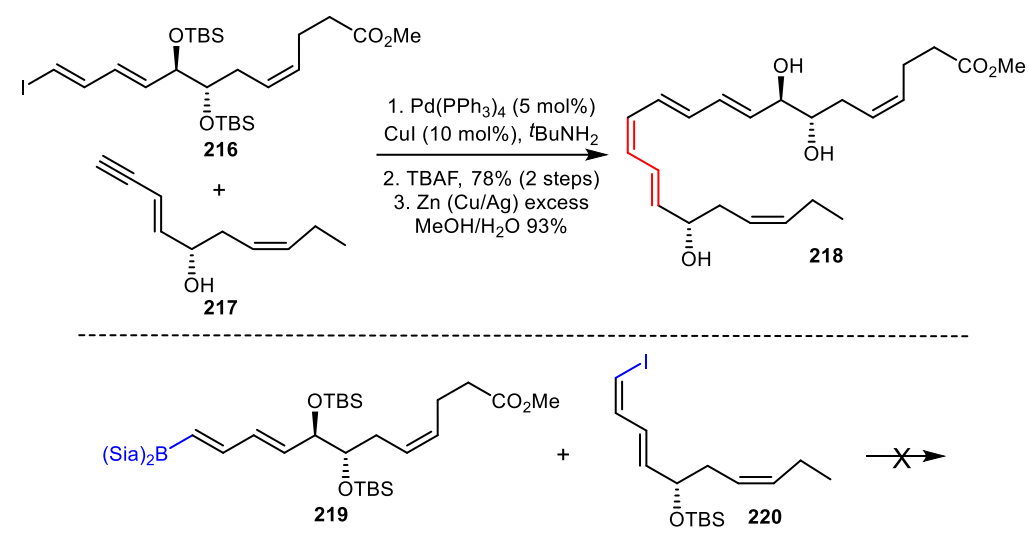

Scheme 85. Total synthesis of resolvin D1 featuring a Sonogashira coupling followed by a Z-selective semihydrogenation.
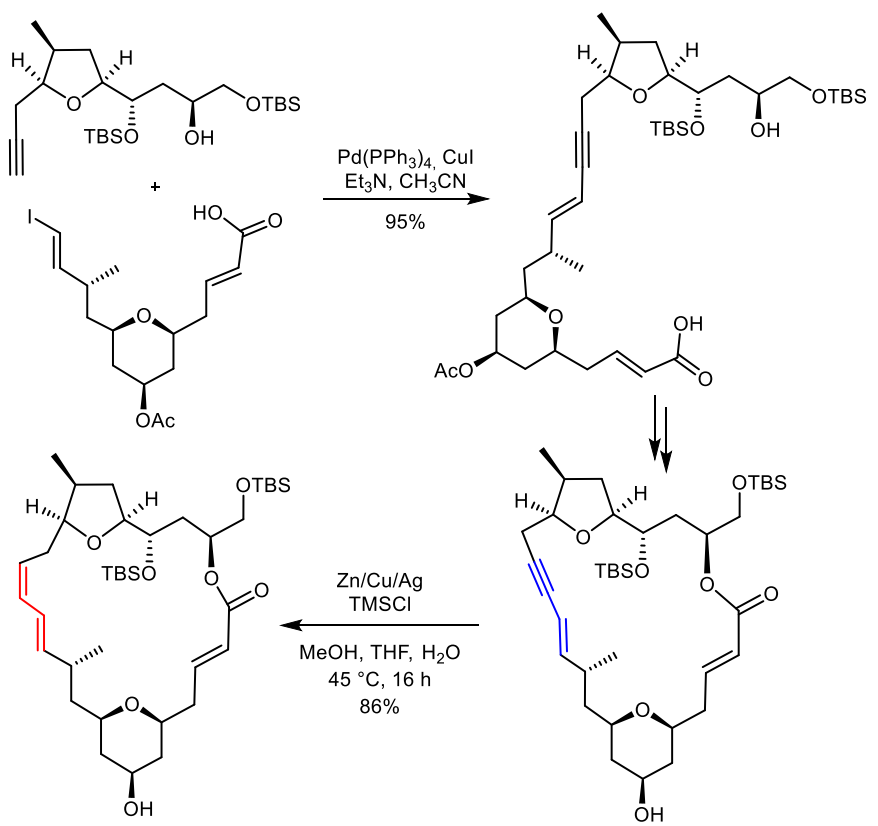

Scheme 86. Sonogashira coupling and alkyne Z-selective reduction during mandelalide A synthesis. 
Alternatively, Negishi has described the accessibility of $E$-ene-yne substrates from vinylboranes and deprotonated alkynes. ${ }^{[203]}$ The development of efficient molybdenum alkylidyne catalysts for ring-closing alkyne metathesis (RCAM) by the Fürstner group shed new light on these strategies. ${ }^{[204-206]}$ Indeed, either $E$-ene-yne or $Z$-eneyne macrocyclic compounds could be efficiently obtained. ${ }^{[207-210]}$ Moreover, Fürstner developed efficient alkyne hydodrofunctionalisation reactions that further expanded the potential of this strategy, primarily for structure-activity relationship

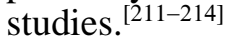

RCAM strategies have been used with E,Z-dienes containing natural products, such as latrunculins, ${ }^{[215,216]}$ mandelalide $\mathrm{A}^{[217,218]}$ disorazole $\mathrm{C}_{1},{ }^{[219]}$ lactimidomycin. ${ }^{[220,221]}$ and rhizoxin D. ${ }^{[222]}$ To highlight the potential of the RCAM strategy, three complementary approaches are highlighted in scheme 87: E-Ene-yne formation and cis semireduction (221) in the total synthesis of the originally assigned structure of mandelalide A (eq (a)); Z-ene-yne (222) formation and alkyne trans-reduction (223) in the total synthesis of lactimidomycin (eq (b)); and a head-to-tail homodimerisation strategy affording $\mathbf{2 2 4}$ in the formal synthesis of disorazole $\mathrm{C}_{1}$ (eq (c)).

During the total synthesis of the tubulin inhibitor WF-1360F, ${ }^{[222]}$ macrocycle 226 was obtained using an efficient RCAM strategy on a complex di-yne substrate (225). Next, various $E$-selective reduction conditions of the ene-yne moiety towards compound $\mathbf{2 2 8}$ were tested; however, they were unsuccessful or appeared poorly stereoselective (Scheme 88). Fortunately, a solution was found that consisted of selectively reducing the alkyne to the $Z$-double bond through the in-situ, reductive decomplexation of a cobalt complex, followed by isomerizing the $Z$ olefin of 227 to the corresponding $E$-configuration in the presence of $\mathrm{PhSH} / \mathrm{AIBN}$. Although very efficient, two-step sequences are required in all of the previously described ene-yne reduction-based strategies.

Another strategy was described by Georg, where the synthesis of strained 10- to 14-membered macrocycles (essentially macrolactones) was achieved through a copper-mediated Castro-Stephens coupling/alkyne reduction tandem reaction using sodium formate as the reducing agent. ${ }^{[199,223,224]}$ This strategy has been used in the total synthesis of oximidine II $(\mathbf{2 2 9} \rightarrow \mathbf{2 3 0}$, Scheme 89) and the formal synthesis of lactimidomycin. The $Z$ selective hydrotelluration of terminal $E$-ene-ynes have been described and can easily be stereospecifically transmetallated into highly ordered cyano-cuprates with retention of their configuration. This methodology $(\mathbf{2 3 1} \rightarrow \mathbf{2 3 2})$ has been used in the total synthesis of macrolactin A (Scheme 90). ${ }^{[225,226]}$

The stereospecific access to $Z$-vinylzinc derivatives from bromo-acetylenic derivative 233, and their subsequent addition to aldehydes, has been described by Walsh and notably illustrated in the synthesis of two ene-yne derivatives $(\mathbf{2 3 4}$, Scheme 91$) .^{[227]}$ In this onepot process, a regioselective cis-hydroboration of the bromo-enyne is followed by the addition of a hydride (from $t \mathrm{BuLi}$ or $\mathrm{KB}(\mathrm{OiPr})_{3} \mathrm{H}$ ) to give the $Z$-vinylborane after a 1,2-metalate rearrangement. Stereospecific transmetallation with $\mathrm{Et}_{2} \mathrm{Zn}$ and addition to the aldehyde affords the $E, Z$-diene derivative.

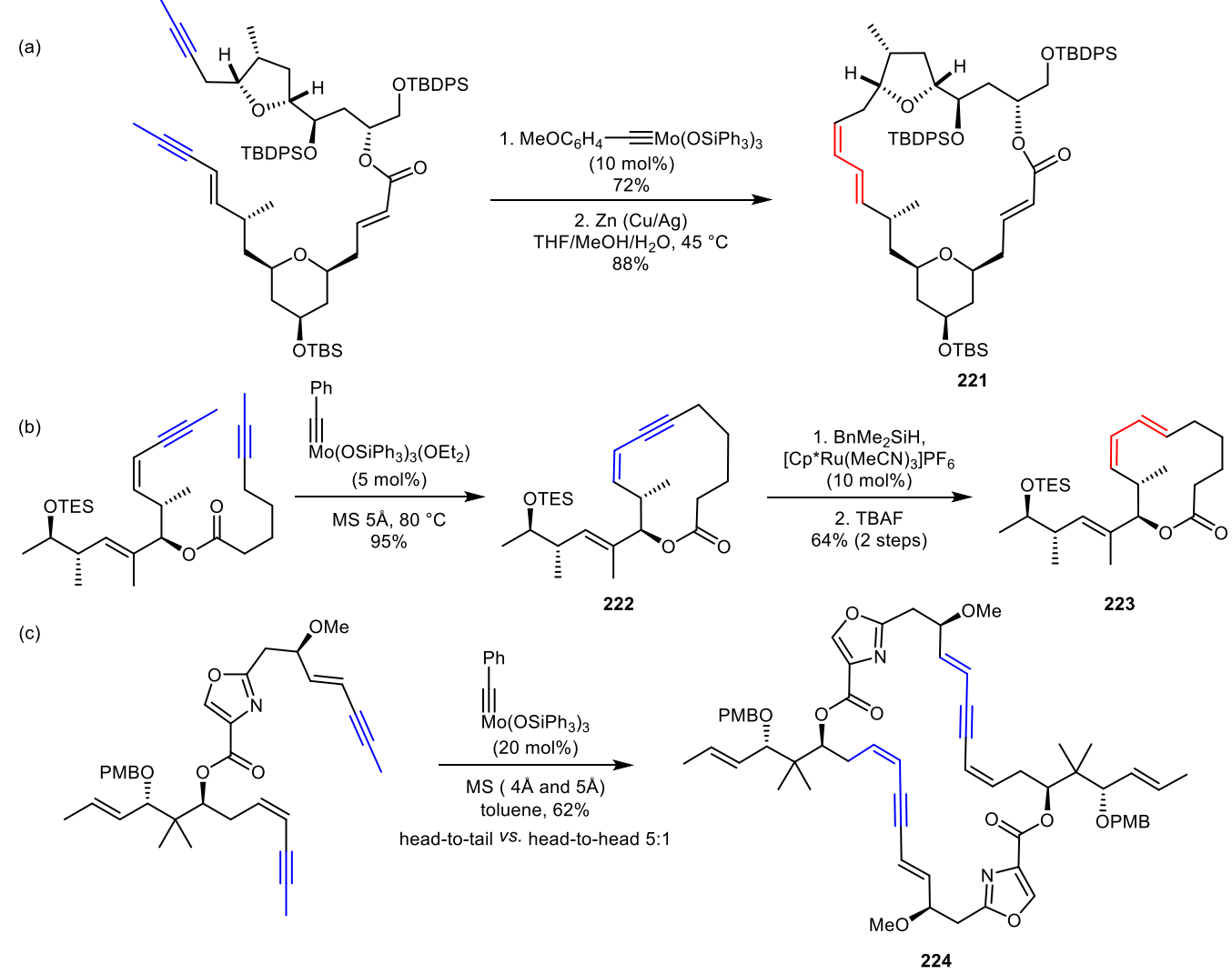

Scheme 87. Ring closing alkyne metathesis (RCAM)/reduction sequences. 


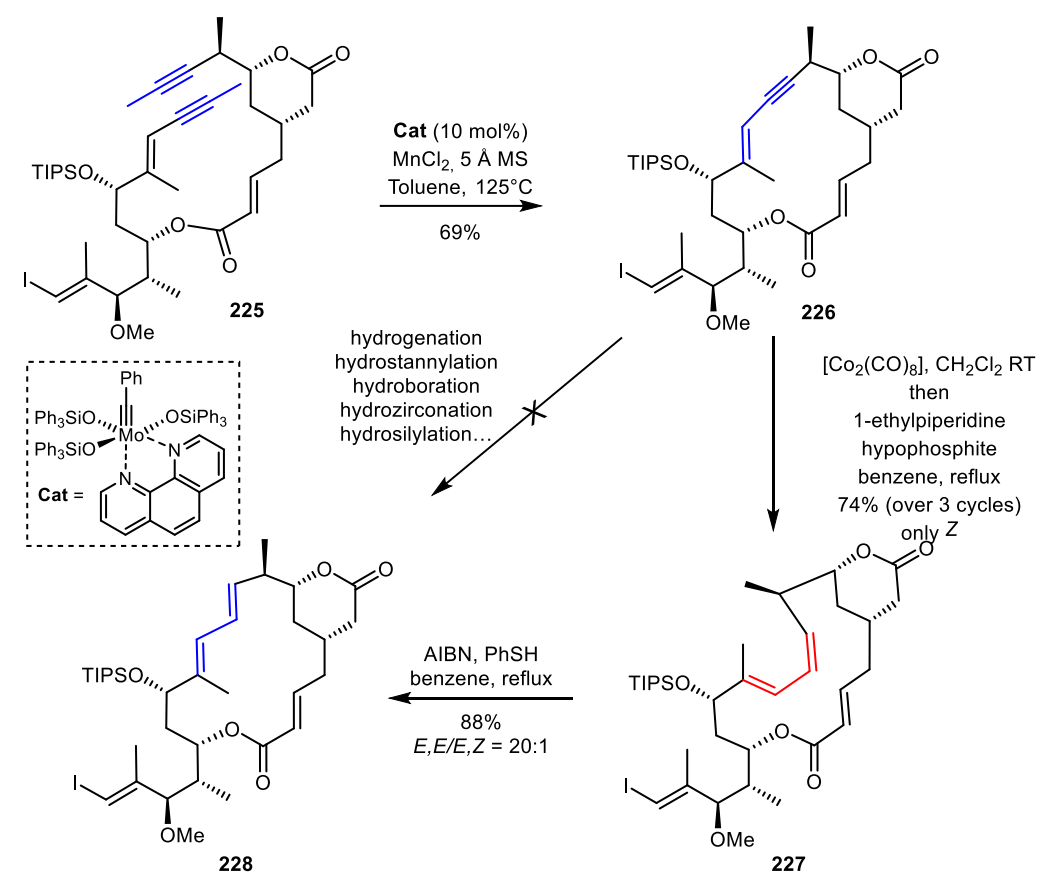

Scheme 88. WF-1360F total synthesis featuring RCAM strategy, Z-selective alkyne reduction and double bond isomerisation.

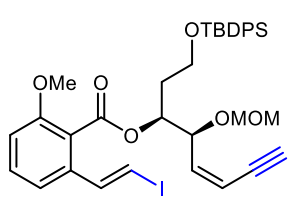

229

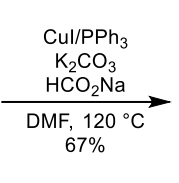
$67 \%$

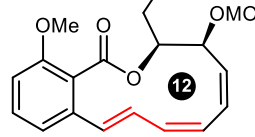

230

Scheme 89. Copper-mediated Castro-Stephens coupling/alkyne reduction tandem reactions.
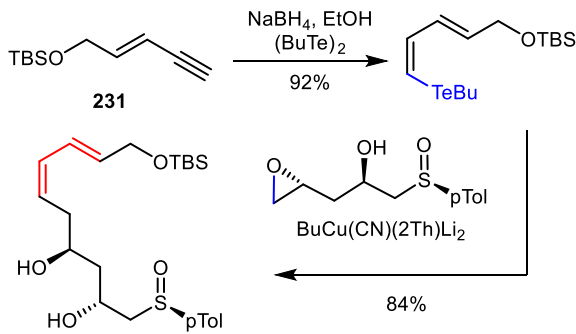

232

Scheme 90. Ene-yne hydrotelluration strategy.
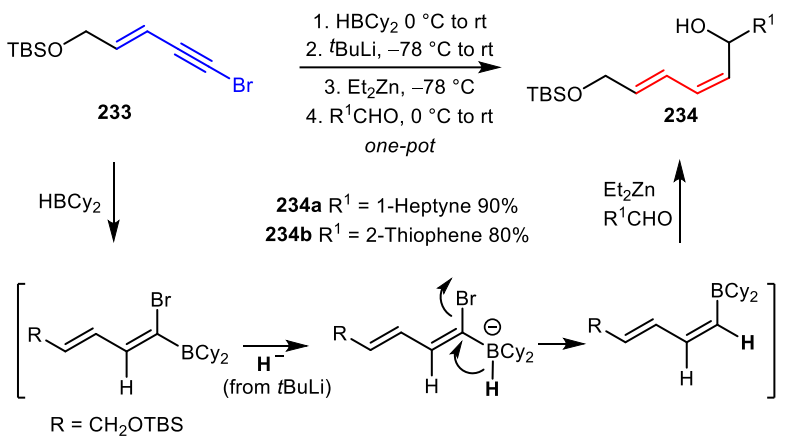

Scheme 91. Stereospecific access to $Z$-vinylzinc derivatives from bromo ene-ynes.

\subsection{Organocatalysed 1,6-Michael additions}

Initially used by Nakagawa in $1977,{ }^{[228]}$ the 1,6addition of nucleophiles to 4-yn-2-en-one derivatives is an efficient method for constructing conjugated $Z, E$ dienes; however, they exhibit variable $Z$ selectivities. ${ }^{[229-233]}$ Furthermore, Ooi described in 2018 a spectacular organocatalysed 1,6-Michael addition of azlactones (235) to enynyl $N$-acyl pyrazoles (236). ${ }^{[234]}$ The use of a P-spiro chiral triaminoiminophosphorane catalyst not only allows the perfect control of the addition regioselectivity (1,6 vs $1,4)$, but also the $Z, E$-configuration of the diene and the enantioselectivity of the quaternary centre in the resulting compounds (237, Scheme 92). 

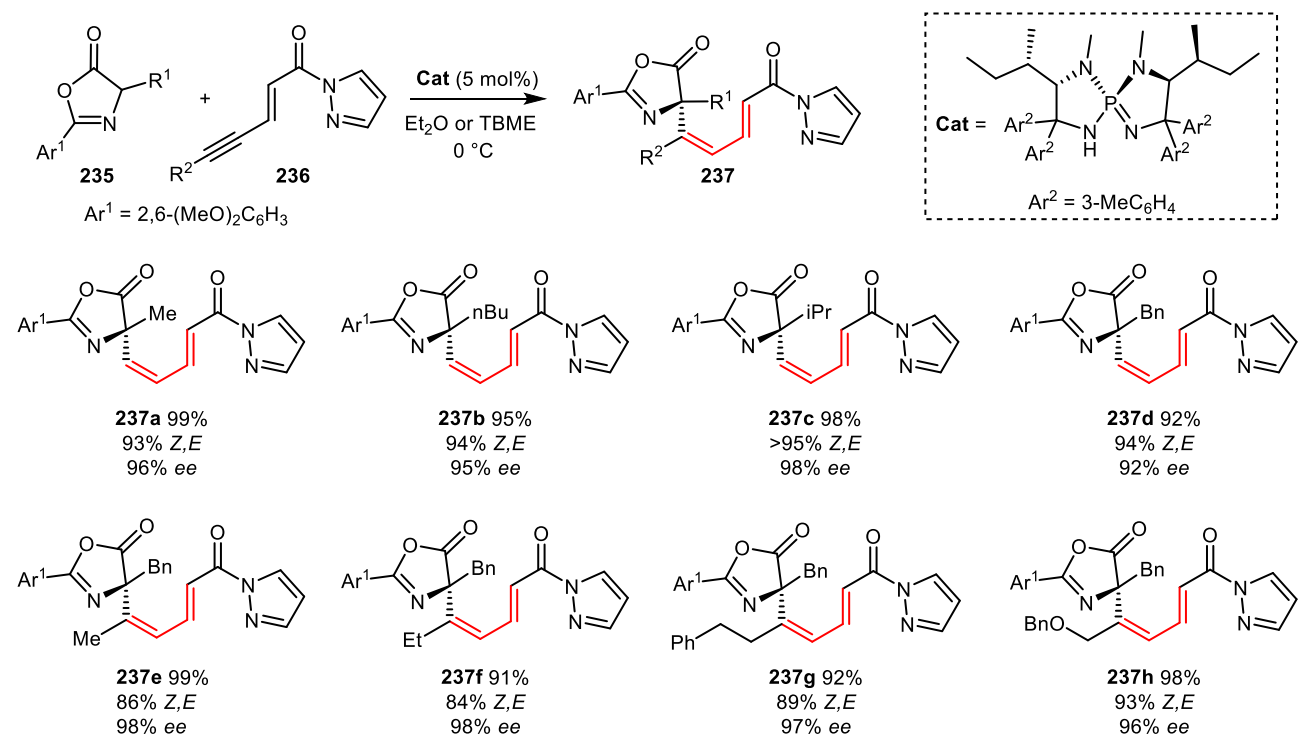

Scheme 92. Organocatalysed 1,6-Michael additions.

\section{Applications in total synthesis: selected examples}

We choose in this final section to highlight a selected number of examples that display the applicability of the aforementioned synthetic methods within the context of complex molecule syntheses. The total synthesis of natural products is an 'adventure', where failures, dead ends, and detours are commonly experienced despite careful retrosynthetic analyses and meticulously planned strategies. ${ }^{[235]}$ The synthesis of chivosazole $\mathrm{F}$ is an example that demonstrates that two different, but complementary, strategies can be used to construct a complex molecule. These two total syntheses will also underline the efficiency of crosscoupling and olefination strategies for the construction of $E, Z$-dienes in complex molecules.

As mentioned in the introduction, E,Z-dienes, and in some cases polyenes, are sensitive moieties prone to isomerisation and degradation. Therefore, they are usually formed in the last steps of the syntheses, often in the dark and with degassed solvents. Furthermore, the smooth removal of the protecting groups in the final steps is essential. The total synthesis of sarain A will emphasise the importance of suitable protecting groups in the presence of inter alia sensitive di- and polyene moieties. Additionally, the total synthesis of myxalamide will feature a highly convergent synthesis using non-protected primary and secondary alcohols, and the total synthesis of both the originally proposed and corrected structure of heronamide $\mathrm{C}$ will demonstrate how subtle changes in the conformation of seco-compounds may impact the cyclisation outcome. Finally, the synthesis of etnangien will stress the significance of preparing alternative strategies for overcoming impasses.
Chivosazoles are natural macrolides isolated from the myxobacterium Sorangium cellulosum. They feature a unique, 31-membered macrolactone, ten stereocenters, an oxazole unit, and nine alkenes that are organised into three different conjugated polyene ranges and possess embedded Z,E-dienes. Kalesse and Paterson devised two different, although complementary synthetic approaches, towards $Z, E$ diene subunits; both employed an intramolecular Pdcatalysed Stille cross-coupling reaction, albeit at different sites (Scheme 93).

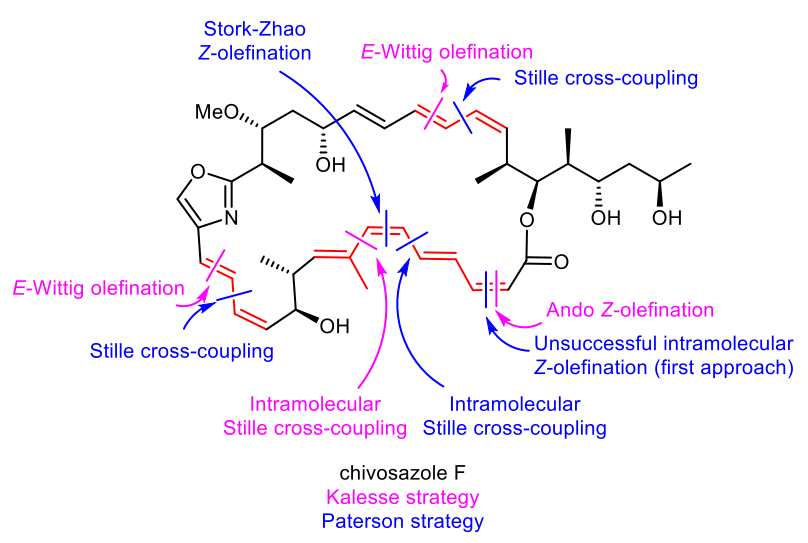

Scheme 93. Chivosazole F structure highlighting the key methodologies used by Kalesse and Paterson for the construction of the $E, Z$-diene subunits.

The strategy proposed by Kalesse for synthesizing chivosazole $\mathrm{F}$ described the late construction of the sensitive polyene systems to avoid isomerisation. The strategy relied on an $E$-selective Wittig olefination to install the top portion of the molecule (i.e. the E,E,Z- 
triene segment) and an intramolecular Stille-type cross-coupling to synthesise the bottom portion (i.e. the $E, Z, E, Z$-tetraene unit, Scheme 94). ${ }^{[236,237]}$ From phosphonate intermediate 238, a Z-selective olefination reaction with enal 239, under Ando conditions, afforded the expected product $\mathbf{2 4 0}$ as a 1:1 mixture of the $E$ and $Z$ isomers, which were separated by column chromatography. Additional TBSdeprotection and oxidation gave intermediate $\mathbf{2 4 1}$ that incorporated a $Z$-enal and a Z,E,Z-triene stannane unit.

The second key fragment, 244, was obtained from an $E$-selective Wittig reaction $(E / Z>10: 1)$ between aldehyde 242 and an in situ prepared, unsaturated phosphonium salt. Subsequent $p$-methoxybenzyl (PMB)-deprotection, alkyne functionalisation through Pd-catalysed hydrostannylation, and the transformation of the allylic alcohol into an allyl bromide provided $\mathbf{2 4 5}$. The stage was then set for the coupling of the two halves, $\mathbf{2 4 1}$ and 245, through the $E$-selective Wittig olefination, which gave the key triene 246. An intramolecular, Pd-catalysed Stille cross-coupling with $\mathbf{2 4 6}$ was then conducted to establish the entire backbone of the natural compound. After a final deprotection of the silyl-ether protecting groups, the total synthesis of chivosazole $\mathrm{F}$ was achieved.

Later on, Paterson proposed a strategy based on $\mathrm{Pd} / \mathrm{Cu}$-mediated Stille cross-couplings and carbonyl olefinations, which only differed by the order of the fragments assembly sequence. ${ }^{[238]}$ In a first attempt, key fragments were connected through three Stille cross-couplings and an intramolecular carbonyl olefination (Ando conditions), which completed the macrocyclisation (Scheme 95). Notably, the use of a sequential, one-pot, four-component process $(247+$ $\mathbf{2 4 8}+\mathbf{2 5 0}+\mathbf{2 5 2} \rightarrow \mathbf{2 5 3}$ ) afforded key intermediate 253 in $56 \%$ yield; whereas, the yield was slightly lower when three, stepwise Stille coupling reactions were run (42\% overall yield). An aldehyde function at the C3 position is required for the macrocyclisation through an HWE olefination; however, attempts to install the aldehyde on 253 proved unsuccessful, and extensive double bond isomerisations were observed on the $E, Z, E$-triene unit.

Consequently, judicious re-ordering of the key fragment assembly offered a novel reaction sequence, where two Stille-type cross-couplings, a carbonyl olefination reaction (Still-Gennari conditions), and then an intramolecular Stille coupling were conducted to successfully synthesise the macrolide backbone (Scheme 96). As for the previous approach, employing a sequential, one-pot reaction with two Stille couplings $(\mathbf{2 5 0}+\mathbf{2 5 4}+\mathbf{2 5 6} \rightarrow \mathbf{2 5 7})$ displayed better yields than isolated cross-couplings $(80 \%$ vs $73 \%$ yields, respectively).

Sarain A is a complex marine alkaloid, featuring a functionalised diazatricycloundecane core that bears five contiguous stereogenic centres, one of which is quaternary (C3), and is flanked by two macrocyclic rings. One of these large rings is a saturated, 13membered ring and the other is a 14-membered macrocycle, which contained an E,Z-diene unit and a vicinal diol function.
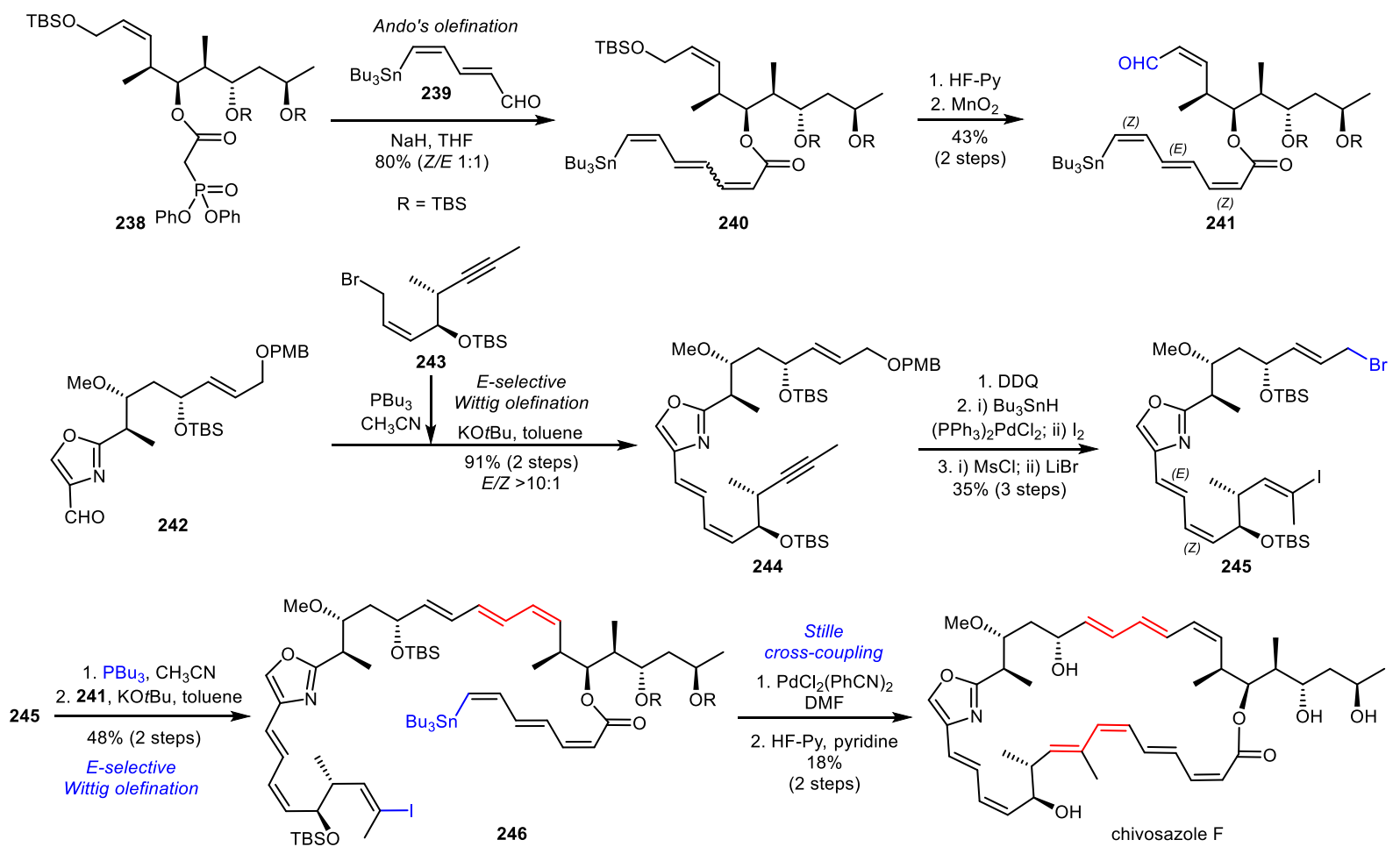

Scheme 94. Total synthesis of chivosazole F by Kalesse. 


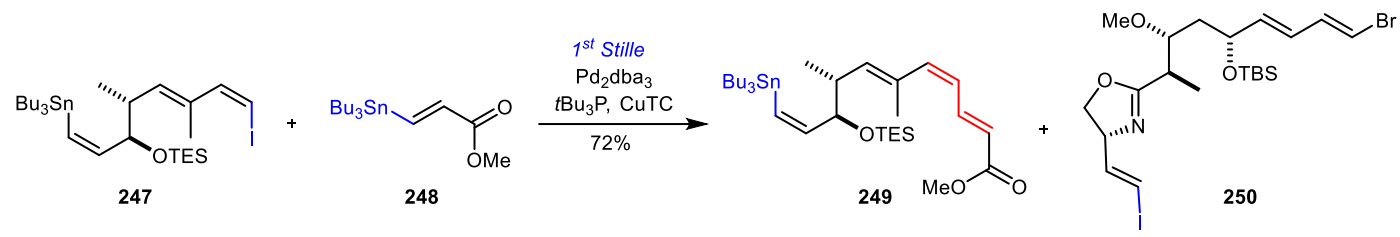

$\underset{t B u_{3} P, C u T C}{\mathrm{Pd}_{2} \mathrm{dba}_{3}} 71 \% 2^{\text {nd }}$ Stille
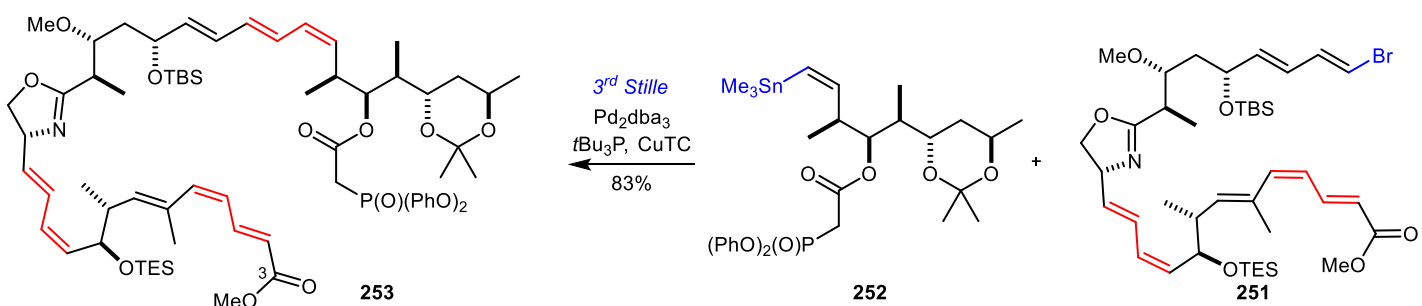

HWE olefination $\Varangle$

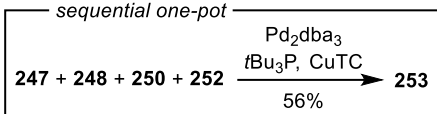

Scheme 95. First approach towards chivosazole F by Paterson. TES = Triethylsilyl.

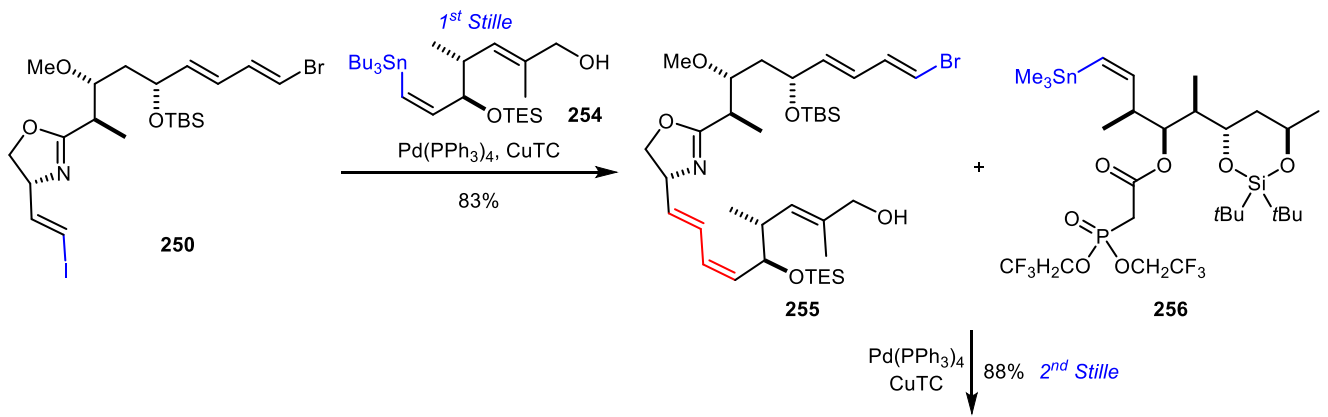

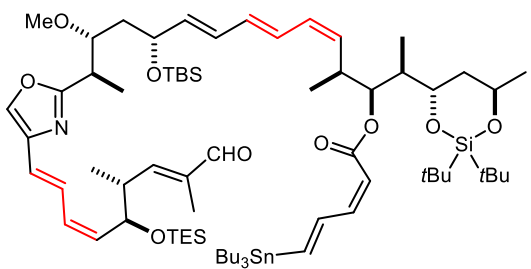

258

$$
\underset{\mathrm{NaHMDS}}{\left[\mathrm{PPh}_{3} \mathrm{CH}_{2}\right]^{+} \mathrm{I}^{-}} \begin{aligned}
& \text { Stork-Zhao } \\
& \text { olefination }
\end{aligned}
$$

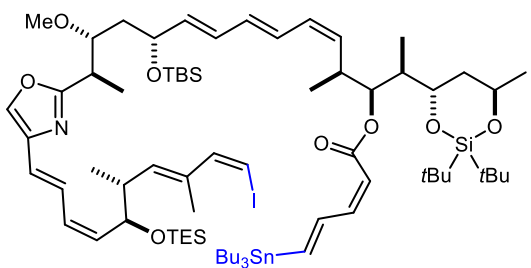

259

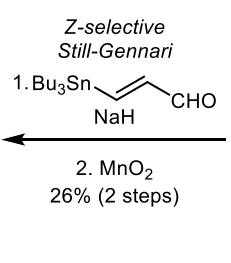

$3^{\text {rd }}$ Stille 1. $\mathrm{Pd}\left(\mathrm{PPh}_{3}\right)_{4}$ $\underset{41 \%}{\stackrel{\text { CuTC }}{\underset{\text { HF-Py }}{\longrightarrow}}}$ (3 steps)

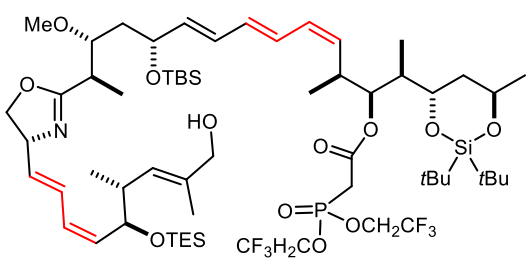

257

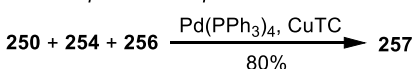

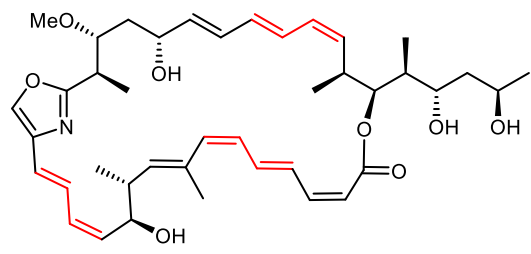

chivosazole $\mathrm{F}$

Scheme 96. Total synthesis of chivosazole F by Paterson. 
Moreover, this natural product also displays a distinctive interaction between tertiary amines and aldehydes in close proximity. This complicates reaction conditions development, purification methods, and characterisation practices. Overman described the first total synthesis of sarain A where an intramolecular, Pd-catalysed Stille cross-coupling reaction, in the presence of $E$-vinyl stannane and $Z$-vinyl iodide intermediate 261, was used to form the 14-membered ring of 262 with simultaneous installation of the E,Zdiene (Scheme 97). ${ }^{[239]}$ There are two important points for this key step. Firstly, the use of a less basic N-O acetal proved to be essential in preventing skeletal rearrangement during the critical, intramolecular Stille cross-coupling reaction. The $\mathrm{N}-\mathrm{O}$ acetal is reduced in the presence of DIBAL-H to unveil the skeleton of sarain A. Second, the Stille cross-coupling was carried out in the presence of excess $\mathrm{LiCl}$. With the sensitive diene (and skipped triene) present, deprotecting the PMB-protected neopentylic alcohol is challenging. TMSI-mediated deprotection lead to low yields and complex mixtures; however, it was fortuitously found that HF.Pyr promoted both TES- and PMBdeprotection.

Other key steps in this enantioselective strategy are: i) an intramolecular Michael addition to form the $\mathrm{C}^{\prime}$ '$\mathrm{C}^{\prime}-\mathrm{C}^{\prime}$ stereotriad; ii) an enoxysilane $/ N$ sulfonyliminium ion cyclisation to install the $\mathrm{C} 3$ quaternary stereocenter and gather the diazatricycloundecane core; and iii) an RCM reaction, in the presence of the first generation Grubbs catalyst, to obtain the 13-membered macrocycle. A great deal of studies and optimisation were required to achieve this total synthesis, and a comprehensive full account was published shortly after. ${ }^{[240]}$

Polyene antibiotic myxalamide A was synthesised by Kobayashi in a highly convergent strategy. The use of a central iodo-substituted (Z)-boronic ester (264) allows for a sequential, one-pot method consisting of Stille/Suzuki-Miyaura cross-coupling reactions for assembling three fragments and directly obtaining the natural compound (Scheme 98). ${ }^{[241]}$ Indeed the two consecutive cross-coupling reactions allow the presence of non-protected primary (compound 263) and secondary (intermediate 265) alcohols. To minimise unwanted olefin $Z \rightarrow E$ isomerisation, the reactions were conducted in the dark and the solvents (reaction and chromatography) were degassed. The left-hand fragment of myxalamide A was obtained using a highly anti-diastereoselective, vinylogous Mukaiyama reaction.

To illustrate the impact of the substrate conformation on the cyclisation outcome, the case of heronamide $\mathrm{C}$ is highlighted. Heronamides are macrocyclic polyenes that display powerful antifungal activities. Their total synthesis and stereochemical configuration confirmations were studied by Kanoh and Kakeya. ${ }^{[178,242]}$ Interesting chemoselectivity issues were observed that depended on the stereochemistry of the vicinal diol starting materials used for the macrocyclisation. An intramolecular Stille crosscoupling (in the dark), starting from 266, was successful in obtaining the originally proposed structure of heronamide C. However, the physicochemical and spectroscopic data of the synthesised $(8 R, 9 S, 19 R)$-heronamide $\mathrm{C}$ did not match with those of the natural product. Suspecting that the natural product has a stereochemistry of $8 S, 9 R, 19 R$, the authors re-synthesised diastereomer diol 267, but the Pd-mediated, intramolecular Stille coupling failed in this case. Attempts to cyclise various other protected diols, non-protected diols, substituted amides, or differently substituted stannanes have also been unsuccessful. Moreover, a C10-C11 pinacol coupling to obtain the corresponding macrocycle also failed. Finally, an intramolecular RCM strategy (in the dark) using 268 as the starting compound was successful in confirming the revised structure of heronamide $\mathrm{C}$ in low yield but with high $Z$ selectivity (Scheme 99).

Another example is the total synthesis of etnangien, which emphasised a modified tactic from the former approach. As previously mentioned (see section 2.9), RCM strategies for the construction of $E, Z$-dienes face some drawbacks, such as low $E / Z$ selectivities, and ring contraction problems.

Indeed, during the stereoselective total synthesis of etnangien and etnangien methyl ester polyketide macrolides, Menche explored both RCM and Heck reactions for forming the 22-membered macrocycle. ${ }^{[180,243]}$ The RCM approach was tried under several conditions and afforded lower conversions of 270 into 271, mainly due to the undesired formation of contracted 20-membered ring $\mathbf{2 7 2}$ via ethylene extrusion (Scheme 100). Moreover, 271 and sideproduct $\mathbf{2 7 2}$ were difficult to separate. Regarding the Heck reaction, macrocyclisation of $\mathbf{2 6 9}$ was successfully performed and afforded the desired 22membered macrocycle (271) in 70\% yield. 

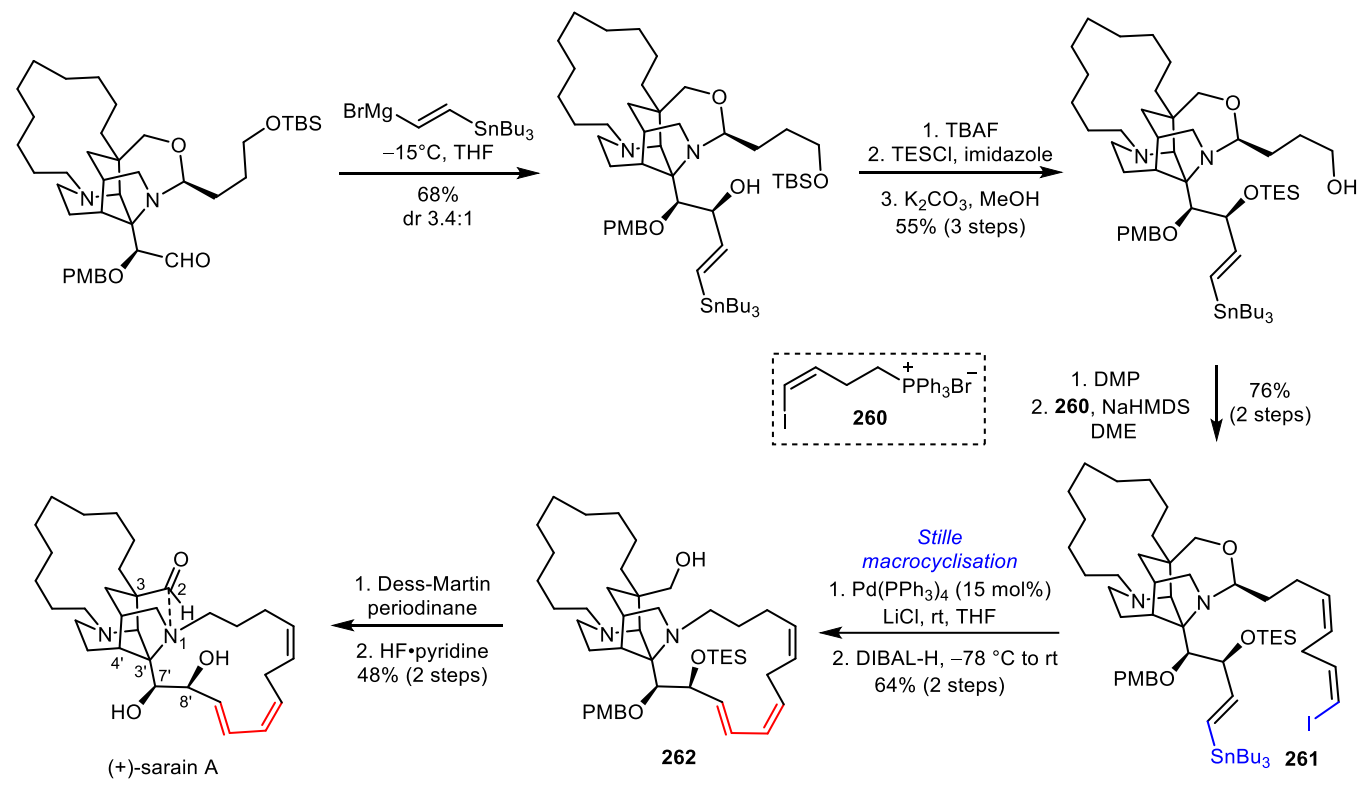

Scheme 97. Stille cross-coupling for the formation of the 14-membered macrocycle of sarain A and installation of the E,Zdiene.

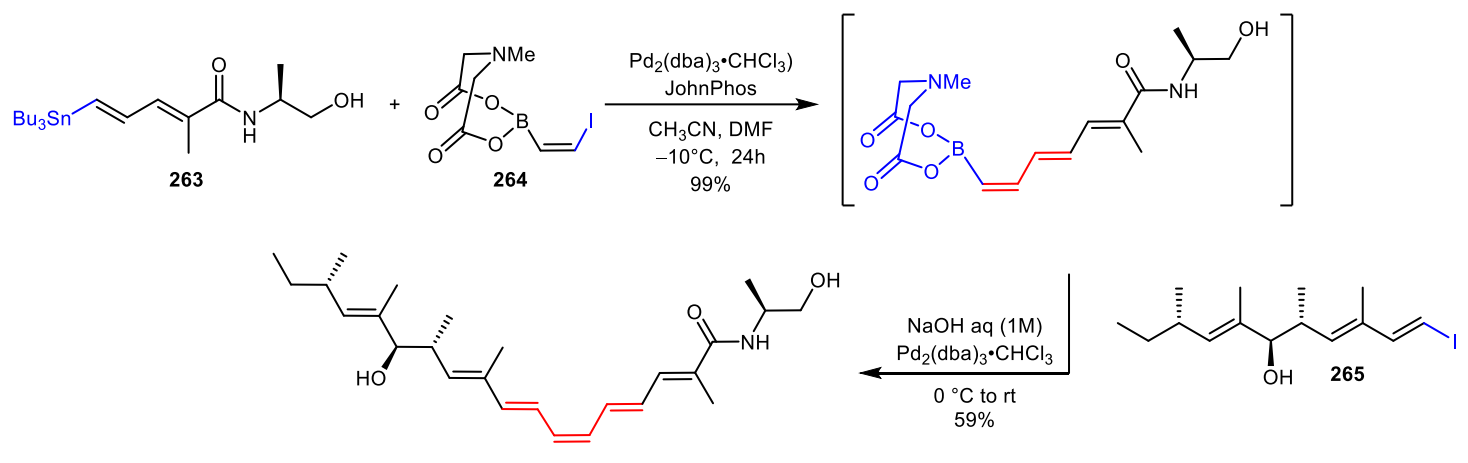

(-)-myxalamide A

Scheme 98. Sequential one-pot Stille/Suzuki-Miyaura cross-couplings on the synthesis of myxalamide A.
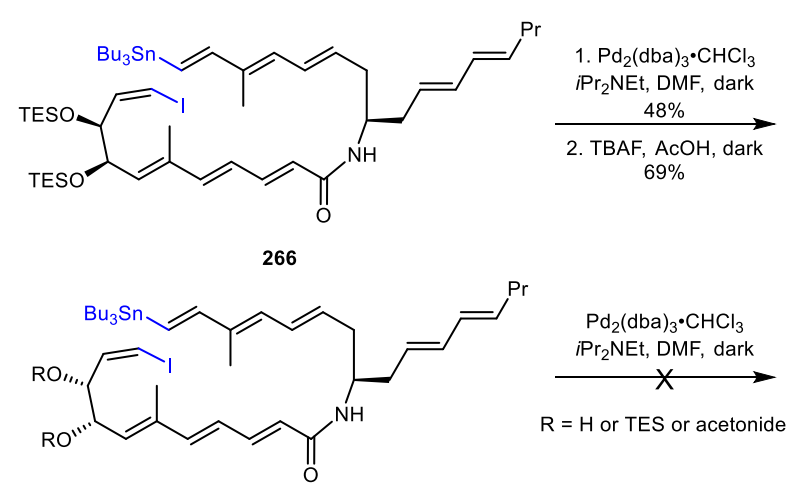

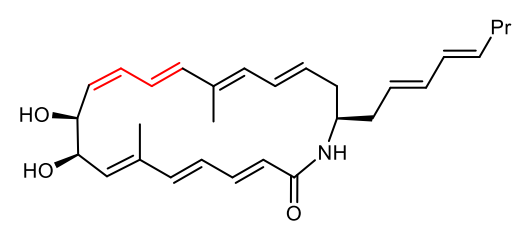

originally proposed structure of

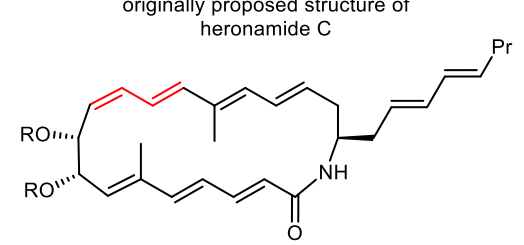<smiles>C=C/C=C\C(C)=C/C=C/CC(C/C=C/C=C/P)NC(=O)/C=C/C=C/C(C)=C/C(C)=C/C(=O)OC</smiles>

268

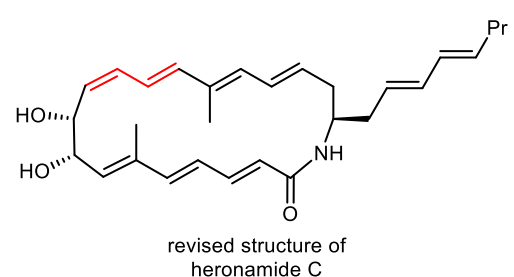

Scheme 99. Cross-coupling and RCM strategies for the synthesis of heronamides. 


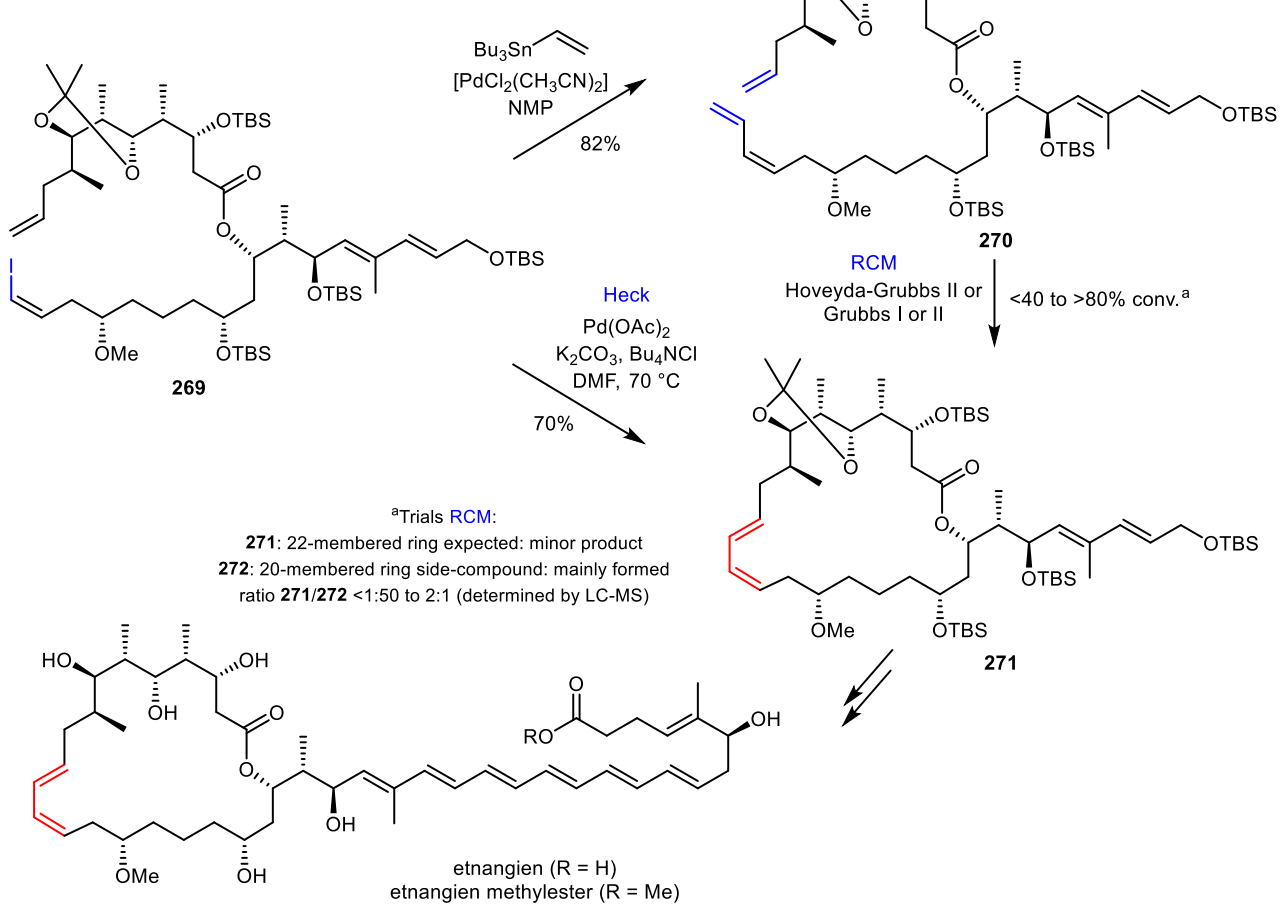

Scheme 100. RCM vs Heck reaction during the synthesis of etnangien and etnangien methylester.

\section{Conclusion}

In this review, we have focused on the use of selective methods towards the formation of $(E, Z)$-1,3-dienes and their application in the total syntheses of selected natural products. Carbonyl olefinations and metalcatalysed cross-coupling reactions are the two approaches primarily used for this purpose; however, other efficient strategies have been developed that afford products from simple substrates in high yields and with high selectivities. Despite the availability of a variety of such strategies, issues related to poor selectivities are observed. It might be assumed that these shortcomings easily be bypassed by simply adjusting the reaction parameters; however, in the field of complex, natural product total syntheses, where chemical complexity and high functionalisation need to be considered, the fine-tuning of reaction conditions is not sufficient enough. Indeed, total syntheses often require two or more fallback, retrosynthetic approaches to prevent unwanted and unexpected reactivities, or even a complete absence of reactivity. When sensitive conjugated polyenes are present, undesired isomerisation issues should also be taken into consideration. Herein, the use of selective olefination reactions towards $(E, Z)-1,3$-dienes has been displayed. The arbitrary choice of describing natural product syntheses was made to provide a comprehensive overview of the main strategies used to date. Carbonyl olefinations and cross-coupling reactions are still the most commonly used strategies to access such complex targets. However, other alternatives (novel or well-known) could prove to be unexpected solutions to achieve (E,Z)-1,3-diene units within complex chemical structures. We hope to have provided a helpful overview on the points covered herein.

\section{Acknowledgements}

We are grateful for the financial support from the Agence Nationale de la Recherche (ANR, ANR-17-CE07-0051-01) and the German Research Foundation (DFG, BE 4799/2-1 and 3-1).

\section{References}

[1] R. Baker, J. W. S. Bradshaw, in: Aliphatic and Related Natural Product Chemistry (Ed. F. D. Gunstone), Specialist Periodical Report, Vol. 3, Royal Society of Chemistry, London, 1983.

[2] J. Prunet, Angew. Chem. Int. Ed. 2003, 42, 28262830.

[3] a) For a review dealing with the stereoselective access to conjugated dienes (all isomers) in the 2005-2010 period, see: M. De Paolis, I. Chataigner, J. Maddaluno, Top Curr. Chem. 2012, 327, 87-146; b) for an account, see: E-i. Negishi, Z. Huang, G. Wang, S. Mohan, C. Wang, H. Hattori, Acc. Chem. Res. 2008, 41, 1474-1485.

[4] M. Furber, R. J. K. Taylor, J. Chem. Soc., Chem. Commun. 1985, 782-783. 
[5] Y. Y. Belosludtsev, B. C. Borer, R. J. K. Taylor, Synthesis 1991, 320-322.

[6] M. Furber, J. M. Herbert, R. J. K. Taylor, J. Chem. Soc., Perkin Trans. 1 1989, 683-690.

[7] R. J. K. Taylor, K. Hemming, E. Faria De Medeiros, J. Chem. Soc., Perkin Trans. 1 1995, 2385-2392.

[8] B. G. Lawhorn, S. B. Boga, S. E. Wolkenberg, D. A. Colby, C.-M. Gauss, M. R. Swingle, L. Amable, R. E. Honkanen, D. L. Boger, J. Am. Chem. Soc. 2006, 128, 16720-16732.

[9] C. P. Burke, N. Haq, D. L. Boger, J. Am. Chem. Soc. 2010, 132, 2157-2159.

[10] H. Andersson, X. Wang, M. Björklund, R. Olsson, F. Almqvist, Tetrahedron Lett. 2007, 48, 69416944.

[11] B. M. Trost, P. G. McDougal, J. Org. Chem. 1984, 49, 458-468.

[12] F. Binns, R. Hayes, S. Ingham, S. T. Saengchantara, R. W. Turner, T. W. Wallace, Tetrahedron 1992, $48,515-530$.

[13] C. Souris, A. Misale, Y. Chen, M. Luparia, N. Maulide, Org. Lett. 2015, 17, 4486-4489.

[14] A. Misale, S. Niyomchon, N. Maulide, Acc. Chem. Res. 2016, 49, 2444-2458.

[15] Y. Sachiko, O. Hideto, S. Takayoshi, T. Hiroaki, Chem. Lett. 1983, 12, 1003-1006.

[16] S. Yamada, H. Ohsawa, T. Suzuki, H. Takayama, J. Org. Chem. 1986, 51, 4934-4940.

[17] T.-s. Chou, M.-L. You, J. Org. Chem. 1987, 52, 2224-2226.

[18] Y. Gaoni, Tetrahedron Lett. 1977, 18, 947-950.

[19] a) R. Bloch, G. Gasparini, C. Girard, Chem. Lett. 1988, 17, 1927-1930; b) R. Bloch, G. Gasparini, J. Org. Chem. 1989, 54, 3370-3373; c) T. Taniguchi, K. Ogasawara, Tetrahedron Lett. 1997, 38, 433436; d) H. Oda, T. Kobayashi, M. Kosugi, T. Migita, Tetrahedron 1995, 51, 695-702.

[20] D. Woody, A. Padarti, H. Han, Org. Lett. 2018, 20, 2472-2476.

[21]D. Tejedor, G. Méndez-Abt, L. Cotos, F. GarcíaTellado, Chem. Soc. Rev. 2013, 42, 458-471.

[22] S. Tsuboi, T. Masuda, A. Takeda, J. Org. Chem. 1982, 47, 4478-4482.

[23] S. Tsuboi, T. Masuda, S. Mimura, A. Takeda, Mark A. Henderson, C. H. Heathcock, Org. Synth. 1988, 66, 22.

[24] L. C. Passaro, F. X. Webster, Synthesis 2003, 8, $1187-1190$

[25] S. Tsuboi, X. H. Wu, S. Maeda, S. Ono, A. Kuroda, K. Kawazu, A. Takeda, Bull. Chem. Soc. Jpn. 1987, 60, 1103-1107.
[26] M. Georgy, P. Lesot, J.-M. Campagne, J. Org. Chem. 2007, 72, 3543-3549.

[27] R. A. Amos, J. A. Katzenellenbogen, J. Org. Chem. 1978, 43, 555-560.

[28] a) D. V. Vidhani, M. E. Krafft, I. V. Alabugin, J. Org. Chem. 2014, 79, 352-364; b) D. V. Vidhani, M. E. Krafft, I. V. Alabugin, Org. Lett. 2013, 15 , $4462-4465$

[29] D. F. Maynard, W. H. Okamura, J. Org. Chem. 1995, 60, 1763-1771.

[30] For an alternative strategy for 1,5-sigmatropic $H$ migration, see: B. Iglesias, A. Torrado, A. R. de Lera, S. López, J. Org. Chem. 2000, 65, 2696-2705.

[31]D. A. Clark, A. A. Kulkarni, K. Kalbarczyk, B. Schertzer, S. T. Diver, J. Am. Chem. Soc. 2006, 128, 15632-15636.

[32] a) V. R. Sabbasani, P. Mamidipalli, H. Lu, Y. Xia, D. Lee, Org. Lett. 2013, 15, 1552-1555; b) Y. Zhao, Y. Wang, Z. Gu, Z.Wang, Org. Biomol. Chem. 2017, 15, 4014-4021.

[33] For selected books, see: a) Handbook of Organopalladium Chemistry for Organic Synthesis (Ed.: E-i. Negishi), John Wiley \& Sons, 2003; b) Metal-Catalysed Cross-Coupling Reactions, Vols. 1 and 2 (Eds.: A. de Meijere, F. Diederich), WileyVCH, Weinheim, 2004; c) Applied Cross-Coupling Reactions, in: Lecture Notes in Chemistry (Ed.: Y. Nishihara), Springer-Verlag, Berlin Heidelberg, 2013; d) Metal-Catalysed Cross-Coupling Reactions and More, Vols. 1, 2 and 3 (Eds.: A. de Meijere, S. Bräse, M. Oestreich), Wiley-VCH, Weinheim, 2014

[34] Cross Coupling (Special Issue), in: Accounts of Chemical Research, November Issue, 2008.

[35] For a selection, see: a) K. C. Nicolaou, P. G. Bulger, D. Sarlah, Angew. Chem. Int. Ed. 2005, 44, 44424489; b) N. Kambe, T. Iwasaki, J. Terao, Chem. Soc. Rev. 2011, 40, 4937-4947; c) C. C. C. Johansson Seechurn, M. O. Kitching, T. J. Colacot, V. Snieckus, Angew. Chem. Int. Ed. 2012, 51, 5062-5085; d) Palladium-Catalysed Coupling Reactions: Practical Aspects and Future Developments (Ed. Á. Molnár), Wiley-VCH, 2013; e) A. Biffis, P. Centomo, A. Del Zotto, M. Zecca, Chem. Rev. 2018, 118, 2249-2295.

[36] a) N. Miyaura, K. Yamada, A. Suzuki, Tetrahedron Lett. 1979, 3437-3440; b) R. Rossi, A. Carpita, M. Grazia Quirici, Tetrahedron 1981, 37, 2617-2623; c) For a review, see: A. J. J. Lennox, G. C. LloydJones, Chem. Soc. Rev. 2014, 43, 412-443.

[37] J. K. Stille, J. H. Simpson, J. Am. Chem. Soc. 1987 , $109,2138-2152$.

[38] For a perspective, see: D. Haas, J. M. Hammann, R. Greiner, P. Knochel, ACS Catal. 2016, 6, 15401552. 
[39] For a review, see: J. F. Normant, A. Alexakis, Synthesis 1981, 841-870.

[40] M. Gardette, N. Jabri, A. Alexakis, J. F. Normant, Tetrahedron 1984, 40, 2741-2750.

[41]Z. Huang, E-i. Negishi, J. Am. Chem. Soc. 2007, $129,14788-14792$.

[42] G. Wang, S. Mohan, E-i. Negishi, Proc. Natl. Acad. Sci. USA 2011, 108, 11344-11349.

[43] N. F. Langille, J. S. Panek, Org. Lett. 2004, 6, 3203-3206.

[44] M. M. Heravi, V. Zadsirjan, P. Hajiabbasi, H. Hamidi, Monatsh. Chem. 2019, 150, 535-591.

[45] V. Fiandanese, G. Marchese, F. Naso, L. Ronzini, D. Rotunno, Tetrahedron Lett. 1989, 30, 243-246.

[46] J. Uenishi, R. Kawahama, Y. Izaki, O. Yonemitsu, Tetrahedron 2000, 56, 3493-3500.

[47] For a review on Hiyama-Denmark cross-couplings, see: Y. Nakao, T. Hiyama, Chem. Soc. Rev. 2011, 40, 4893-4901.

[48]F. Urbitsch, B. L. Elbert, J. Llaveria, P. E. Streatfeild, E. A. Anderson, Org. Lett. 2020, 22, $1510-1515$.

[49] C. Cordovilla, C. Bartolomé, J. M. MartínezIlarduya, P. Espinet, ACS Catal. 2015, 5, 30403053 .

[50] A. B. Smith III, S. Dong, J. B. Brenneman, R. J. Fox, J. Am. Chem. Soc. 2009, 131, 12109-12111.

[51] X. Franci, S. L. X. Martina, J. E. McGrady, M. R. Webb, C. Donald, R. J. K. Taylor, Tetrahedron Lett. 2003, 44, 7735-7740.

[52] A. B. Smith III, S. Dong, Org. Lett. 2009, 11, 10991102.

[53] R. Rossi, F. Bellina, A. Catanese, L. Mannina, D. Valensin, Tetrahedron 2000, 56, 479-487.

[54] D. J. Lipomi, N. F. Langille, J. S. Panek, Org. Lett. 2004, 6, 3533-3536.

[55]L. C. Dias, C. da Costa S. Gonçalves, Adv. Synth. Catal. 2008, 350, 1017-1021.

[56] J. S. Yadav, P. Dutta, J. Org. Chem. 2016, 81, 1786-1797.

[57] P. A. Roethle, I. T. Chen, D. Trauner, J. Am. Chem. Soc. 2007, 129, 8960-8961.

[58] M. B. Andrus, S. D. Lepore, J. Am. Chem. Soc. 1997, 119, 2327-2328.

[59] T. Nagasawa, S. Kuwahara, Org. Lett. 2013, 15, 3002-3005.

[60] M. Heinrich, J. J. Murphy, M. K. Ilg, A. Letort, J. Flasz, P. Philipps, A. Fürstner, Angew. Chem. Int. Ed. 2018, 57, 13575-13581.
[61] M. Heinrich, J. J. Murphy, M. K. Ilg, A. Letort, J. Flasz, P. Philipps, A. Fürstner, J. Am. Chem. Soc. 2020, 142, 6409-6422.

[62] R. W. Armstrong, J.-M. Beau, S. H. Cheon, W. J. Christ, H. Fujioka, W. H. Ham, L. D. Hawkins, H. Jin, S. H. Kang, Y. Kishi, M. J. Martinelli, W. W. McWhorter, Jr., M. Mizuno, M. Nakata, A. E. Stutz, F. X. Talamas, M. Taniguchi, J. A. Tino, K. Ueda, J.-i. Uenishi, J. B. White, M. Yonaga, J. Am. Chem. Soc. 1989, 111, 7525-7530.

[63] N. Miyaura, H. Suginome, A. Suzuki, Tetrahedron 1983, 39, 3271-3277.

[64] For another example of sex pheromones synthesis, see: A. Khrimian, J. A. Klun, Y. Hijji, Y. N. Baranchikov, V. M. Pet'ko, V. C. Mastro, M. H. Kramer, J. Agric. Food Chem. 2002, 50, 6366-6370.

[65]H. Fuwa, T. Suzuki, H. Kubo, T. Yamori, M. Sasaki, Chem. Eur. J. 2011, 17, 2678-2688.

[66]H. Lei, J. Yan, J. Yu, Y. Liu, Z. Wang, Z. Xu, T Ye, Angew. Chem. Int. Ed. 2014, 53, 6533-6537.

[67] G. A. Molander, L. A. Felix, J. Org. Chem. 2005, 70, 3950-3956.

[68] G. A. Molander, F. Dehmel, J. Am. Chem. Soc. 2004, 126, 10313-10318.

[69]Z. Wang, X. Lu, A. Lei, Z. Zhang, J. Org. Chem. 1998, 63, 3806-3807.

[70]Z. Ma, X. Yang, Y. Zhang, X. Huang, Y. Tao, Synlett 2012, 23, 581-584.

[71] Y. Tao, X. Yang, Y. Jin, Q. Wang, Synth. Commun. 2013, 43, 415-424.

[72] R. G. Iafe, D. G. Chan, J. L. Kuo, B. A. Boon, D. J. Faizi, T. Saga, J. W. Turner, C. A. Merlic, Org. Lett. 2012, 14, 4282-4285.

[73] B. A. Boon, A. G. Green, P. Liu, K. N. Houk, C. A. Merlic, J. Org. Chem. 2017, 82, 4613-4624.

[74] A. Piontek, E. Bisz, M. Szostak, Angew. Chem. Int Ed. 2018, 57, 11116-11128.

[75] C.-L. Sun, A. Fürstner, Angew. Chem. Int. Ed. 2013, 52, 13071-13075.

[76] D. M. Hodgson, M. J. Fleming, S. J. Stanway, J. Org. Chem. 2007, 72, 4763-4773.

[77] M. Šiaučiulis, N. Ahlsten, A. P. Pulis, D. J. Procter, Angew. Chem. Int. Ed. 2019, 58, 8779-8783.

[78] For selected reviews, see: a) I. P. Beletskaya, A. V. Cheprakov, Chem. Rev. 2000, 100, 3009-3066; b) J. Le Bras, J. Muzart, Chem. Rev. 2011, 111, 11701214; c) D. McCartney, P. J. Guiry, Chem. Soc. Rev. 2011, 40, 5122-5150; d) S. Jagtap, Catalysts 2017, 7, 267.

[79] For selected examples of $E, E$-diene synthesis through Heck reactions, see: a) A. S. Gruber, D. Zim, G. Ebeling, A. L. Monteiro, J. Dupont, Org. Lett. 2000, 2,1287-1290; b) A. F. Littke, G. C. Fu, 
J. Am. Chem. Soc. 2001, 123, 6989-7000; c) A. Fürstner, C. Aïssa, C. Chevrier, F. Teplý, C. Nevado, M. Tremblay, Angew. Chem. Int. Ed. 2006, 45, 5832-5837; d) M. Lemhadri, A. Battace, F. Berthiol, T. Zair, H. Doucet, M. Santelli, Synthesis 2008, 7, 1142-1152.

[80] K. M. Reddy, V. Yamini, K. K. Singarapu, S. Ghosh, Org. Lett. 2014, 16, 2658-2660.

[81] M. H. Nguyen, M. Imanishi, T. Kurogi, A. B. Smith, III J. Am. Chem. Soc. 2016, 138, 3675-3678.

[82] a) M. Nazari, J. D. Serrill, X. Wan, M. H. Nguyen, C. Anklin, D. A. Gallegos, A. B. Smith, III, E. Ishmael, K. L. McPhail, J. Med. Chem. 2017, 60, 7850-7862; b) M. H. Nguyen, M. Imanishi, T. Kurogi, X. Wan, J. E. Ishmael, K. L. McPhail, A. B. Smith III, J. Org. Chem. 2018, 83, 4287-4306.

[83] V. Yamini, K. M. Reddy, A. S. Krishna, J. K. Lakshmi, S. Ghosh, J. Chem. Sci. 2019, 131, 1-24.

[84] N. Hénaff, A. Whiting, Tetrahedron 2000, 56, 5193-5204.

[85] A. S. Batsanov, J. P. Knowles, A. Whiting, J. Org. Chem. 2007, 72, 2525-2532.

[86] a) A. S. Batsanov, J. P. Knowles, B. Samsam, A. Whiting, Adv. Synth. Catal. 2008, 350, 227-233; b) J. P. Knowles, V. E. O'Connor, A. Whiting, Org. Biomol. Chem. 2011, 9, 1876-1886.

[87] J. Franke, M. Bock, R. Dehn, J. Fohrer, S. B. Mhaske, A. Migliorini, A. A. Kanakis, R. Jansen, J. Herrmann, R. Müller, A. Kirschning, Chem. Eur. J. 2015, 21, 4272-4284.

[88] D. Paul, S. Das, R. K. Goswami, J. Org. Chem. 2017, 82, 7437-7445.

[89] Y. Hatamoto, S. Sakaguchi, Y. Ishii, Org. Lett. 2004, 6, 4623-4625.

[90] a) Y-H. Xu, J. Lu, T.-P. Loh, J. Am. Chem. Soc. 2009, 131, 1372-1373; b) Y.-H. Xu, W.-J. Wang, Z.-K. Wen, J. J. Hartley, T.-P. Loh, Tetrahedron Lett. 2010, 51, 3504-3507.

[91] H. Yu, W. Jin, C. Sun, J. Chen, W. Du, S. He, Z. Yu, Angew. Chem. Int. Ed. 2010, 49, 5792-5797.

[92] Y. Zhang, Z. Cui, Z. Li, Z.-Q. Liu, Org. Lett. 2012, $14,1838-1841$.

[93] T. Besset, N. Kuhl, F. W. Patureau, F. Glorius, Chem. Eur. J. 2011, 17, 7167-7171.

[94] J. Zhang, T.-P. Loh, Chem. Commun., 2012, 48, 11232-11234.

[95]F. Li, C. Yu, J. Zhang, G. Zhong, Org. Lett. 2016, $18,4582-4585$.

[96] C. Yu, F. Li, J. Zhang, G. Zhong, Chem. Commun. 2017, 53, 533-536.

[97]F. Li, C. Yu, J. Zhang, G. Zhong, Org. Biomol. Chem. 2017, 15, 1236-1244.
[98] R. Feng, W. Yu, K. Wang, Z. Liu, Y. Zhang, Adv. Synth. Catal. 2014, 356, 1501-1508.

[99] X.-H. Hu, J. Zhang, X.-F. Yang, Y.-H. Xu, T.-P. Loh, J. Am. Chem. Soc. 2015, 137, 3169-3172.

[100] M. Boultadakis-Arapinis, M. N. Hopkinson, F. Glorius, Org. Lett. 2014, 16, 1630-1633.

[101] X.-H. Hu, X.-F. Yang, T.-P. Loh, Angew. Chem. Int. Ed. 2015, 54, 15535-15539.

[102] T. Li, J. Zhang, C. Yu, X. Lu, L. Xu, G. Zhong, Chem. Commun. 2017, 53, 12926-12929.

[103] M. Liu, P. Yang, M. K. Karunananda, Y. Wang, P. Liu, K. M. Engle, J. Am. Chem. Soc. 2018, 140, 5805-5813.

[104] V. G. Zaitsev, D. Shabashov, O. Daugulis, J. Am. Chem. Soc. 2005, 127, 13154-13155.

[105] T. Deguchi, H.-L. Xin, H. Morimoto, T. Ohshima, ACS Catal. 2017, 7, 3157-3161.

[106] K. Meng, Y. Sun, J. Zhang, K. Zhang, X. Ji, L. Ding, G. Zhong, Org. Lett. 2019, 21, 8219-8224.

[107] T. Li, C. Shen, Y. Sun, J. Zhang, P. Xiang, X. Lu, G. Zhong, Org. Lett. 2019, 21, 7772-7777.

[108] B. Jiang, M. Zhao, S.-S. Li, Y.-H. Xu, T.-P. Loh, Angew. Chem. Int. Ed. 2018, 57, 555-559.

[109] B. N. Thomas, P. J. Moon, S. Yin, A. Brown, R. J. Lundgren, Chem. Sci. 2018, 9, 238-244.

[110] Modern Carbonyl Olefination (Ed.: T. Takeda), Wiley-VCH, Weinheim, 2004.

[111] For selected reviews, see: a) B. E. Maryanoff, A. B. Reitz, Chem. Rev. 1989, 89, 863-927; b) P. A. Byrne, D. G. Gilheany, Chem. Soc. Rev. 2013, 42, 6670-6696; c) P. T. Parvatkar, P. S. Torney, S. G. Tilve, Curr. Org. Synth. 2013, 10, 288-317.

[112] H. Y. Zeng, L. Shi, J. Yang, Z. Cai, J. Org. Chem. 1987, 52, 3558-3560.

[113] R. M. de Figueiredo, R. Berner, J. Julis, T. Liu, D. Türp, M. Christmann, J. Org. Chem. 2007, 72, 640642.

[114] Y. Suganuma, S. Tanabe, Y. Sugihara, Y. Kobayashi, Tetrahedron 2018, 74, 1151-1159.

[115] K. Nishimura, T. Sakaguchi, Y. Nanba, Y. Suganuma, M. Morita, S. Hong, Y. Lu, B. Jun, N. G. Bazan, M. Arita, Y. Kobayashi, J. Org. Chem. 2018, 83, 154-166.

[116] A. Huefner, C. Hoeller, G. Reznicek, Monats. Chem. 2004, 135, 447-459.

[117] C. Kugel, J.-P. Lellouche, J.-P. Beaucourt, G. Niel, J.-P. Girard, J.-C. Rossi, Tetrahedron Lett. 1989, 30, 4947-4950.

[118] Y. Suganuma, S. Saito, Y. Kobayashi, Synlett 2009, 30, 338-342. 
[119] M. T. Crimmins, B. W. King, J. Am. Chem. Soc. 1998, 120, 9084-9085.

[120] J. A. Marshall, M. P. Bourbeau, J. Org. Chem. 2002, 67, 2751-2754.

[121] J. L. Vicario, A. Job, M. Wolberg, M. Müller, D. Enders, Org. Lett. 2002, 4, 1023-1026.

[122] N. Arai, N. Chikaraishi, S. Omura, I. Kuwajima, Org. Lett. 2004, 6, 2845-2848.

[123] R. Ando, Y. Amano, H. Nakamura, N. Arai, I. Kuwajima, Bioorg. Med. Chem. Lett. 2006, 16, 3315-3318.

[124] S. Zhou, H. Chen, W. Liao, S-H. Chen, G. Li, R. Ando, I. Kuwajima, Tetrahedron Lett. 2005, 46, 6341-6344.

[125] M. Christmann, U. Bhatt, M. Quitschalle, E. Claus, M. Kalesse, Angew. Chem. Int. Ed. 2000, 39, 4364-4366.

[126] M. Tortosa, N. A. Yakelis, W. R. Roush, J. Am. Chem. Soc. 2008, 130, 2722-2723.

[127] J. D. White, M. S. Jensen, Tetrahedron 1995, 51, 5743-5756.

[128] J. D. White, M. Kawasaki, J. Am. Chem. Soc. 1990, 112, 4991-4993.

[129] J. D. White, M. Kawasaki, J. Org. Chem. 1992, $57,5292-5300$.

[130] N. Veerasamy, A. Ghosh, J. Li, K. Watanabe, J. D. Serrill, J. E. Ishmael, K. L. McPhail, R. G. Carter, J. Am. Chem. Soc. 2016, 138, 770-773.

[131] a) B. L. Pagenkopf, J. Krüger, A. Stojanovic, E. M. Carreira, Angew. Chem. Int. Ed. 1998, 37, 31243126; b) G. Bluet, B. Bazán-Tejeda, J.-M. Campagne, Org. Lett. 2001, 3, 3807-3810; c) G. Bluet, J.-M. Campagne, J. Org. Chem. 2001, 66, 4293-4298; d) B. Bazán-Tejeda, G. Bluet, G. Broustal, J.-M. Campagne, Chem. Eur. J. 2006, 12, 8358-8366.

[132] R. Schäckel, B. Hinkelmann, F. Sasse, M. Kalesse, Angew. Chem. Int. Ed. 2010, 49, 16191622.

[133] D. B. Tulshian, B. Fraser-Reid, J. Am. Chem. Soc. 1981, 103, 474-475.

[134] D.-J. Dong, H.-H. Li, S.-K. Tian, J. Am. Chem. Soc. 2010, 132, 5018-5020.

[135] D.-J. Dong, Y. Li, J.-Q. Wang, S.-K. Tian, Chem. Commun. 2011, 47, 2158-2160.

[136] D. J. Peterson, J. Org. Chem. 1968, 33, 780-784.

[137] D. J. Ager, Synthesis 1984, 384-398.

[138] L. F. van Staden, D. Gravestock, D. J. Ager, Chem. Soc. Rev., 2002, 31, 195-200.

[139] Y. Ikeda, J. Ukai, N. Ikeda, H. Yamamoto, Tetrahedron 1987, 43, 731-741.
[140] S. Kuroda, T. Katsuki, M. Yamaguchi, Tetrahedron Lett. 1987, 28, 803-804.

[141] K. Mikami, T. Maeda, T. Nakai, Tetrahedron Lett. 1986, 27, 4189-4190.

[142] A. Alexakis, D. Jachiet, Tetrahedron 1989, 45, 381-389.

[143] F. Babudri, V. Fiandanese, G. Marchese, A. Punzi, Tetrahedron 2001, 57, 549-554.

[144] A. G. Angoh, D. L. J. Clive, J. Chem. Soc., Chem. Commun. 1984, 534-536.

[145] I. Fleming, I. T. Morgan, A. K. Sarkar, J. Chem. Soc., Perkin Trans. 1 1998, 2749-2764.

[146] M. Julia, J.-M. Paris, Tetrahedron Lett. 1973, 14, 4833-4836.

[147] P. R. Blakemore, J. Chem. Soc., Perkin Trans. 1 2002, 2563-2585.

[148] D. Schweitzer, J. J. Kane, D. Strand, P. McHenry, M. Tenniswood, P. Helquist, Org. Lett. 2007, 9, 4619-4622.

[149] A. B. Charette, C. Berthelette, D. St-Martin, Tetrahedron Lett. 2001, 42, 5149-5153.

[150] D. Menche, J. Hassfeld, J. Li, K. Mayer, S. Rudolph, J. Org. Chem. 2009, 74, 7220-7229.

[151] M. Nazaré, H. Waldmann, Chem. Eur. J. 2001, 7, 3363-3376.

[152] H. Hopf, A. Krüger, Chem. Eur. J. 2001, 7, 43784385.

[153] B. Schmidt, O. Kunz, Eur. J. Org. Chem. 2012 , 1008-1018 and refs cited therein.

[154] For a review, see: V. Boucard, G. Broustal, J.-M. Campagne, Eur. J. Org. Chem. 2007, 225-236.

[155] G. Cardillo, M. Orena, S. Sandri, Tetrahedron 1976, 32, 107-108.

[156] W. R. Roush, A. P. Spada, Tetrahedron Lett. 1983, 24, 3693-3696.

[157] E. J. Corey, G. Schmidt, Tetrahedron Lett. 1979, 20, 2317-2320.

[158] S. Masamune, B. Imperiali, D. S. Garvey, J. Am. Chem. Soc. 1982, 104, 5528-5531.

[159] Y. Feng, J. Liu, Y. P. Carrasco, J. B. MacMillan, J. K. De Brabander, J. Am. Chem. Soc. 2016, 138 , 7130-7142.

[160] B. Schmidt, S. Audörsch, O. Kunz, Synthesis 2016, 48 , 4509-4518.

[161] B. Schmidt, S. Audörsch, J. Org. Chem. 2017, 82, 1743-1760.

[162] B. Schmidt, O. Kunz, Beilstein J. Org. Chem. 2013, 9, 2544-2555.

[163] Y. Sonoda, Y. Suzuki, J. Chem. Soc., Perkin Trans. 2 1996, 401-404; b) H. C. Kwon, C. A. 
Kauffman, P. R. Jensen, W. Fenical, J. Org. Chem. 2009, 74, 675-684.

[164] W. von Doering, C. Sotiriou-Leventis, W. R. Roth, J. Am. Chem. Soc. 1995, 117, 2747-2757.

[165] S. Saint-Auret, H. Abdelkafi, D. Le Nouen, L. Guenin-Macé, C. Demangel, P. Bisseret, N. Blanchard, Org. Biomol. Chem. 2017, 15, 75187522 .

[166] A.-C. Chany, C. Tresse, V. Casarotto, N. Blanchard, Nat. Prod. Rep. 2013, 30, 1527-1567.

[167] L. C. Dias, E. C. de Lucca Jr., J. Org. Chem. 2017, $82,3019-3045$.

[168] B. Vaz, R. Alvarez, A. R. de Lera, Tetrahedron 2016, 72, 3898-3904.

[169] P. Zhang, J. P. Morken, J. Am. Chem. Soc. 2009, $131,12550-12551$

[170] In the absence of catalyst, the E,E-diene is obtained.

[171] For some exception in Suzuki cross-coupling reactions, see: G.-P. Lu, K. R. Voigtritter, C. Cai, B. H. Lipshutz, J. Org. Chem. 2012, 77, 3700-3703.

[172] X. Zeng, Q. Hu, M. Qian, E-i. Negishi, J. Am. Chem. Soc. 2003, 125, 13636-13637.

[173] For a related reaction involving ene-yne Sonogashira cross-coupling reactions, see: J. Uenishi, K. Matsui, M. Ohmi, Tetrahedron Lett. 2005, 46, 225-228.

[174] R. M. Garbaccio, S. J. Stachel, D. K. Baeschlin, S. J. Danishefsky, J. Am. Chem. Soc. 2001, 123, 10903-10908.

[175] T. Bach, A. Lemarchand, Synlett 2002, 13021304.

[176] A. Fürstner, C. Nevado, M. Waser, M. Tremblay, C. Chevrier, F. Teplý, C. Aïssa, E. Moulin, O. Müller, J. Am. Chem. Soc. 2007, 129, 9150-9161.

[177] J. Gagnepain, E. Moulin, A. Fürstner, Chem. Eur. J. 2011, 17, 6964-6972.

[178] N. Kanoh, S. Itoh, K. Fujita, K. Sakanishi, R. Sugiyama, Y. Terajima, Y. Iwabuchi, S. Nishimura, H. Kakeya, Chem. Eur. J. 2016, 22, 8586-8595.

[179] X. Wang, J. A. Porco, J. Am. Chem. Soc. 2003, $125,6040-6041$.

[180] P. Li, J. Li, F. Arikan, W. Ahlbrecht, M. Dieckmann, D. Menche, J. Org. Chem. 2010, 75, 2429-2444.

[181] L. A. Paquette, K. Basu, J. C. Eppich, J. E. Hofferberth, Helv. Chim. Acta 2002, 85, 3033-3051.

[182] D. Gallenkamp, A. Fürstner, J. Am. Chem. Soc. 2011, 133, 9232-9235.

[183] E. T. Kiesewetter, R. V. O’Brien, E. C. Yu, S. J. Meek, R. R. Schrock, A. H. Hoveyda, J. Am. Chem. Soc. 2013, 135, 6026-6029.
[184] V. M. Marx, M. B. Herbert, B. K. Keitz, R. H. Grubbs, J. Am. Chem. Soc. 2013, 135, 94-97.

[185] E. C. Yu, B. M. Johnson, E. M. Townsend, R. R. Schrock, A. H. Hoveyda, Angew. Chem. Int. Ed. 2016, 55, 13210-13214.

[186] S.-X. Luo, J. S. Cannon, B. L. H. Taylor, K. M. Engle, K. N. Houk, R. H. Grubbs, J. Am. Chem. Soc. 2016, 138, 14039-14046.

[187] A. W. H. Speed, T. J. Mann, R. V. O’Brien, R. R. Schrock, A. H. Hoveyda, J. Am. Chem. Soc. 2014, 136, 16136-16139.

[188] H. Zhang, E. C. Yu, S. Torker, R. R. Schrock, A. H. Hoveyda, J. Am. Chem. Soc. 2014, 136, $16493-$ 16496.

[189] C. Oger, L. Balas, T. Durand, J.-M. Galano, Chem. Rev. 2013, 113, 1313-1350.

[190] M. Bock, R. Dehn, A. Kirschning, Angew Chem. Int. Ed. 2008, 47, 9134-9137.

[191] M. Avignon-Tropis, J. R. Pougny, Tetrahedron Lett. 1989, 30, 4951-4952.

[192] F. Huang, Y. Zhang, Y. Yao, W. Yang, Y. Tao, RSC Adv. 2017, 7, 35575-35580.

[193] I. G. Alonso, L. T. Yamane, V. S. de FreitasBlanco, L. F. T. Novaes, M. Franz-Montan, E. de Paula, M. V. N. Rodrigues, R. A. F. Rodrigues, J. C. Pastre, Tetrahedron 2018, 74, 5192-5199.

[194] M. Aursnes, J. E. Tungen, A. Vik, J. Dalli, T. V. Hansen, Org. Biomol. Chem. 2014, 12, 432-437.

[195] D. Paul, S. Saha, R. K. Goswami, Org. Lett. 2018, 20, 4606-4609.

[196] P. Wipf, T. H. Graham, J. Am. Chem. Soc. 2004, 126, 15346-15347.

[197] S. Chang, S. Hur, R. Britton, Angew. Chem. Int. Ed. 2015, 54, 211-214.

[198] K. C. Nicolaou, S. E. Webber, J. Am. Chem. Soc. 1984, 106, 5734-5736.

[199] W. Li, C. M. Schneider, G. I. Georg, Org. Lett. 2015, 17, 3902-3905.

[200] Reaction stopped at $80 \%$ conversion: expected product $(56 \%)$, starting material $(20 \%)$, and overreduced alkane compound $(24 \%)$ were observed.

[201] M. Morita, S. Wu, Y. Kobayashi, Org. Biomol. Chem. 2019, 17, 2212-2222.

[202] T. M. Brütsch, P. Bucher, K.-H. Altmann, Chem. Eur. J. 2016, 22, 1292-1300.

[203] E-i. Negishi, T. Yoshida, A. Abramovitch, G. Lew, R. M. Williams, Tetrahedron 1991, 47, 343 356

[204] J. Heppekausen, R. Stade, R. Goddard, A. Fürstner, J. Am. Chem. Soc. 2010, 132, 1104511057. 
[205] P. Persich, J. Llaveria, R. Lhermet, T. de Haro, R. Stade, A. Kondoh, A. Fürstner, Chem. Eur. J. 2013, 19, 13047-13058.

[206] J. Hillenbrand, M. Leutzsch, A. Fürstner, Angew. Chem. Int. Ed. 2019, 58, 15690-15696 and refs cited therein.

[207] G. Valot, D. Mailhol, C. S. Regens, D. P. O'Malley, E. Godineau, H. Takikawa, P. Philipps, A. Fürstner, Chem. Eur. J. 2015, 21, 2398-2408.

[208] S. Schaubach, K. Gebauer, F. Ungeheuer, L. Hoffmeister, M. K. Ilg, C. Wirtz, A. Fürstner, Chem. Eur. J. 2016, 22, 8494-8507.

[209] J. Willwacher, N. Kausch-Busies, A. Fürstner, Angew. Chem. Int. Ed. 2012, 51, 12041-12046.

[210] D. Mailhol, J. Willwacher, N. Kausch-Busies, E. E. Rubitski, Z. Sobol, M. Schuler, M.-H Lam, S. Musto, F. Loganzo, A. Maderna, A. Fürstner, J. Am. Chem. Soc. 2014, 136, 15719-15729.

[211] F. Lacombe, K. Radkowski, G. Seidel, A. Fürstner, Tetrahedron 2004, 60, 7315-7324.

[212] P. Karier, F. Ungeheuer, A. Ahlers, F. Anderl, C. Wille, A. Fürstner, Angew. Chem. Int. Ed. 2019, 58 , 248-253.

[213] Z. Meng, L. Souillart, B. Monks, N. Huwyler, J. Herrmann, R. Müller, A. Fürstner, J. Org. Chem. 2018, 83, 6977-6994.

[214] L. Vitellozzi, G. D. McAllister, T. Genski, R. J. K. Taylor, Synthesis 2016, 48, 48-56.

[215] A. Fürstner, L. Turet, Angew. Chem. Int. Ed. 2005, 44, 3462-3466.

[216] A. Fürstner, D. de Souza, L. Turet, M. D. B. Fenster, L. Parra-Rapado, C. Wirtz, R. Mynott, C. W. Lehmann Chem. Eur. J. 2007, 13, 115-134.

[217] J. Willwacher, A. Fürstner, Angew. Chem. Int. Ed. 2014, 53, 4217-4221.

[218] J. Willwacher, B. Heggen, C. Wirtz, W. Thiel, A. Fürstner, Chem. Eur. J. 2015, 21, 10416-10430.

[219] K. J. Ralston, H. C. Ramstadius, R. C. Brewster, H. S. Niblock, A. N. Hulme, Angew. Chem. Int. Ed. 2015, 54, 7086-7090.

[220] K. Micoine, A. Fürstner, J. Am. Chem. Soc. 2010, $132,40,14064-14066$.

[221] K. Micoine, P. Persich, J. Llaveria, M-H. Lam, A. Maderna, F. Loganzo, A. Fürstner, Chem. Eur. J. 2013, 19, 7370-7383.

[222] C. M. Neuhaus, M. Liniger, M. Stieger, K.-H. Altmann, Angew. Chem. Int. Ed. 2013, 52, 58665870 .

[223] W. Li, G. I. Georg, Chem. Commun. 2015, 51, 8634-8636.
[224] C. M. Schneider, K. Khownium, W. Li, J. T. Spletstoser, T. Haack, G. I. Georg, Angew. Chem. Int. Ed. 2011, 50, 7855-7857.

[225] F. C. Tucci, A. Chieffi, J. V. Comasseto, J. P. Marino, J. Org. Chem. 1996, 61, 4975-4989.

[226] J. P. Marino, M. S. McClure, D. P. Holub, J. V. Comasseto, F. C. Tucci, J. Am. Chem. Soc. 2002, 124, 1664-1668.

[227] S.-J. Jeon, E. L. Fisher, P. J. Carroll, P. J. Walsh, J. Am. Chem. Soc. 2006, 128, 9618-9619.

[228] M. Osuka, Y. Yoshikawa, S. Akiyama, M. Nakagawa, Tetrahedron Lett. 1977, 3719-3722.

[229] L.-H. Zhou, X.-Q. Yu, L. Pu, Tetrahedron Lett. 2010, 51, 425-427.

[230] A. S. Chavan, J.-C. Deng, S.-C. Chuang, Molecules 2013, 18, 2611-2622.

[231] S. Sakthivel, A. Sharma, R. Balamurugan, Eur. J. Org. Chem. 2017, 3941-3946.

[232] S. Saulnier, A. A. Golovanov, A. Y. Ivanov, I. A. Boyarskaya, A. V. Vasilyev, J. Org. Chem. 2016 , 81, 1967-1980.

[233] S. Saulnier, A. A. Golovanov, A. V. Vasilyev, RSC Adv. 2016, 6, 103546-103555.

[234] D. Uraguchi, R. Shibazaki, N. Tanaka, K. Yamada, K. Yoshioka, T. Ooi, Angew. Chem. Int Ed. 2018, 57, 4732-4736.

[235] M. A. Sierra, M. C. de la Torre, Angew. Chem. Int. Ed. 2000, 39, 1538-1559.

[236] T. Brodmann, D. Janssen, M. Kalesse, J. Am. Chem. Soc. 2010, 132, 13610-13611.

[237] D. Janssen, M. Kalesse, Synlett 2007, 2667-2670.

[238] S. Williams, J. Jin, S. B. J. Kan, M. Li, L. J Gibson, I. Paterson, Angew. Chem. Int. Ed. 2017, $56,645-649$.

[239] N. K. Garg, S. Hiebert, L. E. Overman, Angew. Chem. Int. Ed. 2006, 45, 2912-2915.

[240] a) M. H. Becker, P. Chua, R. Downham, C. J. Douglas, N. K. Garg, S. Hiebert, S. Jaroch, R. T. Matsuoka, J. A. Middleton, F. W. Ng, L. E. Overman, J. Am. Chem. Soc. 2007, 129, 11987 12002; b) M. H. Becker, P. Chua, R. Downham, C. J. Douglas, N. K. Garg, S. Hiebert, S. Jaroch, R. T. Matsuoka, J. A. Middleton, F. W. Ng, L. E. Overman, J. Am. Chem. Soc. 2018, 140, 5319-5319.

[241] K. Fujita, R. Matsui, T. Suzuki, S. Kobayashi, Angew. Chem. Int. Ed. 2012, 51, 7271-7274.

[242] K. Sakanishi, S. Itoh, R. Sugiyama, S. Nishimura, H. Kakeya, Y. Iwabuchi, N. Kanoh, Eur. J. Org. Chem. 2014, 1376-1380.

[243] P. Li, J. Li, F. Arikan, W. Ahlbrecht, M. Dieckmann, D. Menche, J. Am. Chem. Soc. 2009 , $131,11678-11679$. 